\title{
Projeto de um módulo de aquisição e pré-processamento de imagem colorida baseado em computação reconfigurável e aplicado a robôs móveis
}

\author{
Vanderlei Bonato
}

Orientador: Prof. Dr. Eduardo Marques

Dissertação apresentada ao Instituto de Ciências Matemáticas e de Computação, como parte dos requisitos para a obtenção do título de Mestre em Ciências da Computação e Matemática Computacional.

USP - São Carlos

Abril de 2004 


\section{Agradecimentos}

Aos meus colegas do laboratório LCR, por terem sido companheiros e amigos e principalmente ao colega Adriano K. Sanches por ter participado da fase de testes do sistema apresentado neste documento.

Ao meu orientador e amigo Prof. Dr. Eduardo Marques, por ter sido conselheiro tanto nas decisões relacionadas a vida acadêmica, como também, nas decisões referentes ao meu futuro profissional.

À minha família e principalmente a Ivete, pela sua compreensão e paciência que teve durante o desenvolvimento deste trabalho. 
A mente que se abre a uma nova idéia jamais voltará ao seu tamanho original...

(Albert Einstein) 


\section{Resumo}

Este trabalho propõe um módulo básico de aquisição e pré-processamento de imagem colorida aplicado a robôs móveis, implementado em hardware reconfigurável, dentro do conceito de sistemas SoC (System-on-a-Chip). O módulo básico é apresentado em conjunto com funções mais específicas de pré-processamento de imagem, que são utilizadas como base para a verificação das funcionalidades implementadas no trabalho proposto. As principais funções realizadas pelo módulo básico são: montagem de frames a partir dos pixels obtidos da câmera digital CMOS, controle dos diversos parâmetros de configuração da câmera e conversão de padrões de cores. Já as funções mais específicas abordam as etapas de segmentação, centralização, redução e interpretação das imagens adquiridas. O tipo de dispositivo reconfigurável utilizado neste trabalho é o FPGA (Field Programmable Gate Array), que permite maior adequação das funções específicas às necessidades das aplicações, tendo sempre como base o módulo proposto. O sistema foi aplicado para reconhecer gestos e obteve a taxa 99,57\% de acerto operando a 31,88 frames por segundo. 


\section{Abstract}

This work proposes a basic module for a mobile robot color image capture and preprocessing, implemented in reconfigurable hardware based on SoC (System-on-a-Chip). The basic module is presented with a specifics image pre-processing function that are used as a base for verify the functionalities implemented in this research. The mains functions implemented on this basic module are: to read the pixels provide by the CMOS camera for compose the frame, to adjust the parameters of the camera control and to convert color space. The specifics image pre-processing functions are used to do image segmentation, centralization, reduction and image classification. The reconfigurable dispositive used in this research is the FPGA (Field-Programmable Gate Array) that permit to adapt the specific function according to the application needs. The system was applied to recognize gesture and had 99,57\% rate of true recognition at 31,88 frames per second. 


\section{Lista de Figuras}

1.1 Ambiente para projeto e implementação . . . . . . . . . . . . . . . 4

2.1 Espectro de freqüência das ondas eletromagnéticas . . . . . . . . . . . 8

2.2 Diagrama de cromaticidade definido pelo CIE-1931 (Swenson, 2000) . . . . 10

2.3 Cubo de cores do modelo RGB . . . . . . . . . . . . . . . . . . . . . 12

2.4 Triangulo HSI no cubo de cor RGB . . . . . . . . . . . . . . . . . 14

2.5 Funções para cálculo de H (Hue) sem utilização de operações trigonométricas 16

2.6 Técnica three-phases de transferência de carga . . . . . . . . . . . . . 18

2.7 Arquitetura de dispositivos CCD . . . . . . . . . . . . . . 20

2.8 Chips disponíveis para implementação de circuitos lógicos (Hamblen e Furman, 2001) . . . . . . . . . . . . . . . . . . . . . 24

2.9 Relação entre as diferentes tecnologia de hardware (Hamblen e Furman, 2001) . . . . . . . . . . . . . . . . . . . . . . . . . . . . . . . . 25

2.10 Diagrama simplificado de um PLA (Brown e Vranesic, 2000) . . . . . . . 26

2.11 Diagrama simplificado de um PAL (Brown e Vranesic, 2000) . . . . . . . . 27

2.12 Estrutura de um CPLD (Brown e Vranesic, 2000) . . . . . . . . . . . . . . 28

2.13 Estrutura geral de um FPGA (Brown e Vranesic, 2000) . . . . . . . . . . 29

2.14 Estrutura de uma LUT de duas entradas (Brown e Vranesic, 2000) . . . . . 30

2.15 Camadas num FPGA da família Stratix (Altera, 2003a) . . . . . . . . . . 34

2.16 Estrutura geral de um neurônio do modelo neural N-tuple (Carvalho, 1994) 35

3.1 Placa de desenvolvimento Nios - Edição Stratix . . . . . . . . . . . . . . 40

3.2 Componentes do sistema com processador Nios . . . . . . . . . . . . . . . 42

3.3 Foto da câmera CMOS (C3188A - 1/3") . . . . . . . . . . . . . . 43

3.4 Diagrama em blocos do circuito integrado OV7620 . . . . . . . . . . . 44

3.5 Câmera CMOS e a placa de desenvolvimento Nios . . . . . . . . . . . . . . 45

4.1 Descrição, compilação e teste do sistema . . . . . . . . . . . . . . . . 48 
4.2 Periféricos e funções do sistema . . . . . . . . . . . . . . . . . . . . . . . . 49

4.3 Diagrama de blocos do sistema de monitoramento . . . . . . . . . . . 50

4.4 RGB $(320 \mathrm{x} 240$ pixels $) \ldots \ldots \ldots \ldots \ldots$. . . . . . . . . . . . 54

4.5 Imagens em RGB (a), Hue (b), Saturation (c) e Intensity (I) com resolução de $320 \times 240$ pixels . . . . . . . . . . . . . . . . . . . 55

5.1 Diagrama de blocos do sistema de Pré-Processamento . . . . . . . . . . . . 59

5.2 Componente $\mathrm{H}(\mathrm{a})$ e imagem binariza $(\mathrm{b}) \ldots \ldots$. . . . . . . . . 60

5.3 Imagem com ruído segmentada (a) e reduzida sem ruído (b) . . . . . . . . 62

5.4 Imagem original (a) e o resultado da centralização (b) . . . . . . . . . . 63

5.5 Conjunto de gestos reconhecidos pelo robô, sendo (a),(c),(e),(g),(i),(k),(m) as imagens em RGB de entrada e (b),(d),(f),(h),(j),(l),(n) as imagens fornecidas à rede neural . . . . . . . . . . . . . . . . . . . . 65

5.6 Diagrama de blocos da rede neural RAM . . . . . . . . . . . . . 66

5.7 Diagrama esquemático da rede neural RAM implementada no FPGA . . . 67

5.8 Diagrama de bloco do Sistema . . . . . . . . . . . . . . . . . . . 70

5.9 Sinais de navegação do sistema (docking) . . . . . . . . . . . . . . 71

5.10 Proposta de um sistema de reconhecimento de gestos com $100 \%$ de acerto . 76 


\section{Lista de Tabelas}

2.1 Características dos FPGA da Altera . . . . . . . . . . . . . . . 31

2.2 Características dos FPGA da Xilinx . . . . . . . . . . . . . . . . . 32

3.1 Características do dispositivo EP1S10F780C6 . . . . . . . . . . . . 38

4.1 Desempenho do sistema. A tabela representa os seguintes dados: Freqüência de Operação (FO), Pixel por Segundo (PS) ou Bits por Segundo*, Tamanho da Imagem (TI) e Frames por Segundo (FS) . . . . . . . . . . . . . . 56

4.2 Recursos utilizados para implementação do sistema de aquisição e préprocessamento de imagem. A tabela representa os seguintes dados: Número de Elementos Lógicos (LE) e a Taxa de Ocupação (TO) do FPGA EP1S10F780C6 56

5.1 Recursos utilizados de Memória RAM (Mem), número de Elementos Lógicos (LE) e a Taxa de Ocupação (TO) de elementos lógicos do FPGA EP1S10F780C6 67

5.2 Desempenho do sistema implementado em hardware dedicado. A tabela representa os seguintes dados: Freqüência de Operação (FO), Pixel por Segundo (PS) ou Bits por Segundo*, Tamanho da Imagem (TI) e Frames por Segundo $(\mathrm{FS}) \ldots \ldots \ldots \ldots$. . . . . . . . . . . . . . 68

5.3 Análise de desempenho da rede neural RAM implementada em hardware dedicado. O desempenho apresentado nesta tabela independe do número de padrões da rede neural, pois são processados paralelamente . . . . . . . 68

5.4 Taxa de Acerto e de Erro para cada gesto apresentado ao sistema com 50 amostras para cada padrão apresentado no treinamento . . . . . . . . . . . 69

5.5 Memória RAM (M), Elementos Lógicos (EL) e Taxa de Ocupação (TO) necessário para implementar o sistema num FPGA EP1S10F780C6 . . . . 71 
5.6 Desempenho dos blocos de pré-processamento de imagem executando a $50 \mathrm{MHz}$ no processador Nios. A tabela representa os seguintes dados: Tempo em milisegundos(TF) para executar um frame, Tamanho da Imagem (TI) e Frame por segundo (FS) . . . . . . . . . . . . . . . . . . . . . . 72

5.7 Análise de desempenho da rede neural RAM implementada em software (50MHz no Processador Nios) . . . . . . . . . . . . . . . . . . . . 72

5.8 Taxa de reconhecimento e de erro para cada padrão . . . . . . . . . . . . 73 


\section{Sumário}

Resumo iv

Abstract $\quad$ v

1 Introdução 1

1.1 Descrição do Sistema Proposto . . . . . . . . . . . . . . . . 2

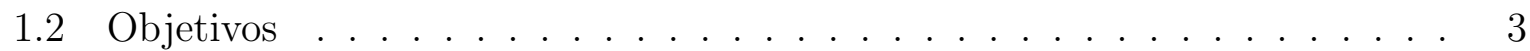

1.3 Justificativa . . . . . . . . . . . . . . . . . . . . . 5

1.4 Organização do Trabalho . . . . . . . . . . . . . . . . . 6

2 Fundamentação Teórica $\quad 7$

2.1 Fundamentos de Cor . . . . . . . . . . . . . . . . 7

2.1.1 Modelos de Cor . . . . . . . . . . . . . . . . . . . 11

2.1.2 Conversão de RGB para HSI . . . . . . . . . . . . . . . . . . . . . . 13

2.2 Tecnologia de Sensores de Imagem Digital . . . . . . . . . . . . . . . . 17

2.2.1 Sensor de Imagem CCD . . . . . . . . . . . . . . . . . . . . . . . . . . . . . . . . .

2.2 .2 Sensor de Imagem CMOS . . . . . . . . . . . . . . . . 20

2.2.3 Fatores que Comprometem a Qualidade da Imagem . . . . . . . . . 21

2.2.4 Comparativo entre CCD e CMOS . . . . . . . . . . . . . 22

2.3 Hardware Reconfigurável . . . . . . . . . . . . . . . . . . . . . . 23

2.3.1 Dispositivos Lógicos Programáveis . . . . . . . . . . . . . . . 25

2.3.2 FPGA de Última Geração . . . . . . . . . . . . . . . . . . . . . . . 29

2.3.3 Projetar ASIC a partir de FPGA . . . . . . . . . . . . . . . 32

2.4 Rede Neural Booleana . . . . . . . . . . . . . . . . . 34

2.4 .1 Modelo N-tuple . . . . . . . . . . . . . . . . . . . . 35

3 Plataforma de Desenvolvimento $\quad 37$

3.1 Kit de Desenvolvimento Nios . . . . . . . . . . . . . . . . . . 37 
3.1.1 Placa de Desenvolvimento Nios . . . . . . . . . . . . . . . . . 38

3.1.2 Ferramentas de Desenvolvimento de Software Embarcado . . . . . . 39

3.1.3 Processador RISC Customizável . . . . . . . . . . . . . . . . . . 40

3.2 Módulo de Câmera CMOS . . . . . . . . . . . . . . . . . . . . . 43

3.3 Conexão da Câmera com a Placa de Desenvolvimento . . . . . . . . . . . . . 44

3.4 Monitoramento da Imagem no Sistema . . . . . . . . . . . . . . . . . . . 45

4 Implementação do Sistema Proposto $\quad 47$

4.1 Monitoramento do Processamento de Imagem . . . . . . . . . . . . . . . . 49

4.2 Sistema de Aquisição e Pré-Processamento Básico de Imagem . . . . . . . 51

4.2 .1 Aquisição da Imagem . . . . . . . . . . . . . . . . . . . . . . . . . . . . . . . . . . . . . . . . 52

4.2.2 Modelos de cor RGB e $\mathrm{YCrCb}$. . . . . . . . . . . . . . . . . 53

4.2 .3 Conversão de RGB para HSI . . . . . . . . . . . . . . . . . . . . . . 54

4.2 .4 Análise dos Resultados . . . . . . . . . . . . . . . . . . 55

5 Aplicações do Sistema Proposto $\quad 57$

5.1 Sistema para Reconhecimento de Gestos . . . . . . . . . . . . . . . . 58

5.1.1 Reconhecimento dos Gestos Através da Rede Neural RAM-Based . 63

5.1 .2 Resultados Obtidos . . . . . . . . . . . . . . . . 66

5.2 Sistema de Visão para Condução de Robôs Móveis . . . . . . . . . . . . . . 69

5.2.1 Resultados Obtidos . . . . . . . . . . . . . . . . 70

$\begin{array}{ll}\text { Conclusão } & 74\end{array}$

$\begin{array}{ll}\text { Trabalhos Futuros } & 76\end{array}$

$\begin{array}{ll}\text { Referências Bibliográficas } & 78\end{array}$ 


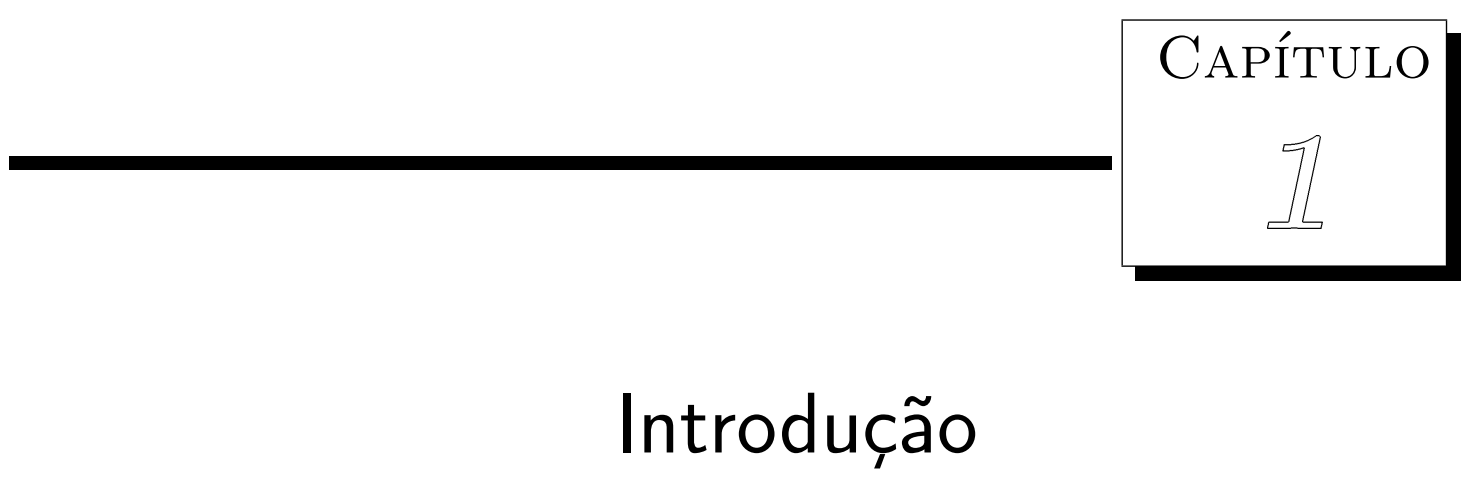

Propor um sistema de aquisição e pré-processamento de imagem para dispositivo reconfigurável é um grande desafio, visto que várias propostas já foram apresentadas para este fim. Porém, muitas não realizam todas as funções exigidas ou não podem ser adaptadas à plataforma necessária, ou ainda os resultados alcançados referentes ao seu desempenho e confiabilidade não são satisfatórios. Contudo, o desafio deste projeto é desenvolver um sistema num dispositivo de hardware reconfigurável comum às etapas básicas de préprocessamento de imagem que possa ser aplicado como base para resolução da maioria dos estudos de casos de visão para robótica.

Para tanto, o sistema deve comportar certos requisitos que são indispensáveis para atingir os objetivos propostos, como: conter funções básicas de pré-processamento de imagem colorida; desempenho em tempo real e possibilidade de implementação em um dispositivo reconfigurável. 


\subsection{Descrição do Sistema Proposto}

O projeto aqui proposto visa desenvolver um módulo básico de aquisição e pré-processamento de imagem colorida de tempo real para robôs móveis implementado em um único circuito integrado, conhecido como SoC (System-on-a-chip). A arquitetura deste circuito integrado é reconfigurável. Deste modo, o desenvolvimento do sistema torna-se mais flexível, o que possibilita a adequação da arquitetura do módulo básico de processamento de imagem com outros módulos mais específicos. O dispositivo reconfigurável é obtido através da tecnologia FPGA (Field-Programmable Gate Array) (K. e Mourad, 1994) (Murgai et. al., 1995) (Oldfield e Dorf, 1995) (Brown e Vranesic, 2000) que possibilita executar algoritmos em hardware e software, conforme a necessidade.

A arquitetura SoC para aquisição e pré-processamento de imagem será integrada a um ambiente para projeto e implementação de controle evolucionário embarcado de robôs móveis reconfiguráveis dinamicamente, como é mostrado através do bloco Módulo de Visão que se encontra em destaque na figura 1.1. Este ambiente vem sendo desenvolvido pelo Laboratório de Computação Reconfigurável - LCR do Instituto de Ciências Matemáticas e de Computação da Universidade de São Paulo. O ambiente apresentado através da figura 1.1 é constituído por um conjunto de dispositivos de FPGA's, cada qual configurado dinamicamente através do controlador de configuração para executar operações de acordo com as necessidade do robô. No caso do robô necessitar do sistema de visão, o dispositivo de FPGA, onde a câmera encontra-se conectada, é configurado para realizar as operações necessárias. O módulo básico de aquisição e processamento de imagem proposto será utilizado na configuração do dispositivo sempre que a funcionalidade de visão for ativada no robô. A partir do módulo básico que realiza o controle da câmera, a montagem dos frames e algumas operações de pré-processamento sobre os frames capturados, o gerenciador de configuração do robô seleciona qual técnica de caracterização de objetos é a mais adequada para executar o trabalho desejado no ambiente em que se encontra. Após a seleção da técnica, o dispositivo é configurado com o módulo básico, com a técnica de caracterização de objetos selecionada e com uma rede neural para exercer a classificação 
dos objetos existentes na cena. Atualmente existem dois modelos de redes neurais implementados e validados em FPGA que podem servir para este fim. Os modelos são o MLP, que foi desenvolvido durante um programa de mestrado (Wolf, 2001) e o N-tuple, que foi desenvolvido em conjunto com este trabalho. Após a configuração e o treinamento da rede neural (treinamento feito on-chip), o módulo de visão encontra-se pronto para ser utilizado pelo robô. Todas as operações citadas anteriormente são realizadas de forma automática pelo gerenciador do robô, que já foi iniciado num programa de mestrado (Gonçalves et. al., 2003).

O sistema proposto está dividido em duas etapas: a primeira realiza operações básicas de processamento e aquisição de imagem e a segunda é dedicada a resolver problemas mais específicos de processamento de imagem. O trabalho proposto está concentrado na primeira etapa do sistema, mas para validar as operações desta etapa é necessário implementar algumas funções também na segunda etapa. Para isso, serão criadas algumas funções específicas para segmentação, filtragem e classificação de objetos contidos na imagem. A classificação destes objetos será feita através do uso de rede neural que recebe como entrada um vetor de características do objeto, ou uma imagem binarizada contendo o objeto, e informa na saída qual a sua identidade.

As características marcantes deste sistema são: 1)realizar operações básicas de aquisição e pré-processamento de imagem colorida em tempo real, o que é extremamente importante para que outras funções de robôs não sejam comprometidas, como por exemplo, o controle de navegação (Maxwell, 2001); 2)implementação em um dispositivo reconfigurável, permitindo o paralelismo e que funções específicas sejam criadas conforme a necessidade do estudo de caso; 3)criação de um core comum para operações de pré-processamento contidas na primeira etapa do sistema; 4)e possuir a característica de sistemas SoC.

\subsection{Objetivos}

Os Objetivos principais deste trabalho são:

- Desenvolver um módulo básico de aquisição e pré-processamento de imagem colorida 


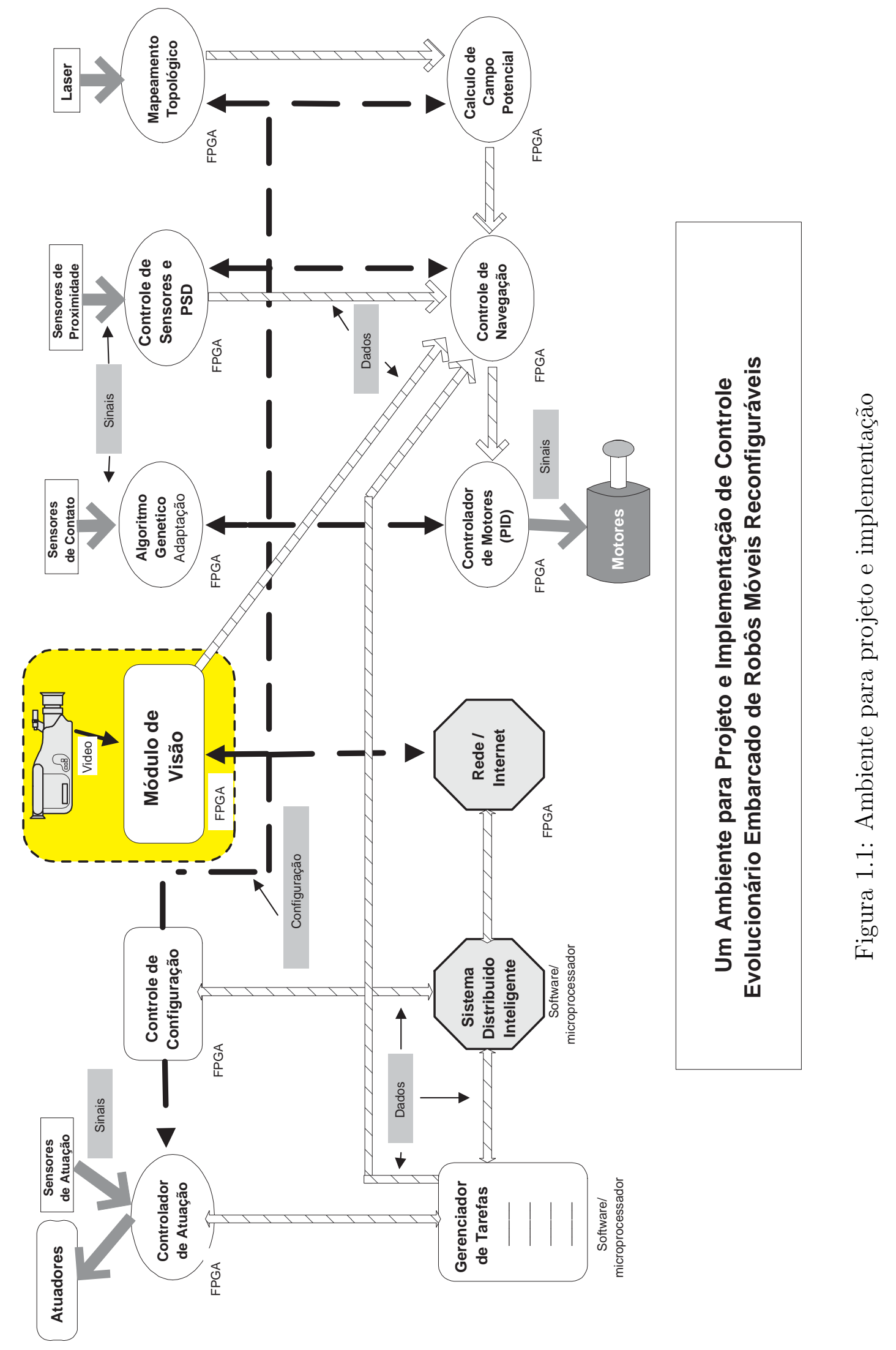


de tempo real em dispositivo FPGA, com a finalidade de servir de base para o desenvolvimento de módulos de visão computacional mais específicos aplicados a robôs móveis.

- Dominar a nova tecnologia da câmera CMOS (Complementary Metal Oxide Semiconductor);

- Contribuir com a evolução do ambiente para projeto e implementação de controle evolucionário embarcado de robôs móveis reconfiguráveis dinamicamente, que vem sendo desenvolvido pelo Laboratório de Computação Reconfigurável - LCR do Instituto de Ciências Matemáticas e de Computação da Universidade de São Paulo;

\subsection{Justificativa}

Conforme Josef Pauli (Pauli, 2001), não existe sistema de visão computacional genérico capaz de atender a todas as necessidades dos problemas relativos a visão computacional, apesar de atualmente existir em diversas técnicas difundidas sobre o assunto. Esta constatação é ratificada analisando-se as publicações científicas e as bibliografias que abordam estas técnicas, tais como por exemplo em Gonzalez e Woods (1992), Costa e Cesar Jr. (2000) e Filho e Neto (1999). Assim, dependendo da aplicação, o projetista escolhe dentre as várias técnicas existentes, a mais adequada para a solução do problema. Caso não exista uma técnica mais adequada à situação, técnicas já existentes podem ser adaptadas ou até mesmo outras criadas.

O sistema proposto não tem como objetivo ser genérico, e sim, conter algumas funções básicas de pré-processamento e aquisição de imagem que possam servir de base para construção de sistemas de visão computacional e conseqüentemente possibilite a otimização do tempo gasto na construção de novos sistemas, deixando o projetista concentrado na parte mais específica. A segmentação, a extração das características dos objetos e a classificação são algumas das funções específicas que dependem da aplicação.

Baseado nos recursos que são fornecidos pelos dispositivos de FPGAs avançados disponíveis no mercado, é possível desenvolver um sistema em hardware para aquisição e 
pré-processamento de imagem colorida que atenda aos requisitos do projeto proposto. Em Altera (2003a) são apresentados dispositivos da família Stratix II para solução de projetos complexos, sendo que alguns destes dispositivos têm disponíveis até 179.400 elementos lógicos (LE) e 10Mbits de memória RAM. Por exemplo, um processador RISC embutido num FPGA, com interface para memória externa, portas de comunicação como Ethernet, UART e I/O, barramentos de dados e de instrução necessita entorno de 5.000 elementos lógicos para ser implementado.

\subsection{Organização do Trabalho}

O capítulo 2 apresenta a fundamentação teórica necessária para o desenvolvimento deste trabalho. Os assuntos abordados são: fundamentos de cor, tecnologia de câmeras, hardware reconfigurável e redes neurais booleanas. O capítulo 3 descreve os recursos de hardware e software que são utilizados para a implementação e validação do sistema. O capítulo 4 apresenta a implementação do módulo de aquisição e pré-processamento de imagem desenvolvido neste trabalho e o capítulo 5 apresenta as aplicações desenvolvidas a partir deste módulo. Por fim, é apresentado as conclusões obtidas e as sugestões para trabalhos futuros. 


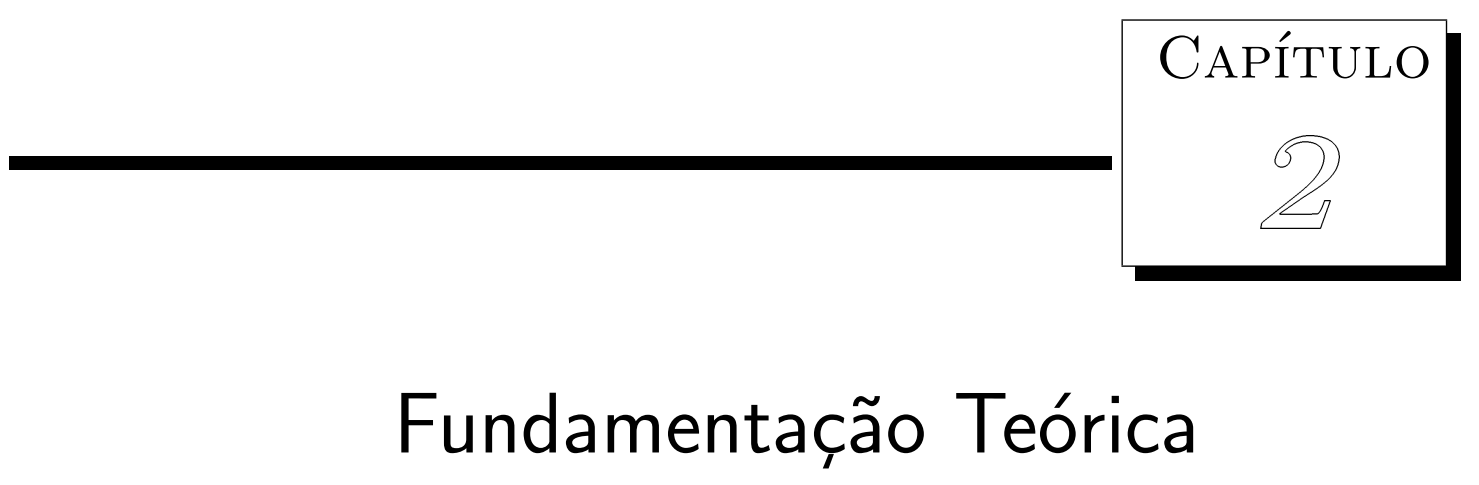

Este capítulo apresenta de forma sucinta a fundamentação teórica dos temas predominantes deste projeto. Inicialmente é introduzido o tema fundamentos de cor, enfatizando os sistemas de cores RGB, YCrCb e HSI utilizados como padrões de cores no trabalho. Em seguida é abordado o tema relacionado às tecnologias de câmeras CCD (Charged Coupled Device) e CMOS (Complementary Metal Oxide Semiconductor), pois é através deste mecanismo que as imagens são capturadas. O próximo conceito apresentado esta relacionado a tecnologia de hardware reconfigurável, com ênfase no FPGA (Field Programmable Gate Array), sendo esta a tecnologia de hardware adotada para a implementação deste trabalho. Por fim, é abordada a rede neural booleana, apresentando o modelo N-tuple baseado em memória de acesso randômico (RAM).

\subsection{Fundamentos de Cor}

Um dos primeiros estudos de cor foram feitos por Isaac Newton no século XVII. Newton mostrou que a luz branca é feita por uma combinação de cores. Usando um prisma ótico, ele foi capaz de separar a luz do sol em um arco-íris de cores variando do azul até o 
vermelho. Além disso, Newton foi capaz de combinar cores para formar outras cores, por exemplo, ele combinou a cor verde com vermelho e produziu o amarelo. A partir deste experimento, Newton concluiu que eram necessárias sete cores para representar todas as cores. No século seguinte, Thomas Young, James Forbes e James Clerk Maxwell mostraram que somente com três cores é possível representar o espectro visível da luz. A demonstração foi realizada usando três fotografias monocromáticas representando o vermelho, o verde e o azul, filtradas de uma imagem de um arco íris. Maxwell recriou a imagem iluminando cada fotografia com a luz correspondente a cor componente da fotografia. Em seguida, ele colocou as imagens com as três cores sobrepostas, produzindo as cores do arco-íris (Weeks Jr., 1996).

A luz é uma onda eletromagnética que se torna visível ou invisível dependendo do seu comprimento de onda. A variação do comprimento de onda no range visível faz com que a cor desta luz também varie. Na figura 2.1 é apresentado o diagrama do espectro eletromagnético variando de 0,001 nanometros até 1000 metros de comprimento de onda. No centro do espectro é apresentado o comprimento de onda que é visível, variando de violeta com 0,4 micrometros até o vermelho com 0,7 micrometros.

\begin{tabular}{|l|c|c|c|c|c|c|}
\hline $\begin{array}{c}\text { Raios } \\
\text { Gamma }\end{array}$ & Raios - X & Ultravioleta & Visível & Infrared & $\begin{array}{c}\text { Micro } \\
\text { Ondas }\end{array}$ & $\begin{array}{c}\text { Comunicação e } \\
\text { Energia Elétrica }\end{array}$ \\
\hline $\begin{array}{l}0,001 \mathrm{~nm} \\
1 \mathrm{~nm}\end{array}$ & $0,4 \mu \mathrm{m}$ & $0,7 \mu \mathrm{m}$ & $30 \mu \mathrm{m}$ & $10 \mathrm{~mm}$ & $1000 \mathrm{~m}$ \\
\hline $\begin{array}{l}\text { Violeta } \\
0,4 \mu \mathrm{m}\end{array}$ & Azul & Ciano & Verde & Amarelo & Laranja & Vermelho \\
\hline
\end{tabular}

Figura 2.1: Espectro de freqüência das ondas eletromagnéticas

O comprimento de onda de 0,7 até 30 micrometros, adjacente ao espectro visível, é o espectro infrared. As câmeras de captura de imagem infravermelho operam neste espectro. Todo o objeto com temperatura acima de zero graus eradia uma energia eletromagnética, se este objeto estiver na temperatura ambiente a energia iradiada é contida no espectro 
eletromagnético infrared.

As cores percebidas em objetos são compostas pela quantidade de luz refletida por ele. A luz emitida por uma fonte incide sobre o objeto e a quantidade desta luz que é refletida compõe a sua cor. Se um objeto refletir a luz de forma balanceada em todo espectro visível, a cor do objeto será branca. A radiação é a quantidade de energia emitida por uma fonte de luz e esta medida é dada em watts (W). Luminância, medida em lumens $(\mathrm{lm})$, é a quantidade de energia que um observador percebe da fonte de luz.

Todas as cores visíveis ao homem são obtidas através da combinação de três cores básicas, o vermelho (R), o verde (G) e o azul (B) (Swenson, 2000). A ciência da cor e suas medidas é conhecida como Calorimetry. As quantidades de vermelho, verde e azul necessárias para formar qualquer cor em particular são denominadas valores triestímulos e são respectivamente denotadas como X, Y e Z. Então, uma cor é especificada por seus coeficientes tricromátricos definidos através das equações 2.1, 2.2 e 2.3, obviamente sendo a soma de X, Y e Z igual a 1.

$$
\begin{aligned}
& x=\frac{X}{X+Y+Z} \\
& y=\frac{Y}{X+Y+Z} \\
& z=\frac{Z}{X+Y+Z}
\end{aligned}
$$

A fim de padronizar as métricas de cores e terminologias foi criado o CIE (Commission Internationale de l'Eclairage). O CIE especificou o comprimento de onda para as três cores primárias, sendo $\mathrm{B}=435,8 \mathrm{~nm}, \mathrm{G}=546,1 \mathrm{~nm}$ e $\mathrm{R}=700 \mathrm{~nm}$. Segundo Gonzalez e Woods (1992), a padronização do comprimento de onda das cores primárias não significa que a combinação destes três componentes sozinhos consegue gerar todo o espectro de cor. A figura 2.2 apresenta o diagrama de cromaticidade definido pelo CIE. Ao longo do eixo horizontal (X) é apresentada a quantidade de vermelho e ao longo do eixo vertical (Y) é apresentada a quantidade de verde em uma cor. A quantidade de azul é definida pela 
equação 2.4. Localizado no centro do gráfico está a cor branca (White Point), dada pela quantidade igual de vermelho, verde e azul. Ao longo da borda externa do gráfico está o comprimento de onda descrevendo o espectro da matiz $(\mathrm{H})$ de várias cores definidas pelo CIE. A saturação da cor aumenta radialmente do centro do gráfico para a borda externa, pontos localizados na borda externa estão completamente saturados.

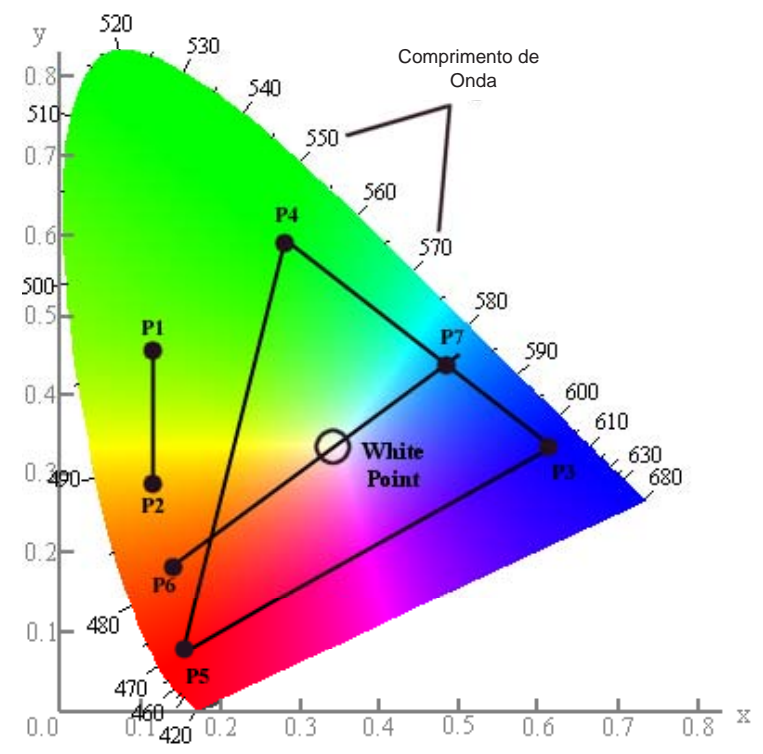

Figura 2.2: Diagrama de cromaticidade definido pelo CIE-1931 (Swenson, 2000)

O diagrama de CIE é utilizado na determinação do comprimento de onda (cor), na percentagem de branco (saturação) e na mistura de duas cores. Dados dois pontos (duas cores) no diagrama de CIE, a linha que conecta estes dois pontos fornece todas as cores que podem ser criadas com a quantidade de duas cores. A mistura de duas cores podem ser estendidas para a mistura de três cores. Para determinar o range de cores que podem ser obtidas a partir de quaisquer três cores dadas no diagrama de crominância, simplesmente conectam-se os três pontos onde se localizam as cores formando um triângulo. Os pontos localizados na região interna ao triângulo, representam todas as possíveis cores que podem ser criadas a partir da combinação das três cores. As cores localizadas fora do triângulo não são obtidas por nenhuma das combinações das três cores. A combinação de mais do que três cores são necessárias para produzir qualquer cor representada no diagrama de cromaticidade CIE. 


$$
Z=1-x-y
$$

\subsubsection{Modelos de Cor}

Modelos de cor, também conhecidos como espaço de cor ou sistema de coordenadas de cor, é uma especificação de um sistema de coordenadas 3-D em um subespaço interno ao sistema, onde cada cor são representadas por um simples ponto (Gonzalez e Woods, 1992). Os modelos de cor são usados para classificar cores com atributos, como matiz (H), saturação (S), crominância (formada pela junção da cor e da saturação) e brilho (Swenson, 2000). Dentre os vários modelos de cores existentes, estes podem ser direcionados ao hardware e ao software (processamento de imagem). Para o hardware, os mais comumente usados, tais como RGB (Red, Green, Blue) para monitores coloridos e para uma ampla variedade de câmeras de video a cores; o CMY para impressoras coloridas (Cyan, Magenta, Yellow); o YIQ que é o padrão para transmissão de sinal (analógico) de vídeo colorido para televisores, o $Y$ corresponde a luminância, $I$ e $Q$ correspondem a cor da imagem; e o YCrCb, que é um modelo de cor inicialmente utilizado em televisão digital e que independe do sistema de codificação de sinal de TV. Devido ao desacoplamento da luminância com as informações de cores da imagem, este modelo de cor pode ser utilizado tanto em televisores coloridos como também em monocromáticos. Vários modelos de cores são direcionados tanto ao harwdware quanto ao software. No software os mais frequentemente utilizados são o RGB, HSI (matiz, saturação, intensidade) e o YIQ.

Os modelos de cores apresentados a seguir, são o RGB, YCbCr e o HSI. Estes modelos são apresentados devido ao seu uso no sistema proposto. A câmera CMOS a ser utilizada no sistema proposto fornece os padrões de cores RGB e YCrCb, já o modelo HSI é gerado pelo próprio hardware dedicado implementado no sistema proposto.

\section{O Modelo de Cor RGB}

O modelo de cor RGB trata a imagem colorida como um conjunto de três imagens independentes em nível de cinza, cada qual representa o componente de cor vermelho, 
verde e azul (Weeks Jr., 1996). Também é definido em Gonzalez e Woods (1992) como sendo formado por conjunto de componentes espectrais primários de vermelho, verde e azul. Este modelo é representado por um cubo num plano de coordenadas cartesianas, conforme figura 2.3. Os valores de RGB estão nos três cantos e nos outros três cantos estão os valores de ciano, magenta e amarelo. O canto localizado na origem é o preto e o mais distante da origem encontra-se o branco. Ao longo da reta que liga o preto e o branco estende-se os níveis de cinza, já as cores são pontos que não se encontram nesta reta e sim em qualquer lugar dentro ou sobre o cubo. Atualmente o RGB é muito utilizado, tanto na reprodução de imagens (monitores) como na captura das mesmas (câmeras coloridas RGB), apesar do grande uso, este modelo de cor não é indicado para processamento de imagem (Gonzalez e Woods, 1992), pois grande parte das operações devem ser feitas nos planos de cores de forma independente, ocorrendo com isso, perda de informação.

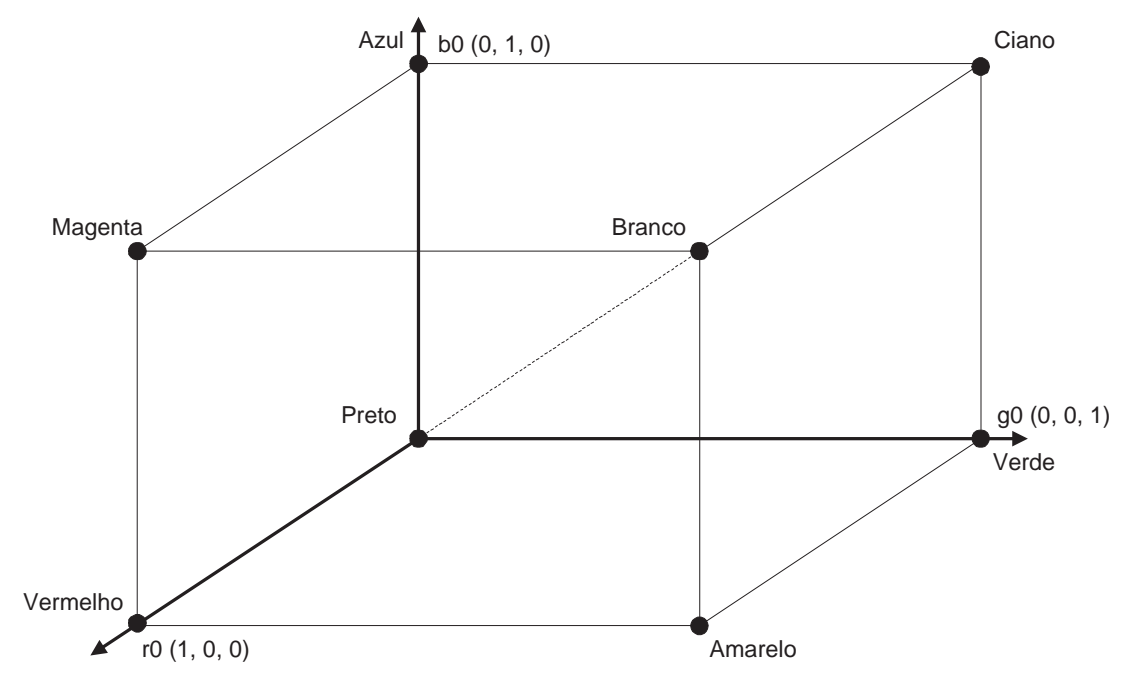

Figura 2.3: Cubo de cores do modelo RGB

\section{O Modelo de Cor $\mathrm{YCrCb}$}

O modelo de cor YCrCb é muito utilizado em video digital e em compressão de imagem no formato JPEG ${ }^{1}$. Neste formato, a informação de luminância é reproduzida pelo componente Y e a informação de crominância pelos componente $\mathrm{Cr}$ e $\mathrm{Cb}$, onde Cr repre-

\footnotetext{
${ }^{1}$ Joint Photographic Experts Group (JPEG) é um grupo que estabelece padrões para armazenar dados digitais compactados de video e audio em arquivos de computadores
} 
senta a cor vermelha e o Cb a cor azul. A equação2.5 apresenta como realizar a conversão do modelo de cor RGB para YCrCb.

$$
\left\{\begin{array}{l}
Y=0,59 G+0,31 R+0,11 B \\
C r=0,713 x(R-Y) \\
C b=0,564 x(B-Y)
\end{array}\right.
$$

\section{O Modelo de Cor HSI}

O modelo de cor HSI representa a cor em termos de matiz (H), saturação $(\mathrm{S})$ e intensidade (I). Matiz é um atributo que descreve uma cor pura, saturação dá a medida do grau de diluição de uma cor pura com o branco e a intensidade é o nível de luminância da imagem (Ramesh et. al., 1995). O modelo de cor HSI é baseado no triângulo de cores de Maxwell, derivado do cubo de cores RGB mostrado na figura 2.3. A figura 2.4 mostra o triângulo de Maxwell como um plano que intercepta o r0, g0 e b0 nas coordenadas $(1,0,0),(0,0,1)$ e $(0,1,0)$. O triângulo que representa o HSI está localizado dentro do cubo de cores RGB, sendo o triângulo bidimensional e o cubo tridimensional. No centro do triângulo cruza uma reta conectando as cores branca e preta, representando todos os tons de cinza de uma cor, correspondendo a $0 \%$ de saturação. Localizado nos vértices estão as três cores primárias. A saturação da cor $(\mathrm{S})$ é medida pelo comprimento do vetor de uma dada cor r, g e b (ponto P da figura 2.4) até o centro do triângulo. Qualquer cor localizada na borda do triângulo está 100\% saturada. O valor da matiz (H) define a posição angular de uma dada cor, podendo estar entre 0 e 359 graus em relação à linha de referência que sai do centro do triângulo para o vértice de cor vermelha.

\subsubsection{Conversão de RGB para HSI}

A única conversão de cor implementada neste sistema é de RGB para HSI, pois os modelos RGB e YCrCb existentes neste sistema são fornecidos diretamente da câmera digital, sendo somente necessário programar a câmera para o fornecer o padrão desejado. A operação de conversão do modelo de cor RGB para HSI e vice-versa é consideravelmente 


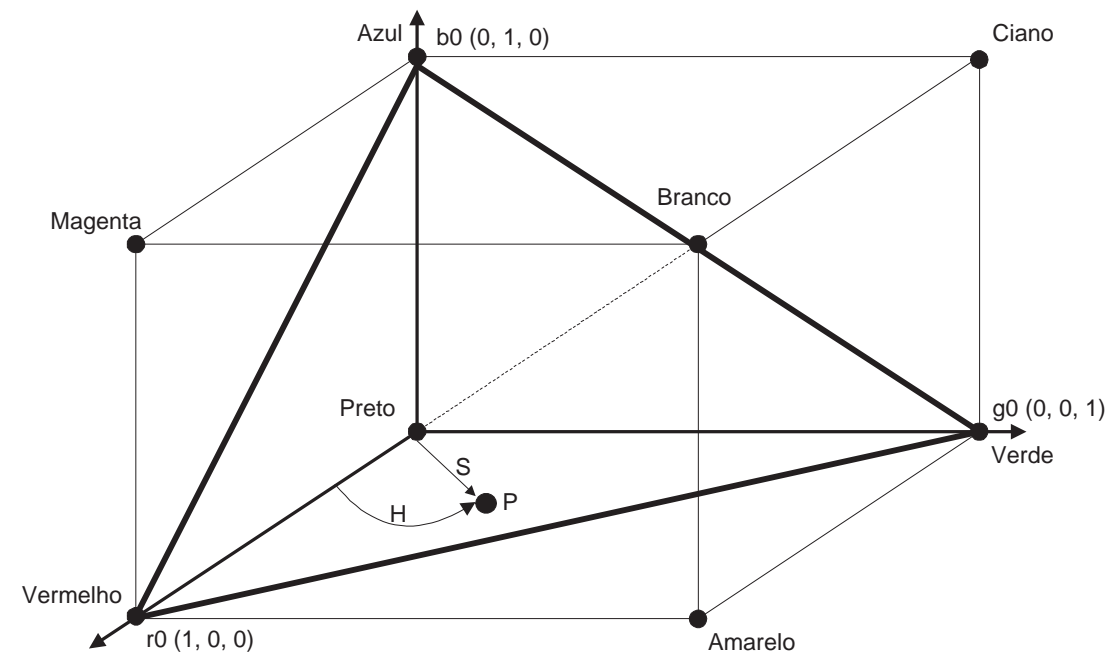

Figura 2.4: Triangulo HSI no cubo de cor RGB

mais complicada do que as operações entre outros modelos de cores existentes (Gonzalez e Woods, 1992). A complexidade desta conversão é devida à utilização de funções trigonométricas para obter o valor de $H$. Deste modo, a utilização desta função no trabalho proposto torna-se difícil, tendo em vista que o sistema é implementado em hardware (FPGA). Bajon apud Swenson (Swenson, 2000) apresenta um método simplificado de realizar a conversão de RGB para HSI. Este método, o qual é apresentado nesta seção, não utiliza funções trigonométricas, facilitando com isso a implementação desta conversão em hardware.

Para obter a equação que realiza a conversão de RGB para HSI e sua inversa, é necessário que o componente hue $(\mathrm{H})$ seja dividido em três regiões, as quais essencialmente dividem as regiões do triângulo ao longo de cada um dos seus vértices (Weeks Jr., 1996). Quando a cor B for a menor dentre $\mathrm{R}, \mathrm{G}$ e B, o valor de hue está localizado na região oposta ao vértice onde se encontra a cor B, ou seja, seu valor varia entre 0 e 120 graus. Do mesmo modo quando o vermelho for a cor de menor valor, o valor de hue encontra-se entre 120 e 240 graus. Por fim, quando o verde for a cor de menor valor, o valor de hue está entre 240 e 360 graus.

O espaço de cor HSI, define suas cores a partir dos valores normalizados (intervalo $[0,1])$ de vermelho, verde e azul, como segue nas equações 2.6, 2.7, 2.8. 


$$
\begin{aligned}
& r=\frac{R}{R+G+B} \\
& g=\frac{G}{R+G+B} \\
& b=\frac{B}{R+G+B}
\end{aligned}
$$

Conforme as equações 2.6, 2.7 e 2.8, os valores de r, g e b também permanecem normalizados no intervalo $[0,1]$, a soma dos três valores é igual a 1. Para valores iguais de $\mathrm{R}, \mathrm{G}$ e $\mathrm{B}$, as três equações que definem a normalização das cores resultam em $1 / 3$, assim a cor resultante é conhecida como achromatic, sendo esta localizada em uma linha que liga as cores preta e branca, no centro do triângulo HSI no espaço de cor RGB.

Utilizando as funções trigonométricas, podemos calcular o valor de $\mathrm{H}$ através da equação 2.9 (Weeks Jr., 1996).

$$
H=\cos ^{-1}\left[\frac{\frac{2}{3}\left(r-\frac{1}{3}\right)-\frac{1}{3}\left(b-\frac{1}{3}\right)-\frac{1}{3}\left(g-\frac{1}{3}\right)}{\sqrt{\frac{2}{3}\left[\left(r-\frac{1}{3}\right)^{2}+\left(b-\frac{1}{3}\right)^{2}+\left(g-\frac{1}{3}\right)^{2}\right]}}\right]
$$

O cálculo do valor de intensidade (I) e saturação (S) no modelo HSI é obtido de forma mais simples do que o cálculo de hue $(\mathrm{H})$, conforme as equações 2.10 e 2.11 apresentadas.

$$
\begin{gathered}
I=\frac{R+G+B}{3} \\
S=1-3 * \min [r, g, b]
\end{gathered}
$$

O método para cálculo de $\mathrm{H}$ sem o uso de funções trigonométricas é apresentado através da figura 2.5. O uso de cada equação depende da relação entre os valores de r, g e b. 


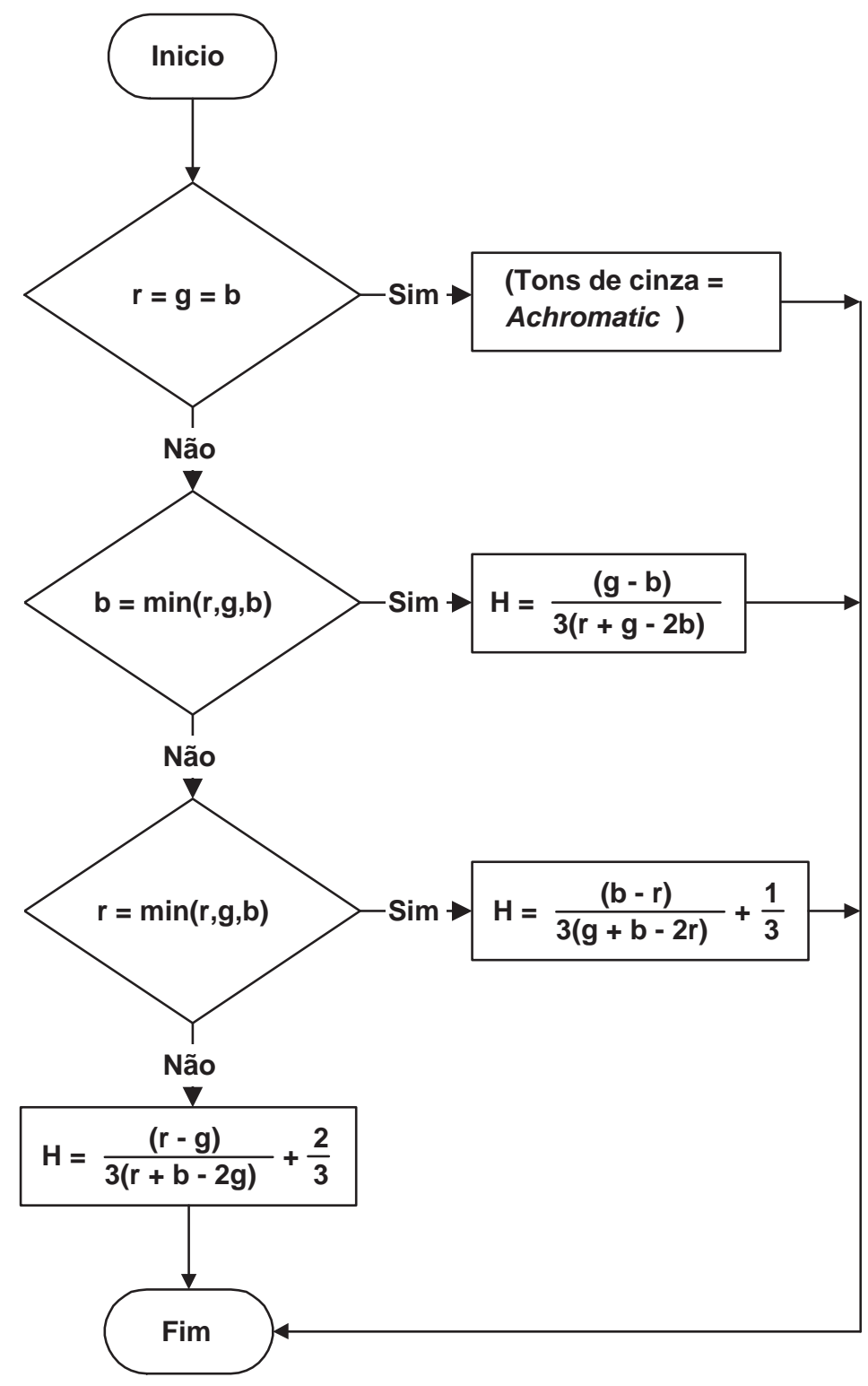

Figura 2.5: Funções para cálculo de H (Hue) sem utilização de operações trigonométricas 


\subsection{Tecnologia de Sensores de Imagem Digital}

Atualmente existem diversos tipos de sensores disponíveis no mercado, sendo que cada qual é caracterizado pela tecnologia que utiliza, consumo de energia, qualidade da imagem, velocidade de captura de frames, tamanho, custo e etc.. Dentre os sensores de imagem mais utilizados atualmente estão os de tecnologia CCD e CMOS (Company, 2003a) que são apresentados nas seções seguintes.

\subsubsection{Sensor de Imagem CCD}

A tecnologia de sensores de imagem CCD foi inventada em 1970 por Willard Boyle e George Smith no laboratório da Bell, nos Estados Unidos (Boyle e Smith, 1970). Deste então, vem sendo utilizada em grande escala em produtos, incluindo máquina de fax, fotocópias, câmeras, scanners e celulares.

O CCD é composto por milhares (ou milhões) de pixels ou células sensitivas à luz que são capazes de produzir uma carga elétrica proporcional ao montante da luz que elas recebem. Normalmente, os pixels são organizados em uma simples linha ou numa matriz bi-dimensional composta por linhas e colunas. Em scanners, por exemplo, os pixels são organizados numa linha, neste caso, é necessário mover o CCD sobre a imagem (ou vice versa). Já as câmeras digitais são formadas por uma matriz de pixels bi-dimensional, dessa forma, uma imagem bi-dimensional pode ser capturada numa única revelação.

Um dos principais parâmetros de um CCD é a resolução, que é igual ao número total de pixels existentes na área sensitiva à luz do dispositivo. Um dos primeiros dispositivos CCD de matriz, desenvolvido por Fairchild em 1974, possuía resolução de 100x100 pixels (de Oregon, 2003). Atualmente, encontram-se dispositivos com resolução de aproximadamente 9000x7000, ou seja, 63 milhões de pixels.

Dispositivos CCD são circuitos integrados que possuem uma janela de vidro que permite a luz chegar até o silício do chip. Os CCD são fabricados utilizando a tecnologia MOS (Metal-Oxide-Semiconductor), onde cada pixel pode ser pensado como sendo um capacitor MOS que converte fótons (luz) em carga elétrica (elétron), sendo esta carga 
armazenada para uma leitura posterior.

\section{Processo de Leitura de Carga}

O processo de leitura de carga é realizado em dois estágios, primeiro a carga do pixel é transferida através da matriz de pixels e depois a carga do pixel é armazenada em um registrador antes de ser digitalizada (Taylor, 1998).

O primeiro processo, a transferência de carga depende do número de gates de que cada pixel é composto. Assim, as técnicas de transferência são chamadas de two-phases(dois gates), three-phases (três gates) ou four-phases (quatro gates).

Tomando como exemplo o processo three-phases (Company, 2003a), visto na figura 2.6, a carga está armazenada no gate $\emptyset 1$ enquanto que os gates $\emptyset 2$ e $\emptyset 3$ estão no estado bloqueado. O gate $\emptyset 2$ é trazido para o nível alto e logo em seguida o gate $\emptyset 1$ vai para o nível baixo. Agora, a carga está armazenada no gate $\emptyset 2$ e é transferida para o gate $\emptyset 3$, manipulando os gates $\emptyset 2$ e $\emptyset 3$ da mesma maneira que foi realizada anteriormente. O ciclo de transferência é completado quando a carga é transportada para o gate $\emptyset 1$ do próximo pixel.

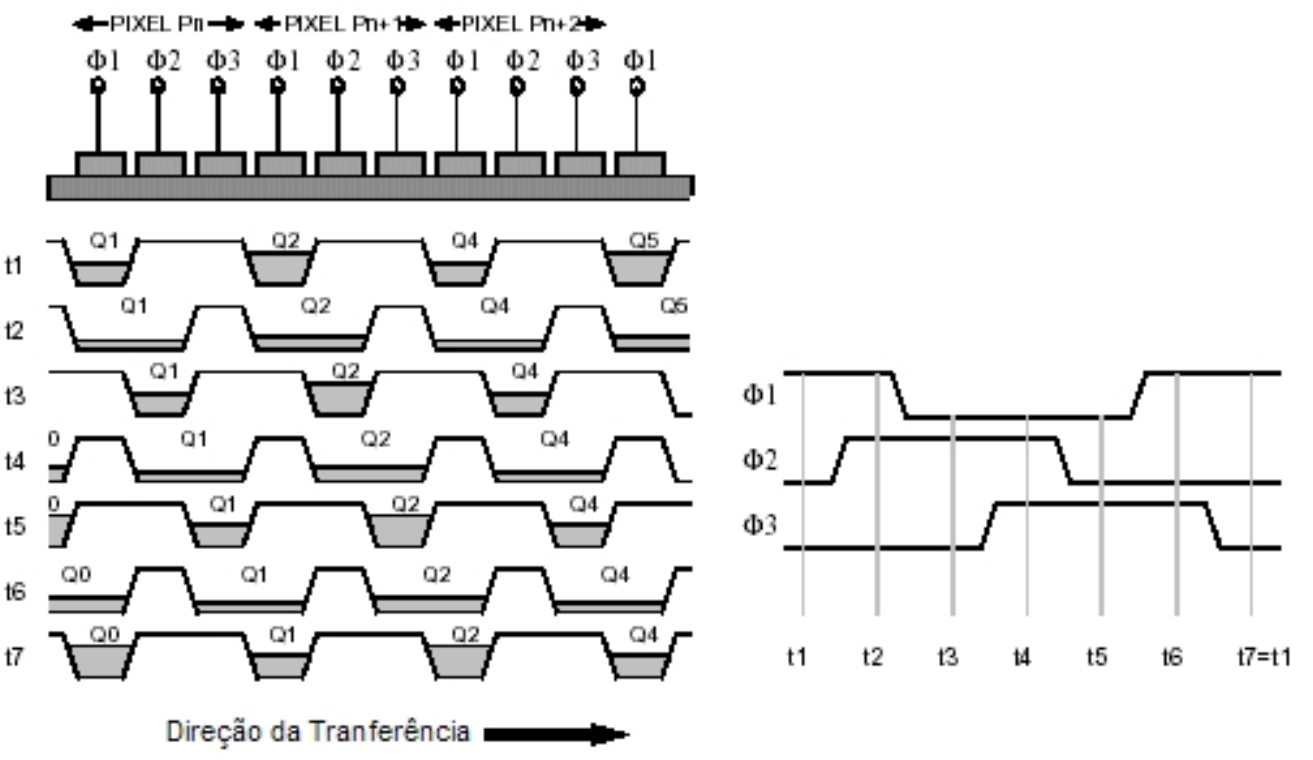

Figura 2.6: Técnica three-phases de transferência de carga

Já o segundo estágio do processo de leitura de carga ocorre após cada linha de pixels ter sua carga transferida para a próxima linha. Além das linhas de pixels, existe no topo e/ou 
na base da matriz de pixels uma linha adicional chamada de registrador de leitura, que armazena as cargas dos pixels localizados no topo da matriz quando uma transferência entre linhas é realizada. A carga armazenada no registrador de leitura é enviada para um conversor ADC (Analog to Digital Converter) e posteriormente armazenada numa memória.

\section{Arquitetura da Matriz de Pixels CCD}

Geralmente as arquiteturas dos dispositivos CCD pertencem a uma das quatro categorias: full frame, frame transfer, split frame transfer e interline transfer (Taylor, 1998). A seguir estas quatro categorias são descritas e apresentadas através da figura 2.7.

- Full Frame: A imagem é transferida diretamente da seção da imagem do sensor ao registrador de leitura. No entanto, somente uma simples linha de pixels por vez pode ser transferida para o registrador de leitura, enquanto que o restante dos pixels da imagem deve aguardar. Durante este período, os pixels que ainda não foram lidos da matriz continuam armazenando informações da imagem, isso pode distorcer e borrar a imagem. Uma solução para este problema é proteger da luz a região de captura da imagem mecanicamente através de uma cobertura (Company, 2003a).

- Frame Transfer: O dispositivo com esta arquitetura utiliza uma seção de armazenamento protegida da luz do mesmo tamanho da matriz de pixels. Após o tempo de integração da imagem, a imagem capturada é transferida para a seção adjacente de armazenamento. Enquanto a próxima cena está sendo capturada, a cena capturada anteriormente é transferida para o registrador de saída (paralelismo de operações). Durante a transferência da imagem capturada para a seção de armazenamento, é necessário proteger a matriz de pixels da luz para evitar os mesmo problemas citados na full frame.

- Split Frame Transfer: Este tipo de dispositivo é semelhante ao frame transfer, exceto pelo fato de que a seção de armazenamento é dividida em duas partes, sendo que cada parte contém um registrador de saída. Esta arquitetura é vantajosa, pois 
permite transferir a imagem da seção de armazenamento ao registrador de saída com a metade do tempo gasto na arquitetura frame transfer.

- Interline Transfer: Nesta arquitetura o dispositivo é composto por colunas de pixels e por colunas de registradores protegidos da luz de forma intercalada. No final do tempo de integração, a imagem capturada é transferida rapidamente para as colunas de registradores. Enquanto um novo frame é capturado, a carga armazenada nas colunas de registradores são transferidas para os registradores de saída. Este tipo de arquitetura não requer o uso de mecanismos para proteção da luz, visto que a imagem capturada é transferida diretamente às colunas de registradores.

Como a tecnologia CCD não permite a integração de circuitos num único chip para o processamento da carga obtida da matriz de pixel, componentes externos ao sensor de imagem CCD devem ser conectados para que uma câmera com esta tecnologia seja construída. Os circuitos normalmente implementados são os conversores ADC, geradores de sinais de sincronismo e controladores de ganho.

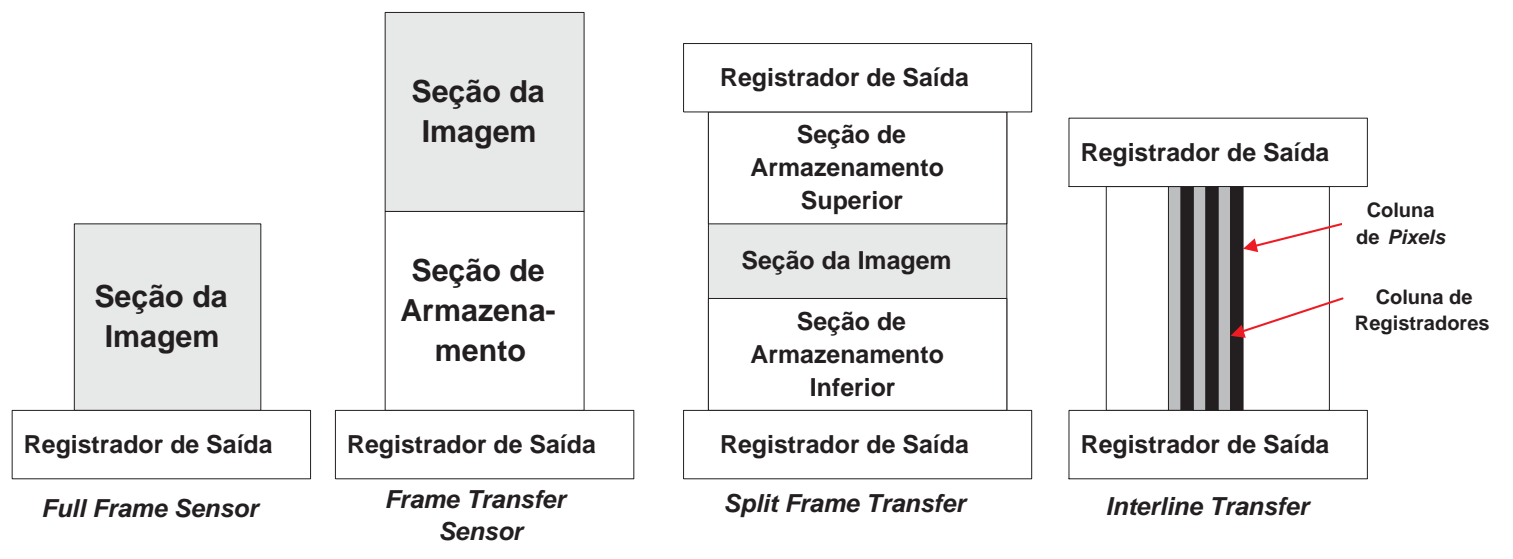

Figura 2.7: Arquitetura de dispositivos CCD

\subsubsection{Sensor de Imagem CMOS}

O primeiro sensor de imagem utilizando a tecnologia CMOS foi produzido pelo laboratório Jet Propulsion Laboratory (JPL) da NASA em 1990 (Technology, 2003). 
Os sensores CMOS, bem como CCD, são formados por elementos sensitivos a luz, cada qual capaz de produzir um sinal elétrico ou carga proporcional a luz que incide nestes elementos. No entanto, o processo para realizar isto é bem diferente em cada tecnologia. No CCD o pixel é baseado num capacitor MOS, já no CMOS o pixel pode ser construído utilizando fotodiodo, transistores, capacitores, ou seja, estes componentes podem ser integrados formando um circuito específico para cada pixel (Company, 2003b).

Existem basicamente dois tipos de sensores de imagem CMOS: passive pixel e active pixel. O dispositivo baseado em passive pixel é composto por um capacitor e um transistor em cada pixel e por um amplificador em cada coluna da matriz de pixels. O capacitor armazena a carga de elétrons obtida durante a captura da imagem e o transistor faz o chaveamento desta carga para o amplificador da coluna correspondente ao pixel. Já no dispositivo baseado em active pixel o amplificador é introduzido junto ao pixel, isso permite que haja um controle na amplificação da carga para cada pixel, mas por outro lado, aumenta a área necessária para construção do mesmo.

\section{Processo de Leitura de Carga}

Ambos dispositivos passive e active pixel usam as mesmas técnicas para leitura dos pixels. As linhas e colunas da matriz são selecionadas por um circuito seletor, a linha selecionada ativa os transistores e a carga de cada pixel é transferida para todas as colunas da matriz. Após, o circuito seleciona a coluna do pixel que deseja ler (Blanc, 2001). Esta carga lida do pixel é convertida para um valor digital através de um ADC e posteriormente armazenado em memória.

A possibilidade de selecionar as linhas e colunas permite acessar pixels individuais ou somente região de interesse dentro da imagem, assim, é possível aumentar o número de frames lidos por segundo.

\subsubsection{Fatores que Comprometem a Qualidade da Imagem}

Os dispositivos, tanto CCD como CMOS, apresentam alguns problemas de conversão de cenas em imagem digital (Taylor, 1998), sendo alguns deles apresentados a seguir: 
- Fill Factor: É o percentual que cada pixel é sensitivo a luz. O ideal seria 100\%, mas na realidade este valor não é obtido devido ao fato do pixel possuir internamente áreas insensíveis à luz.

- Dark current noise: É definido por uma carga não desejável que se acumula no pixel devido variação de temperatura que ocorre no ambiente onde o dispositivo está operando.

- Quantum efficiency (QE): É a proporção do número de elétrons detectados, dividido pelo produto do número de fótons incidentes num determinado período e multiplicado pelo número dos elétrons que cada fóton pode gerar.

- Blooming: É o efeito que ocorre quando, durante o período de integração da imagem, o potencial de carga de elétrons é excedido. Normalmente é causado pela presença de um objeto com brilho excessivo. Quando ocorre este excesso, os elétrons fluem para as regiões vizinhas criando uma área da imagem saturada.

\subsubsection{Comparativo entre CCD e CMOS}

Existem algumas diferenças entre as tecnologias CCD e CMOS, as quais são apresentadas a seguir:

- O sensor de image CMOS pode conter vários circuitos no mesmo chip (System-on-aChip), eliminando os vários chips necessários para o CCD. Isso permite redução no tamanho, no consumo de energia e no custo. A redução do custo não ocorre somente pela integração de circuitos no mesmo chip, é também obtida porque a tecnologia CMOS não é desenvolvida especificamente para desenvolvimento de sensores CMOS, como é o caso da tecnologia utilizada no CCD. Esta tecnologia, é aplicada também no desenvolvimento da maioria dos circuitos integrados existentes no mercado atual, como microprocessadores, microcontroladores e DSP (Digital Signal Processing).

- Enquanto sensores de imagem CMOS se sobressaem na captura de imagem com alta intensidade luminosa, sofrem com a baixa quantidade de luz. A sensibilidade 
com a luz é reduzida porque parte do pixel é preenchido com circuitos que foram integrados ao chip. O percentual do pixel que é dedicado a coletar a luz é chamado de fill factor.

- Atualmente, os sensores de imagens CMOS adquirem imagem no modo contínuo (imagem completa) em torno de 1 Gigapixel por segundo. Isso ocorre graças à possibilidade de arquiteturas paralelas e à integração de funções em um único chip, reduzindo capacitâncias, indutâncias e atrasos de propagação (Blanc, 2001).

- Os sensores CCD são aplicados em produtos como filmadoras e câmeras digitais de alta qualidade, os quais normalmente são utilizados na ciência e astrologia. Sensores CMOS, normalmente são aplicados em sistemas portáteis, tais como biométricos, automotivos e robóticos, onde não se requer alta definição. Baixo consumo de energia e tamanho reduzido também são características dos sensores CMOS (Blanc, 2001).

\subsection{Hardware Reconfigurável}

A maneira como os sistemas digitais são elaborados tem evoluído drasticamente nas últimas 4 décadas. Até a década de 60, os sistemas digitais eram construídos a partir de componentes discretos, tais como, transistores e resistores. Com o surgimento de circuitos integrados (chips), foi possível integrar transistores dentro de uma única pastilha de silício. Apesar de inicialmente a tecnologia permitir integrar poucos transistores, atualmente com a evolução desta tecnologia, é possível integrar 14 milhões de transistores por $\mathrm{cm}^{3}$, podendo atingir 100 milhões até 2012 (Brown e Vranesic, 2000). Esta evolução permitiu que uma grande variedade de chips fossem construídos nestas pastilhas de silício, as quais são apresentadas na figura 2.8 .

Tradicionalmente os chips realizam operações pré-definidas pelo fabricante, assim, para a elaboração de um circuito com lógica definida pelo usuário, há necessidade do uso de tipos diferentes de chips, trazendo diversas desvantagens ao sistema, como: aumento da área necessária para a conexão; perda de performance devido ao atraso existente nas portas 


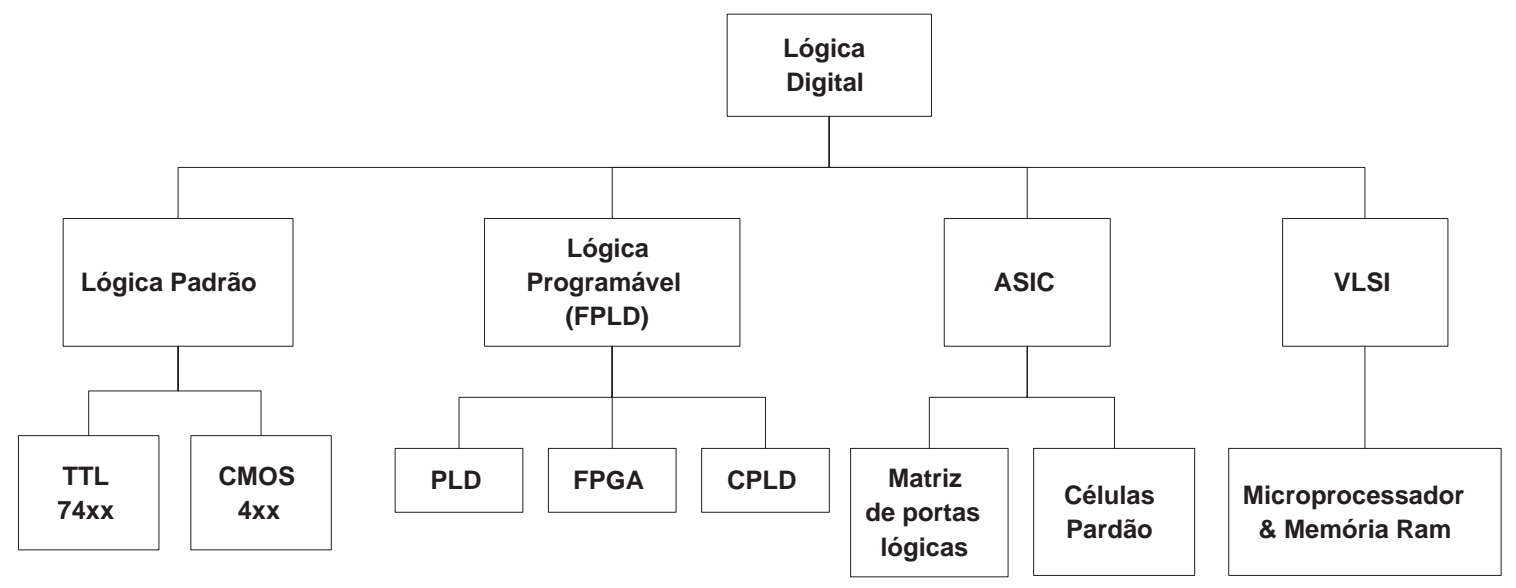

Figura 2.8: Chips disponíveis para implementação de circuitos lógicos (Hamblen e Furman, 2001)

de entrada e saída e aumento do consumo de energia. Para contornar estes problemas, surgiram outros tipos de circuitos integrados (chips), os quais possuem as funcionalidades definidas não mais pelo fabricante, e sim, pelo usuário. Dentre estes tipos, existem os chips VLSI (Very Large Scale Integration), ASIC (Application Specific Integrated Circuit), PLD (Programmable Logic Device), CPLD (Complex Programmable Logic Device) e FPGA (Field Programmable Gate Array). A funcionalidade existente num chip do tipo ASIC e VLSI é definida pelo usuário, mas implementada pelo fabricante devido a tecnologia necessária para este processo, a qual possui um custo elevado. Esta funcionalidade é fixa, ou seja, após o chip ter sido fabricado não é possível realizar upgrades em suas funções. Apesar desta desvantagem, este tipo de chip geralmente tem baixo consumo de energia, seu desempenho é alto devido a sua especificidade e o custo do sistema tende a baixar quando for produzido em larga escala. O PLD, o FPGA e o CPLD permitem ao usuário definir e implementar a funcionalidade do chip. Deste modo, o custo de desenvolvimento e o tempo necessário para a obtenção do produto (time-to-market) é inferior ao ASIC, porém o desempenho cai, a densidade e a complexidade aumentam (Hamblen e Furman, 2001). Através da figura 2.9 pode-se constatar a relação entre as tecnologias mencionadas anteriormente. 


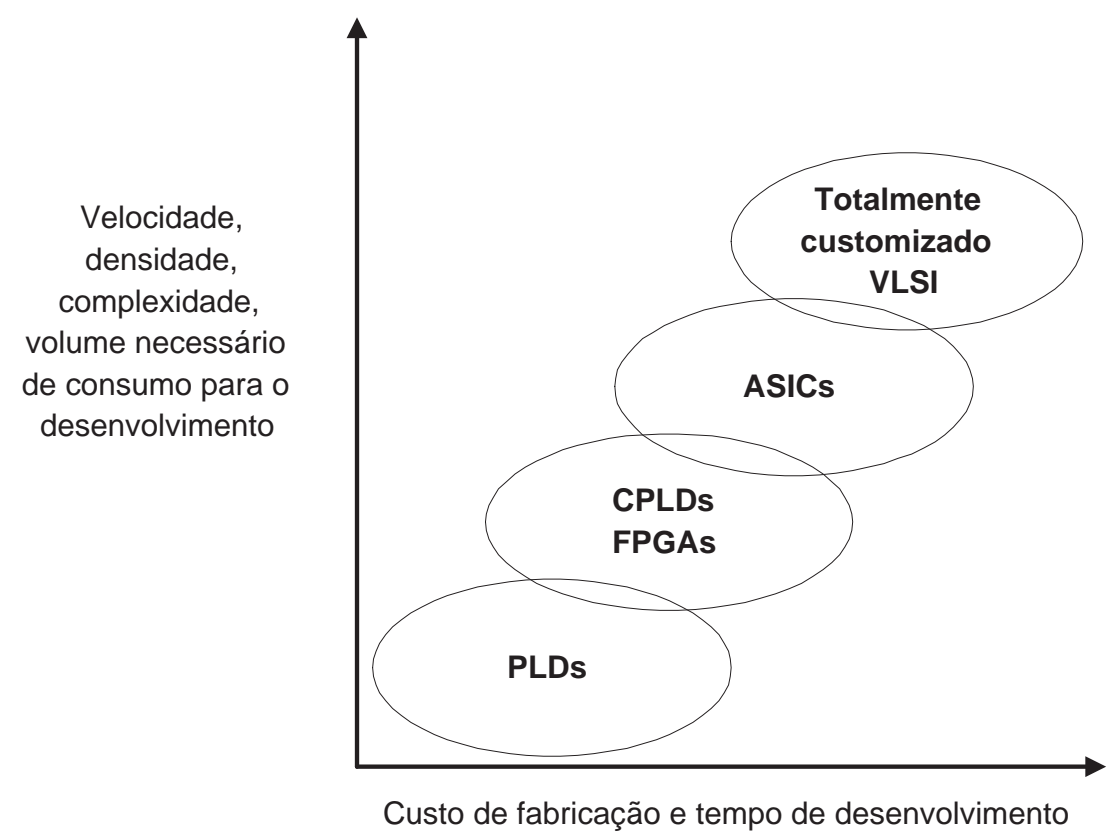

Figura 2.9: Relação entre as diferentes tecnologia de hardware (Hamblen e Furman, 2001)

\subsubsection{Dispositivos Lógicos Programáveis}

Os chips que permitem a programação de seu circuito pelo usuário foram introduzidos nos anos 70 e são conhecidos como PLD (Brown e Vranesic, 2000). O PLD é um chip de propósito geral para implementar circuitos lógicos, o qual contém uma coleção de elementos lógicos que podem ser customizados de diferentes maneiras. O PLD pode ser visto como uma "caixa preta" que contém portas lógicas e chaves (switches) programáveis. As chaves programáveis permitem conectar as portas lógicas internas ao PLD para implementar qualquer circuito lógico necessário.

\section{PLA (Programmable Logic Array)}

Há vários tipos de PLD disponíveis no mercado. O primeiro desenvolvido foi o PLA, introduzido pela Philips, que basicamente compreende uma coleção de portas AND que tem suas saídas conectadas a um conjunto de portas OR, conforme apresentado na figura 2.10. O PLA é baseado na idéia de que as funções lógicas podem ser implementadas na forma de soma de produtos, sendo a soma representada pelas portas OR e o produto pelas portas AND. As conexões entre estas portas lógicas, tanto no plano AND como no 
plano OR, são determinadas pelas chaves programáveis, as quais realizam a configuração do circuito conforme a função lógica que se deseja implementar no chip.

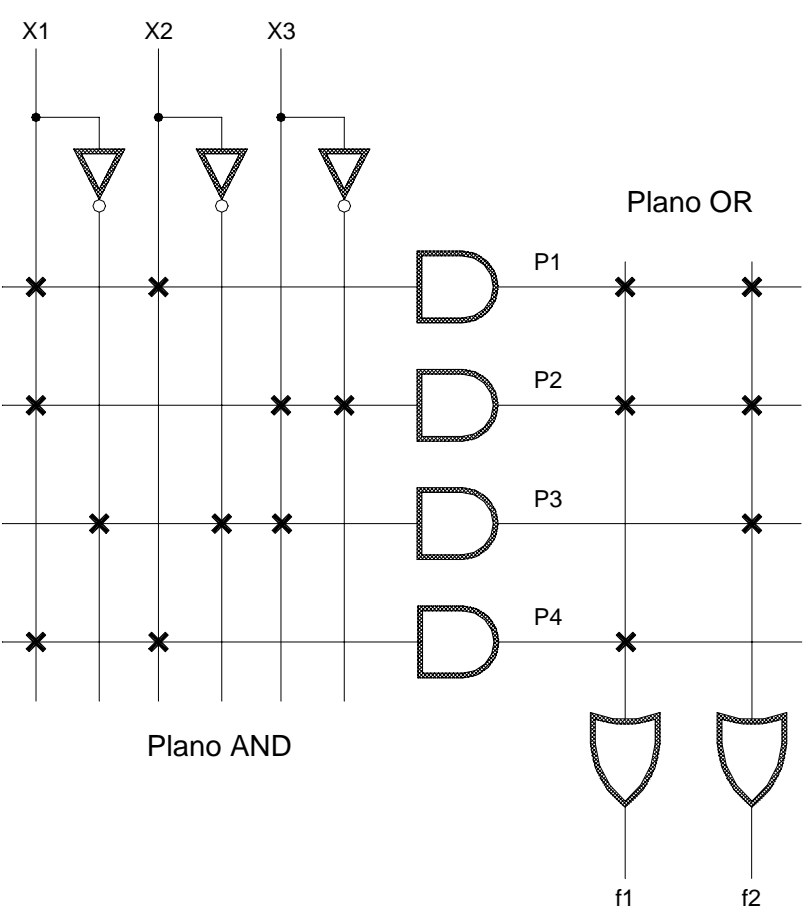

Figura 2.10: Diagrama simplificado de um PLA (Brown e Vranesic, 2000)

\section{PAL (Programmable Array Logic)}

As chaves programáveis do plano AND e OR no PLA apresentam duas dificuldades para a fabricação destes dispositivos: elas são difíceis de serem fabricadas corretamente e reduzem o desempenho dos circuitos implementados nos PLA devido ao atraso de propagação dos sinais elétricos (Brown e Vranesic, 2000). Para superar estas deficiências, foi desenvolvido um dispositivo similar, conhecido como PAL, que possui as portas do plano AND programáveis e as do plano OR fixas. Devido ao melhor desempenho, maior simplicidade de fabricação e conseqüentemente menor custo em relação ao PLA, os dispositivos PAL tem se tornado mais populares em aplicações práticas. A figura 2.11 apresenta um diagrama simplificado de um circuito lógico do dispositivo PAL. 


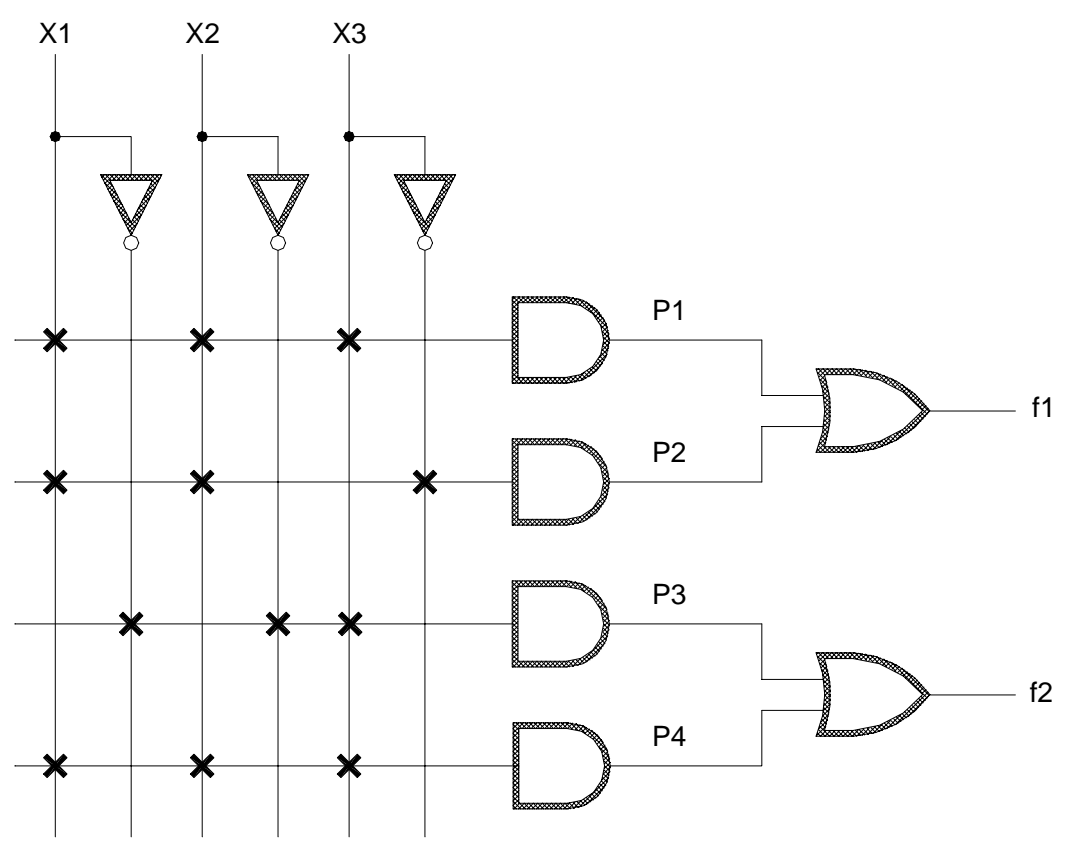

Plano AND

Figura 2.11: Diagrama simplificado de um PAL (Brown e Vranesic, 2000)

\section{CPLD (Complex Programmable Logic Device)}

Os circuitos implementados nos dispositivos do tipo PLA e PAL são diretamente limitados ao número de entradas e saídas existentes nestes dispositivos, pois os circuitos devem ser implementados na estrutura de soma de produtos. Para implementação de circuitos que requeiram um número maior de entradas e saídas, foi desenvolvido um chip mais sofisticado, conhecido por CPLD. Este chip é constituído por multiplos blocos do tipo SPLD, os quais são similares aos circuitos do tipo PLA ou PAL. Todos os blocos são interconectados através de chaves programáveis e são conectados a subcircuitos chamados de bloco de $I / O$, os quais estão ligados aos pinos de entrada e saída do dispositivo. A estrutura do CPLD é apresentada através da figura 2.12.

\section{FPGA (Field Programmable Gate Array)}

Um FPGA é um dispositivo que não implementa a função lógica no método tradicional: portas dedicadas. Cada elemento lógico individual é na verdade uma pequena matriz de memória que é programada diretamente com a função desejada, a partir da 


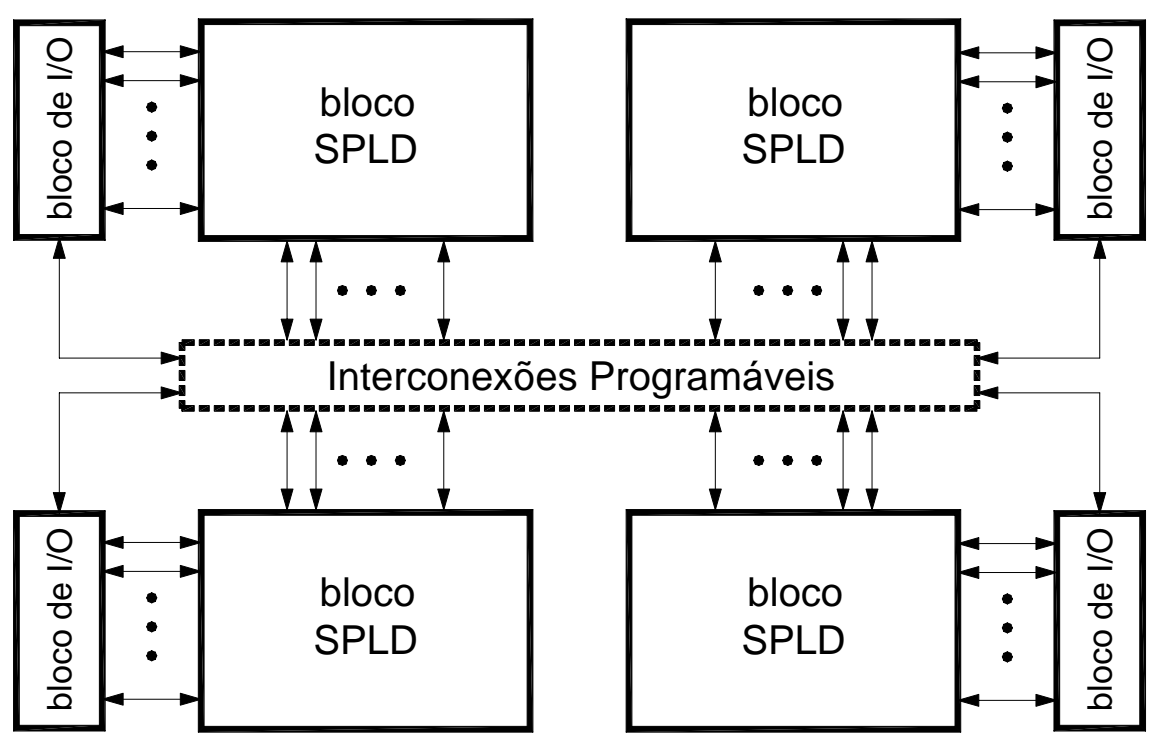

Figura 2.12: Estrutura de um CPLD (Brown e Vranesic, 2000)

tabela verdade (Berger, 2002). Esta matriz de memória está localizada nos blocos lógicos existentes no FPGA. A estrutura geral do FPGA é apresentada na figura 3.1, que apresenta três tipos de recursos: os blocos de $I / O$ para conectar os pinos de entrada e saída do dispositivo; os blocos lógicos dispostos num arranjo bi-dimensional e um conjunto de chaves de interconexões organizadas como canais de roteamento horizontal e vertical entre as linhas e colunas dos blocos lógicos.

Os canais de conexão entre os blocos lógicos são constituídos por condutores internos e pelas chaves existentes no FPGA, que são definidos conforme a necessidade de comunicação. Cada bloco lógico em um FPGA tipicamente contém um pequeno número de entradas e uma saída. Os mais comuns são os baseados em LUT (LookUp Table), as quais contém células de armazenamento que são usadas para implementar uma pequena função lógica. Cada célula é capaz de armazenar um simples valor lógico 0 ou 1 . LUT de vários tamanhos podem ser criadas, onde o tamanho é definido pelo número de entradas. A figura 2.14 apresenta a estrutura de uma pequena LUT com duas entradas $x 1$ e $x 2$, e uma saída $f$, que é capaz de implementar qualquer função de duas variáveis. Devido a tabela verdade de duas variáveis possuir quatro combinações possíveis, esta LUT tem quatro células de armazenamento. As variáveis de entrada $x 1$ e x2 são usadas como seletores 


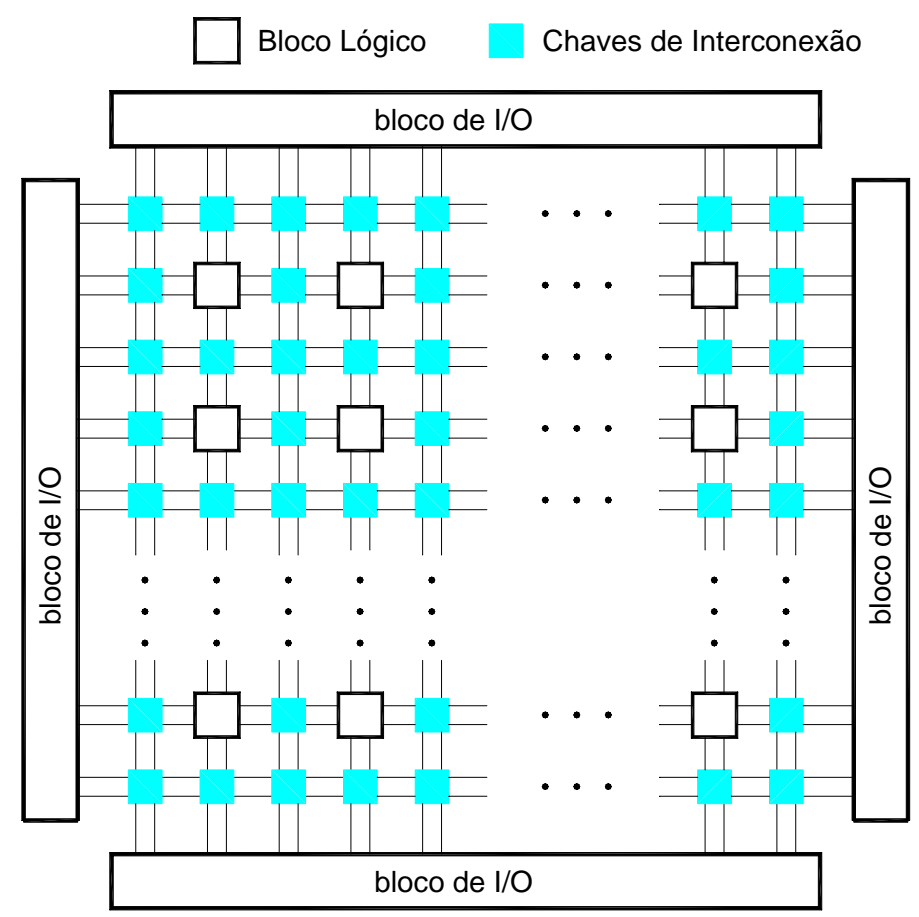

Figura 2.13: Estrutura geral de um FPGA (Brown e Vranesic, 2000)

de entrada dos três multiplexadores, que dependendo dos valores de $x 1$ e $x 2$ selecionam o conteúdo de uma das quatro células como saída da LUT. Os FPGA disponíveis no mercado geralmente possuem LUT de quatro ou cinco entradas.

Quando um circuito lógico é implementado em um FPGA, os blocos lógicos são programados para realizarem as funções necessárias, e as chaves de interconexão são programadas para definir o canal de comunicação entre estes blocos lógicos. As células de armazenamento nas LUT em um FPGA são voláteis, deste modo, todas as vezes que o dispositivo for energizado deverá ter suas LUT programadas. Freqüentemente uma pequena memória para armazenar estes dados, chamada de PROM (Programable Read Only), é incluída no circuito da placa onde encontra-se o FPGA. As células no FPGA são carregadas automaticamente da PROM quando o chip é energizado.

\subsubsection{FPGA de Última Geração}

Atualmente existem diversos fabricantes de dispositivos FPGA, dentre os quais podemos citar as empresas Altera, Xilinx, Actel, Cypress Semiconductor, QuickLogic e 


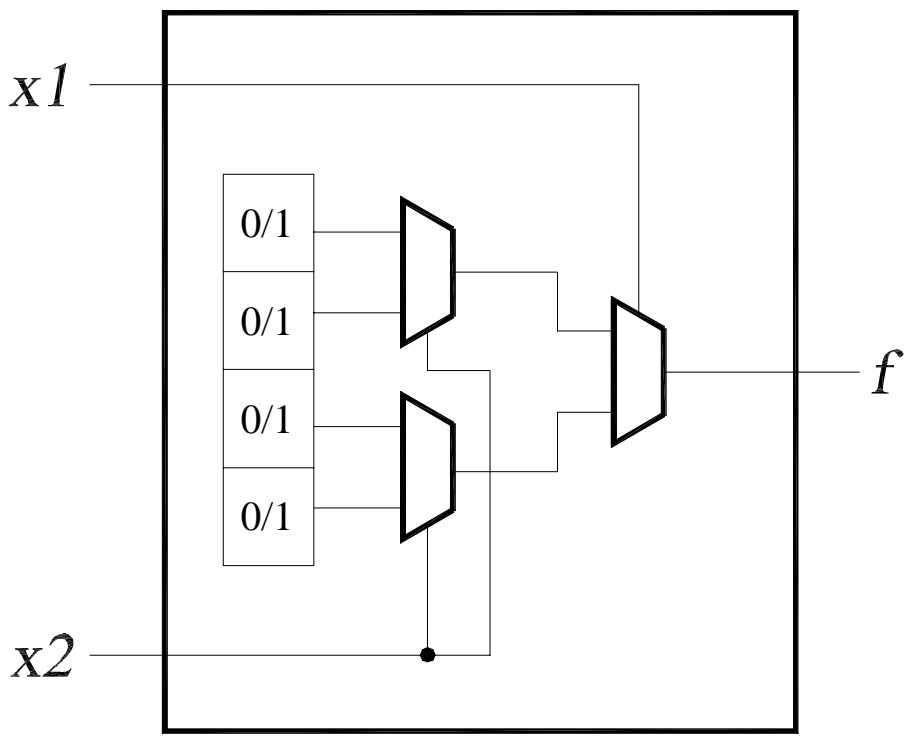

Figura 2.14: Estrutura de uma LUT de duas entradas (Brown e Vranesic, 2000)

Lattice/Vantis Corporation. As empresas Altera e Xilinx são as que representam a maior parte deste mercado, oferecendo uma grande variedade de dispositivos.

Os dispositivos FPGA fornecidos pela empresa Altera são agrupados em famílias conforme suas principais características, sendo a família Stratix para alta densidade, Cyclone para baixo custo, Excalibur para processador embutido e Stratix GX para transceiver embutido. A tabela 2.1 apresenta os dispositivos que constituem estas famílias e suas principais características.

Os elementos lógicos apresentados na tabela 2.1 correspondem aos blocos básicos que constituem os PLD, os quais são utilizados pela Altera para determinar o tamanho dos dispositivos. A medida da capacidade dos dispositivos apresentada através de elementos lógicos é considerada mais tangível do que a medida apresentada através de portas lógicas (Altera, 2003a).

As famílias de dispositivos de FPGA da empresa Xilinx são classificadas em VirtexII Pro, Virtex-II, Virtex-E Extended Memory, Virtex-E, Virtex, Spartan-3, Spartan-IIE, Spartan-II e Spartan/XL. Estas famílias podem ser agrupadas em dois grandes grupos, o Virtex para sistemas que requeiram alta performance e densidade e a Spartan para sistemas sensíveis ao custo. Devido a grande quantidade de dispositivos e famílias de 


\begin{tabular}{|c|c|c|c|c|c|c|}
\hline Família & FPGA & $\begin{array}{l}\text { Elementos } \\
\text { Lógicos }\end{array}$ & $\begin{array}{l}\text { Total de } \\
\text { RAM Bits }\end{array}$ & $\begin{array}{l}\text { Blocos } \\
\text { de DSP }\end{array}$ & PLL & $\begin{array}{l}\text { Pinos de } \mathrm{I} / \mathrm{O} \\
\text { para uso geral }\end{array}$ \\
\hline \multirow{7}{*}{ Stratix } & EP1S10 & 10.570 & 920.448 & 6 & 6 & 426 \\
\hline & EP1S20 & 18.460 & 1669248 & 6 & 6 & 586 \\
\hline & EP1S25 & 25.660 & 1.944 .576 & 6 & 6 & 706 \\
\hline & EP1S30 & 32.470 & 3.317 .184 & 10 & 10 & 726 \\
\hline & EP1S40 & 41.250 & 3.423 .744 & 14 & 12 & 822 \\
\hline & EP1S60 & 57.120 & 5.215 .104 & 18 & 12 & 1.022 \\
\hline & EP1S80 & 79.040 & 7.427 .520 & 22 & 12 & 1.238 \\
\hline \multirow{5}{*}{ Cyclone } & EP1C3 & 2.910 & 59.904 & - & 1 & 104 \\
\hline & EP1C4 & 4.000 & 78.336 & - & 2 & 301 \\
\hline & EP1C6 & 5.980 & 92.160 & - & 2 & 185 \\
\hline & EP1C12 & 12.060 & 239.616 & - & 2 & 249 \\
\hline & EP1C20 & 20.060 & 294.912 & - & 2 & 301 \\
\hline \multirow{3}{*}{ Excalibur } & EPXA1 & 4.160 & 393.216 & - & 1 & 246 \\
\hline & EPXA2 & 16.640 & 1.572 .864 & - & - & 488 \\
\hline & EXPA10 & 38.400 & 4.194 .304 & - & - & 711 \\
\hline \multirow{3}{*}{ Stratix GX } & $\begin{array}{l}\text { EP1SGX10C } \\
\text { EP1SGX10D }\end{array}$ & 10.570 & 920.448 & 6 & 4 & 366 \\
\hline & $\begin{array}{l}\text { EP1SGX25C } \\
\text { EP1SGX25D } \\
\text { EP1SGX25F }\end{array}$ & 25.660 & 1.944 .576 & 10 & 4 & $462 / 614$ \\
\hline & $\begin{array}{l}\text { EP1SGX40D } \\
\text { EP1SGX40G }\end{array}$ & 41.250 & 3.423 .744 & 14 & 8 & 638 \\
\hline \multirow{6}{*}{ Stratix II } & EP2S15 & 15.600 & 419.328 & 12 & 2 & 365 \\
\hline & EP2S30 & 33.880 & 1.369 .728 & 16 & 2 & 499 \\
\hline & EP2S60 & 60.440 & 2.544 .192 & 36 & 4 & 717 \\
\hline & EP2S90 & 90.960 & 4.520 .488 & 48 & 4 & 901 \\
\hline & EP2S130 & 132.540 & 6.747 .840 & 63 & 4 & 1109 \\
\hline & EP2S180 & 179.400 & 9.383 .040 & 96 & 4 & 1173 \\
\hline
\end{tabular}

Tabela 2.1: Características dos FPGA da Altera 
FPGA da Xilinx, é abordada somente a famílias Virtex-II Pro, a qual faz parte da mais nova geração (quarta geração) de dispositivos do grupo Virtex e a Spartan-3, a família mais recente do grupo Spartan. As características dos dispositivos pertencentes a estas famílias são apresentados através da tabela 2.2 .

\begin{tabular}{|c|c|c|c|c|c|}
\hline Família & FPGA & $\begin{array}{l}\text { Células } \\
\text { Lógicas }\end{array}$ & BRAM (Kbits) & $\begin{array}{c}\text { Processadores } \\
\text { PowerPC }\end{array}$ & $\begin{array}{c}\text { Multiplicador } \\
\text { 18x18 Bits }\end{array}$ \\
\hline \multirow{10}{*}{ Virtex-II Pro } & XC2VP2 & 3.168 & 216 & 0 & 12 \\
\hline & $\mathrm{XC} 2 \mathrm{VP} 4$ & 6.768 & 504 & 1 & 28 \\
\hline & $\mathrm{XC2VP7}$ & 11,088 & 792 & 1 & 44 \\
\hline & XC2VP20 & 20,880 & 1.584 & 2 & 88 \\
\hline & XC2VP30 & 20,880 & 2.448 & 2 & 136 \\
\hline & $\mathrm{XC} 2 \mathrm{VP} 40$ & 43,632 & 3.456 & 2 & 192 \\
\hline & XC2VP50 & 53,136 & 4.176 & 2 & 232 \\
\hline & XC2VP70 & 74,448 & 5.904 & 2 & 328 \\
\hline & XC2VP100 & 99,216 & 7.992 & 2 & 444 \\
\hline & XC2VP125 & 125,136 & 10.008 & 4 & 556 \\
\hline \multirow{8}{*}{ Spartan-3 } & XC3S50 & 1.728 & 72 & - & 4 \\
\hline & XC3S200 & 4.320 & 216 & - & 12 \\
\hline & XC3S400 & 8.064 & 288 & - & 16 \\
\hline & XC3S1000 & 17.280 & 432 & - & 24 \\
\hline & XC3S1500 & 29.952 & 576 & - & 32 \\
\hline & XC3S2000 & 46.080 & 720 & - & 40 \\
\hline & XC3S4000 & 62.208 & 1.728 & - & 96 \\
\hline & XC3S5000 & 74.880 & 1.872 & - & 104 \\
\hline
\end{tabular}

Tabela 2.2: Características dos FPGA da Xilinx

As células lógicas da tabela 2.2 correspondem aos blocos básicos dos dispositivos da Xilinx, que servem para indicar a capacidade dos seus FPGA. Nesta tabela também é apresentado o número de processadores da IBM PowerPC 406 que são integrados dentro dos dispositivos Virtex-II Pro.

\subsubsection{Projetar ASIC a partir de FPGA}

A implementação de chips do tipo ASIC é um processo que requer alta tecnologia para o seu desenvolvimento, portanto, este processo é realizado somente por empresas especializadas (Hamblen e Furman, 2001). O custo de cada unidade destes chips depende diretamente da quantidade a ser fabricada, normalmente o valor para fabricar apenas algumas unidades é extremamente alto. Isso faz com que o FPGA seja freqüentemente 
utilizado na fase de projeto e verificação do sistema, pois o mesmo pode ser programado e reprogramado diretamente pelo usuário, ao contrário do ASIC, que não pode ser programado. Porém, o uso do FPGA não é adequado para a produção em larga escala de sistemas, pois é $50 \%$ mais lento e consome $40 \%$ a mais de energia do que, por exemplo, um ASIC produzido pela empresa Altera (Altera, 2004). Além disso, o seu tamanho é maior e seu custo fica elevado. Quando a produção for em larga escala, o custo do FPGA fica superior ao do ASIC, essa inversão ocorre porque no FPGA, existem diversos recursos que são utilizados para permitir a reconfigurabilidade, já no ASIC, não são necessários.

As Empresas fabricantes de chips procuram tornar cada vez mais próxima a distância existente entre a arquitetura de um chip ASIC e de um FPGA para que ocorra a redução do custo e do tempo gasto neste processo de migração. Uma maneira adotada pela empresa Altera para realizar esta aproximação, foi desenvolver chips do tipo ASIC com características semelhantes ao FPGA. A construção de um FPGA da família Stratix é realizada através da integração de diversas camadas, conforme podemos constatar na figura 2.15. A camada mais profunda contém a memória, blocos de DSP (Digital Signal Process), PLL (Phase Locked Loop), EL(Logic Elements) e o roteamento interno entre estes componentes. Nas camadas superiores, é realizado o roteamento de sinal e de configuração, a distribuição da alimentação e a interface com os pinos (Flip-Chip ${ }^{2}$ ). O ASIC com características semelhantes ao FPGA é composto por duas camadas, onde a camada mais profunda possui matrizes bases que são desenvolvidas para remover o circuito de configuração, roteamento programável e a programabilidade da memória e da lógica. No nível superior, é reservada uma camada para o projeto do usuário. Como somente a camada superior precisa ser criada, isso permite acelerar o processo de migração e conseqüentemente obter os benefícios citados anteriormente.

\footnotetext{
${ }^{2}$ Flip-chip é uma tecnologia criada pela IBM em 1964 para interconectar circuitos integrados em suas bases.
} 


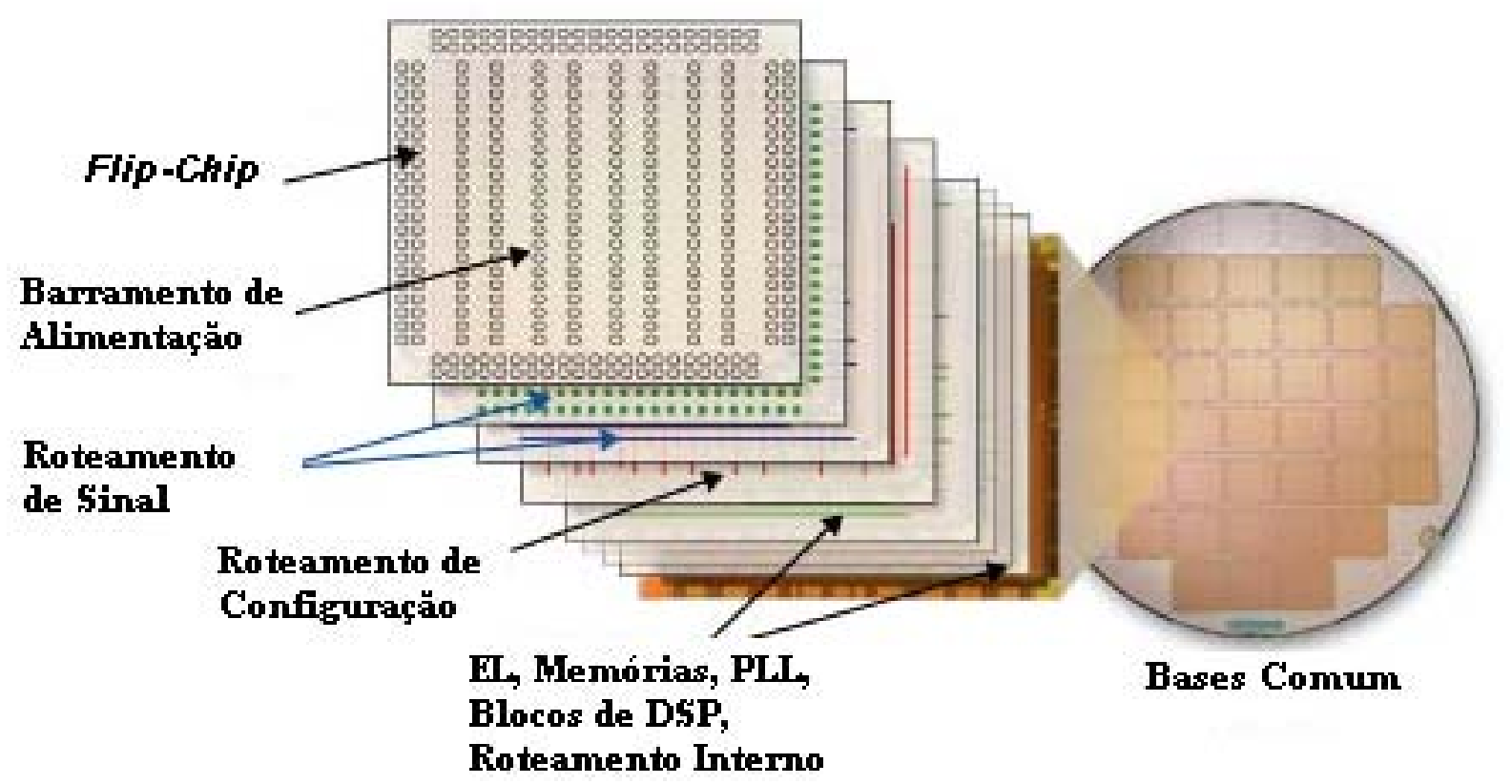

Figura 2.15: Camadas num FPGA da família Stratix (Altera, 2003a)

\subsection{Rede Neural Booleana}

A rede neural booleana não foi desenvolvida com o objetivo de entender e modelar o cérebro humano, como nos modelos apresentados em McCullough e Pitts (1943) apud Carvalho (1994), mas sim, para servir como uma ferramenta de engenharia para aplicação em reconhecimento de padrões através de uma abordagem diferente para construção de rede neural (Carvalho, 1994).

Os neurônios da rede neural booleana recebem e produzem somente dados binários, o que limita a sua aplicação em sistemas que operam somente com este tipo de dado. Apesar desta restrição, este tipo de rede é eficiente, pode ser facilmente implementada no hardware e seus algoritmos de aprendizagem normalmente são rápidos (single shot) (Carvalho, 1994) (Austin, 1998).

Há um grande número de redes neurais booleanas, que podem ser divididas em dois grupos. O primeiro grupo é composto por arquiteturas nas quais os neurônios são baseados em unidades de memória de acesso randômico (Random Access Memory - RAM), por isso essas arquiteturas são conhecidas por modelo baseado em RAM. O segundo grupo contém as arquiteturas que restringem as funções representadas por suas unidades de memória 
para um número reduzido de funções booleanas ou usa peso binário (Carvalho, 1994). Nessa dissertação é adotado o modelo N-tuple do primeiro grupo, que será apresentado a seguir.

\subsubsection{Modelo N-tuple}

O modelo N-tuple é a base para a construção de diversos modelos neurais booleanos. Cada neurônio ou unidade de processamento recebe como entrada um N-tuple (conjunto de bits) de $\mathrm{N}$ bits, por isso, este modelo é conhecido por N-tuple. Os valores destes bits são usados para endereçar uma das $2^{N}$ palavras de $\mathrm{M}$ bits de um dispositivo de memória de acesso randômico (RAM), onde M é o número de padrões. O número de bits (N) de uma unidade de processamento (neurônio) pode endereçar $2^{N}$ diferentes células, onde cada célula pode armazenar uma palavra de M-bits. Isso significa que um neurônio pode computar $\mathrm{M} \mathrm{x} 2^{2^{N}}$ diferentes funções binárias. A figura 2.16 apresenta um neurônio típico existente no modelo $\mathrm{N}$-tuple, onde $\mathrm{N}=2$ e $\mathrm{M}$, que representa o número de padrões, é igual a 36.

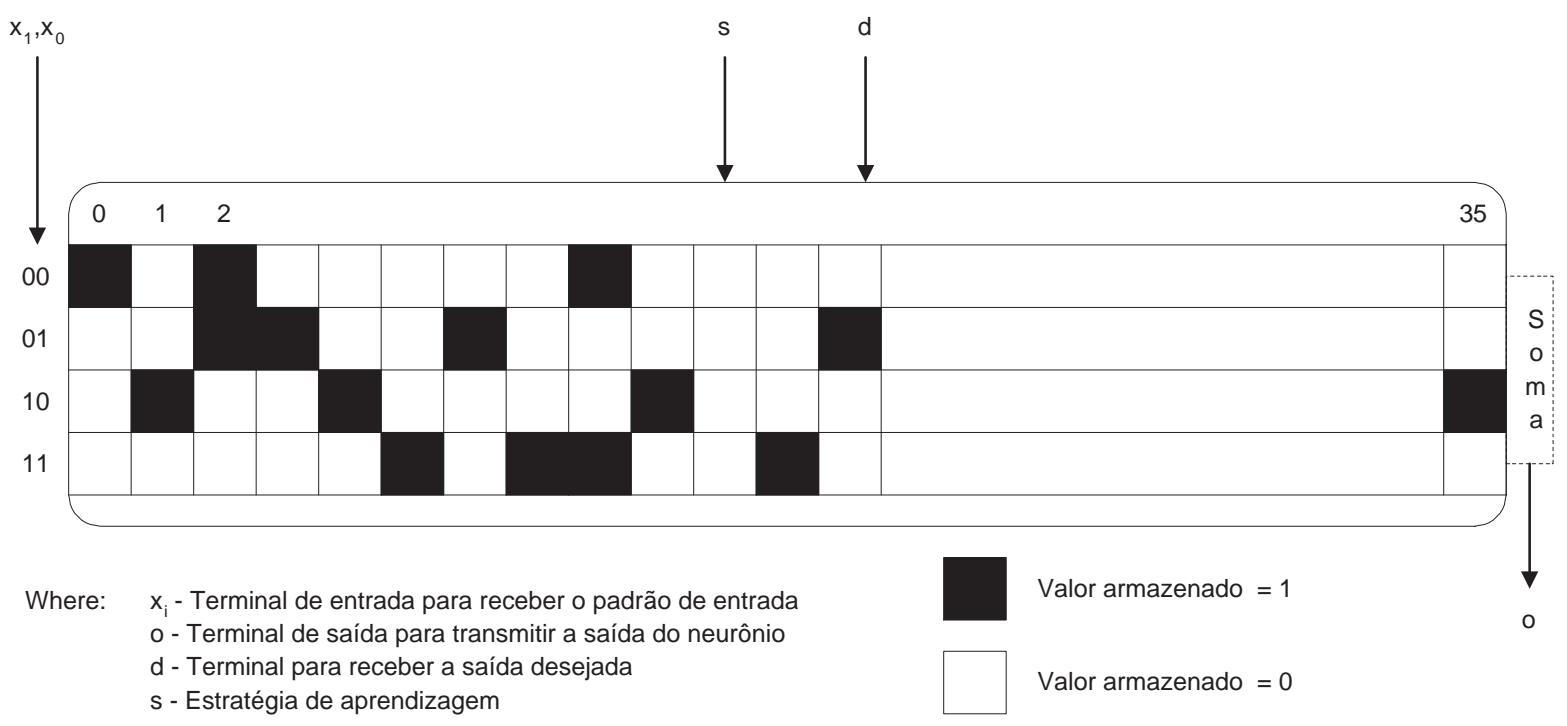

Figura 2.16: Estrutura geral de um neurônio do modelo neural N-tuple (Carvalho, 1994)

Uma rede neural N-tuple é composta por um conjunto de neurônios capaz de cobrir todos os bits de uma imagem de entrada através de suas N-tuples. Para realizar o treinamento, inicialmente todas as palavras de todos os neurônios são inicializados com 0 e para 
cada padrão apresentado a rede neural, o bit da palavra endereçada correspondente ao padrão é definido para 1. Para o reconhecimento, um padrão desconhecido é apresentado à rede neural e os bits das células das palavras endereçadas que estiverem em nível lógico 1 são contados para cada padrão. O contador do padrão que tiver maior número é indicado como vencedor.

Além do modelo de rede neural booleana N-tuple, existem vários outros modelos baseados em RAM, sendo os mais conhecidos os modelos SLAM, PLN, pRAM, GSN e SDM. Estes não serão abordados, pois a rede neural adotada neste trabalho é o modelo N-tuple. 


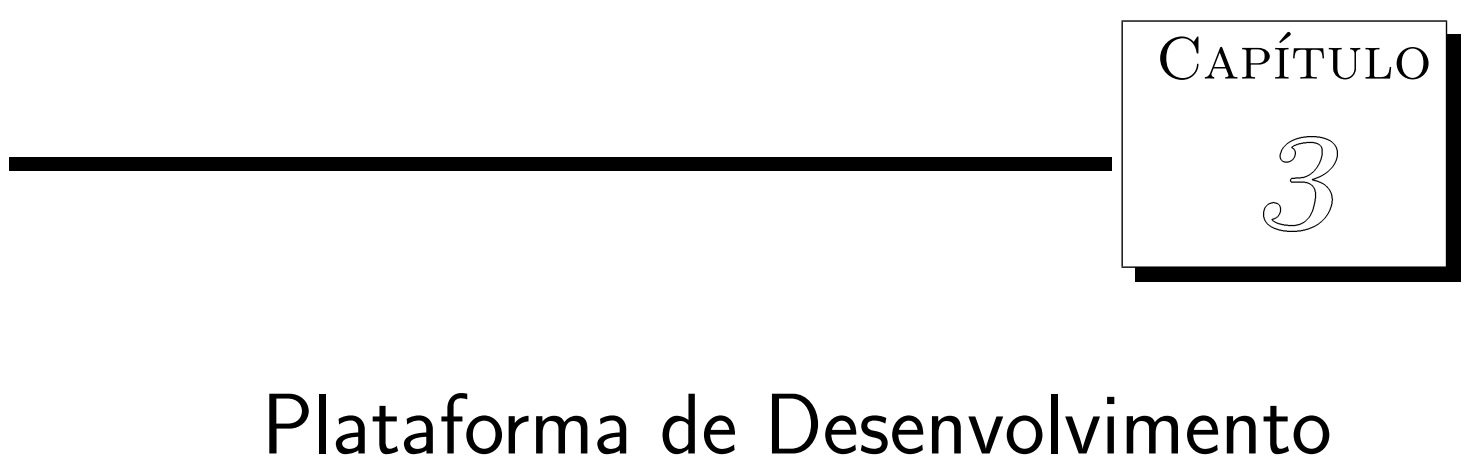

Este capítulo descreve os recursos de hardware e software que são utilizados no desenvolvimento deste trabalho e a maneira como estes recursos são utilizados. O hardware apresentado é composto pelo Kit de desenvolvimento Nios e por uma câmera digital de tecnologia CMOS; o software apresentado é composto por um conjunto de ferramentas de desenvolvimento de sistemas em chips programáveis, que são integradas pela ferramenta EDA (Electronic Design Automation) Quartus II.

\subsection{Kit de Desenvolvimento Nios}

A implementação e validação do sistema proposto em FPGA (Field Programmable Gate Array), é realizada utilizando-se o Kit de desenvolvimento Nios (edição Stratix) (Altera, 2003f), o qual é basicamente composto por uma placa com FPGA da família Stratix e por ferramentas de desenvolvimento de software embarcado, fornecido pela empresa Altera (Altera, 2003a). O propósito deste Kit é fornecer uma estrutura para acelerar o desenvolvimento de sistemas embarcados em chips, conhecidos como SOPC (SystemOn-a-Programable-Chip). Nas seções seguintes são apresentadas as informações relativas 
ao Kit de desenvolvimento que são consideradas relevantes ao sistema proposto.

\subsubsection{Placa de Desenvolvimento Nios}

A placa de desenvolvimento Nios fornece uma plataforma para o desenvolvimento de hardware de sistemas embarcados baseados no dispositivo de FPGA EP1S10F780C6 da família Stratix. Este dispositivo é composto por 10.570 elementos lógicos (LEs) e 920 Kbits de memória on-chip.

\section{Características da Placa}

As características citadas a seguir apresentam os recursos fornecidos pela placa de desenvolvimento Nios. Estas informações são importantes, pois através delas é possível constatar quais funcionalidades podem ser implementadas neste hardware.

- FPGA EP1S10F780C6 da família Stratix. Suas principais características são apresentadas através da tabela 3.1 ;

\begin{tabular}{|l|l|}
\hline Elementos Lógicos (LE) & 10.570 \\
\hline Blocos de Memória RAM (32 X 18 bits) & 94 \\
\hline Blocos de Memória RAM (128 X 36 bits) & 60 \\
\hline Blocos de Memória RAM (4K X 144 bits) & 1 \\
\hline Blocos DSP & 6 \\
\hline PLL (Phase Locked Loop) & 6 \\
\hline Pinos disponíveis ao Usuário & 426 \\
\hline
\end{tabular}

Tabela 3.1: Características do dispositivo EP1S10F780C6

- 8 Mbytes de memória flash;

- 1 Mbyte de memória SRAM (Ram Estática Assíncrona);

- 16 Mbytes de memória SDRAM (Ram Dinâmica Síncrona);

- Lógica para configuração da Stratix a partir da memória flash;

- Dispositivo ethernet MAC/PHY;

- Tensões 5,0, 3,3 e 1,5 Vcc disponíveis nos barramento de expansão; 
- Conector para cartão de memória FlashTM;

- Conector Mictor para executar debug de hardware and software;

- Duas portas DB9 de comunicação RS-232;

- Quatro botões do tipo push-button, oito LED e dois display de 7-segmentos para uso geral;

- Conector e cabo JTAG para download de datastream (dados de configuração do FPGA);

- Oscilador de $50 \mathrm{MHz}$ ligado ao FPGA;

- Circuito de Power-on reset (circuito que é acionado toda vez que o sistema for energizado).

A figura 3.1 apresenta a placa de desenvolvimento Nios, edição Stratix, o FPGA e as portas de comunicação existentes. Todos os acessórios necessários para a conexão desta placa, como a fonte de alimentação e cabo de programação, são fornecidos junto ao kit de desenvolvimento.

\subsubsection{Ferramentas de Desenvolvimento de Software Embarcado}

O ambiente de desenvolvimento é composto por um conjunto de ferramentas de desenvolvimento de sistemas em chips programáveis, conhecido como SOPC, as quais são integradas pela ferramenta EDA (Electronic Design Automation) Quartus II. Este ambiente compreende todas as fases de desenvolvimento de sistemas em FPGA e CPLD, que envolvem a descrição do projeto, síntese da lógica programada, roteamento e inserção da lógica obtida a partir da síntese no dispositivo, análise de tempos, simulação e por fim, programação e configuração do dispositivo (Altera, 2003d).

O Quartus II permite a instalação de diversos recursos que facilitam e otimizam o esforço necessário para o desenvolvimento de projetos. Neste ambiente há um megawizard para auxiliar o usuário durante a inserção de funções em seu sistema, dentre estas 


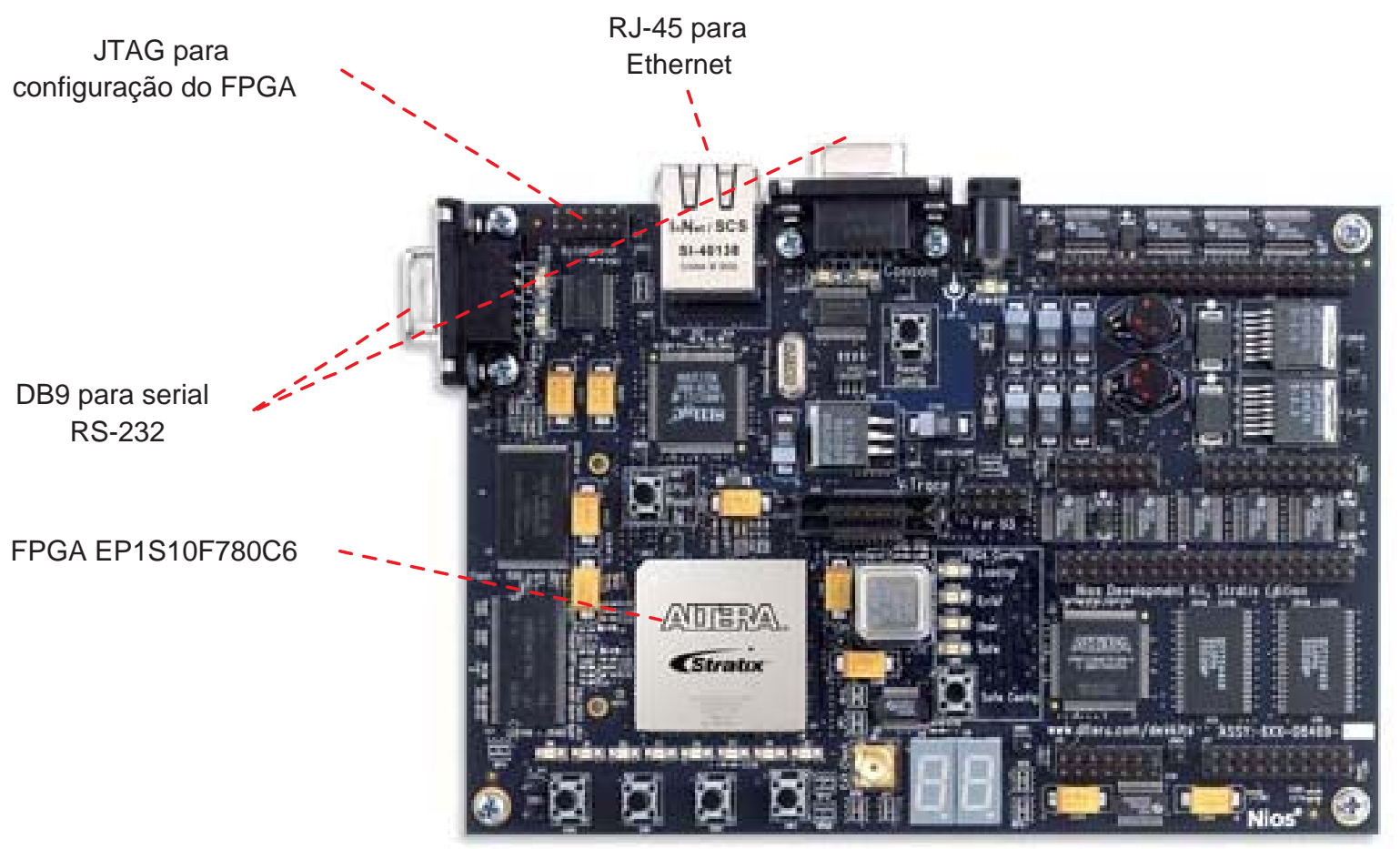

Figura 3.1: Placa de desenvolvimento Nios - Edição Stratix

funções podemos citar os componentes que realizam operações aritméticas, memórias, portas lógicas, DSP e processadores embutidos.

\subsubsection{Processador RISC Customizável}

O processador RISC (Reduced Instruction Set Computer) de propósito geral, customizável, é constituido por um soft-core desenvolvido pela empresa Altera para ser embutido nos dispositivos lógicos programáveis (PLD), que é conhecido como processador NIOS (Altera, 2003e). Atualmente o processador NIOS suporta variações de arquitetura de 32 e 16 bits, ambas variações usam instruções de 16 bits. As principais características da arquitetura Nios são:

- Largura do barramento de dados e de endereço de 16 ou 32 bits;

- Unidade lógica e aritmética (ULA) de 16 ou 32 bits;

- Registradores internos de 16 ou 32 bits;

- Conjunto de instruções de 16 bits; 
- Freqüência máxima de operação 125MHz;

- Suporte para memória on-chip ou off-chip;

- Conjunto de 512 registradores de propósito geral;

- Pipeline de 5 estágios, com dados e instruções separados;

- Há um barramento específico para busca de instruções. O esquema de busca especulativa de instruções assume que o salto nunca será tomado, este esquema é conhecido como branch-not-taken;

- Memória cache para instruções, quando habilitada, o processador executa uma instrução por ciclo de clock;

- Lógica customizada para a ULA.

O processador Nios utiliza em torno de 1000 elementos lógicos quando configurado em 16 bits e 1500 em 32 bits. O FPGA EP1S10F780C6 existente na placa de desenvolvimento, abordada anteriormente, possui 10.570 elementos lógicos. A partir deste valor podemos estimar qual o percentual de hardware necessário para a sua implementação no FPGA.

Sistemas baseados em processadores embutidos Nios incluem um ou mais processadores e o barramento Avalon (barramento designado à conexão de processadores e periféricos on-chip (Altera, 2003b)). Também podem incluir múltiplos barramentos mestres, no caso de existir mais de um processador.

A figura 3.2 mostra um exemplo de um sistema particular contendo uma CPU Nios com cache de instruções e de dados, um on-chip debug core, um controlador de acesso direto a memória (DMA), diversos periféricos (UART, PIO, ethernet e interface de memória) e um multi-master Avalon Switch utilizado para realizar a conexão dos componentes do sistema.

On-chip debug core é um módulo que oferece recursos ao projetista para realizar o debug de processador embutido. Este recurso é opcional, mas caso seja selecionado, o módulo de debug provê um conjunto de características incluindo controle de execução, 


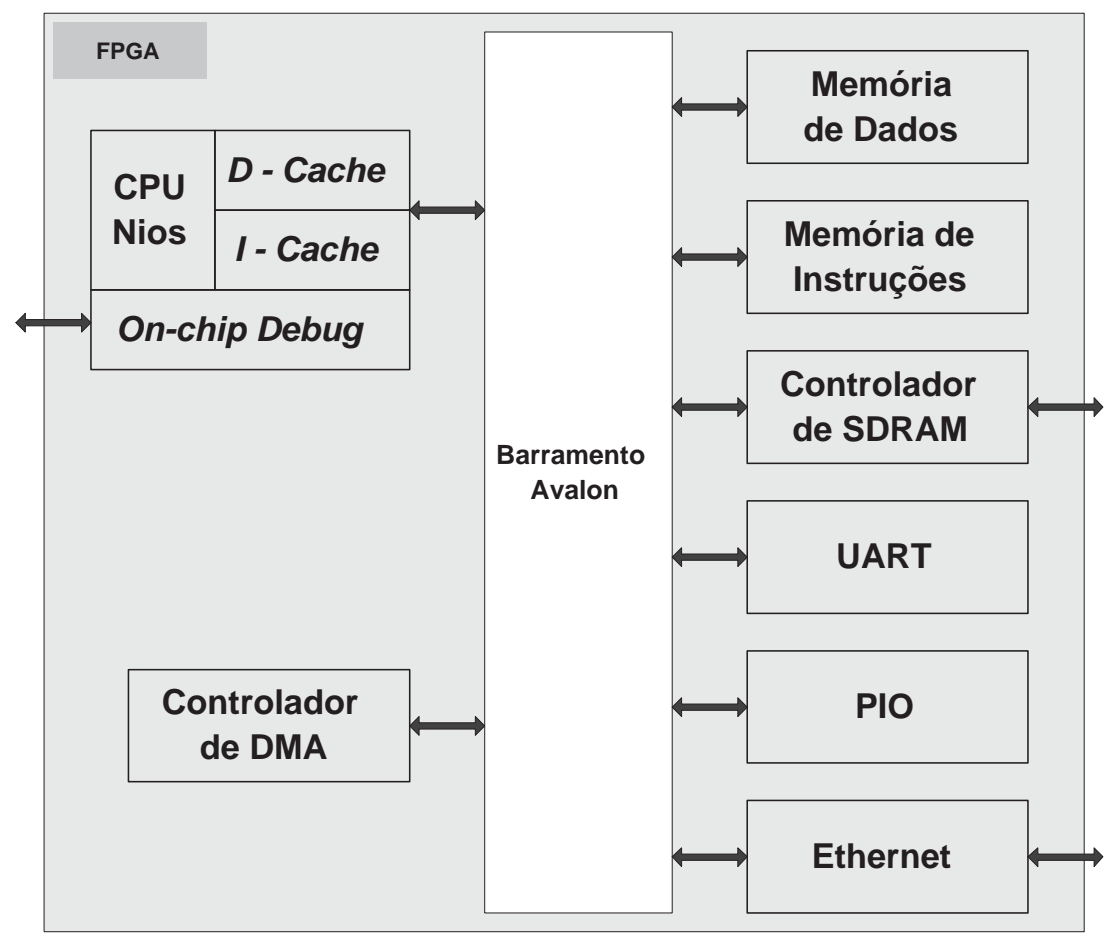

Figura 3.2: Componentes do sistema com processador Nios

pontos de parada do hardware, pontos de parada do software, on-chip trace e off-chip trace.

\section{Ferramentas GNUpro para Software Embarcado}

As ferramentas do GNUpro são baseadas no padrão industrial de software livre do GNU, distribuído pela empresa Red Hat. Todos os processadores embutidos da Altera suportam as ferramentas de desenvolvimento e de debug do GNUpro (Altera, 2003c), que são otimizadas para este tipo de processador, fornecendo um ambiente de desenvolvimento familiar para o projetista, incluindo:

- Compilador C (gcc) and $\mathrm{C}++(\mathrm{g}++)$;

- Debugger (gdb) a nível de código e assembler;

- Assembler GNU (gas);

- Linker GNU (ld);

- Software code profiler (gprof) GNU; 
- Insight Debugger;

- Utilitários binários específicos do processador Nios.

\subsection{Módulo de Câmera CMOS}

A imagem é adquirida através de um módulo de câmera CMOS com saída digital colorida (C3188A - 1/3") (Electronics, 2003). Este módulo fornece os sinais da imagem continuamente em formato binário de 8/16 bits de largura através de uma porta. Estes sinais são lidos e tratados pelo sistema a fim de obter os frames da imagem. Neste módulo de câmera também existe sinais de controle da imagem, tais como: exposição, gama, ganho, balanço, janela ativa, que são programados através da interface I2C presente na câmera. Na figura 3.3 é apresentado uma foto desta câmera junto a uma régua, onde podemos verificar o seu tamanho em centímetros.

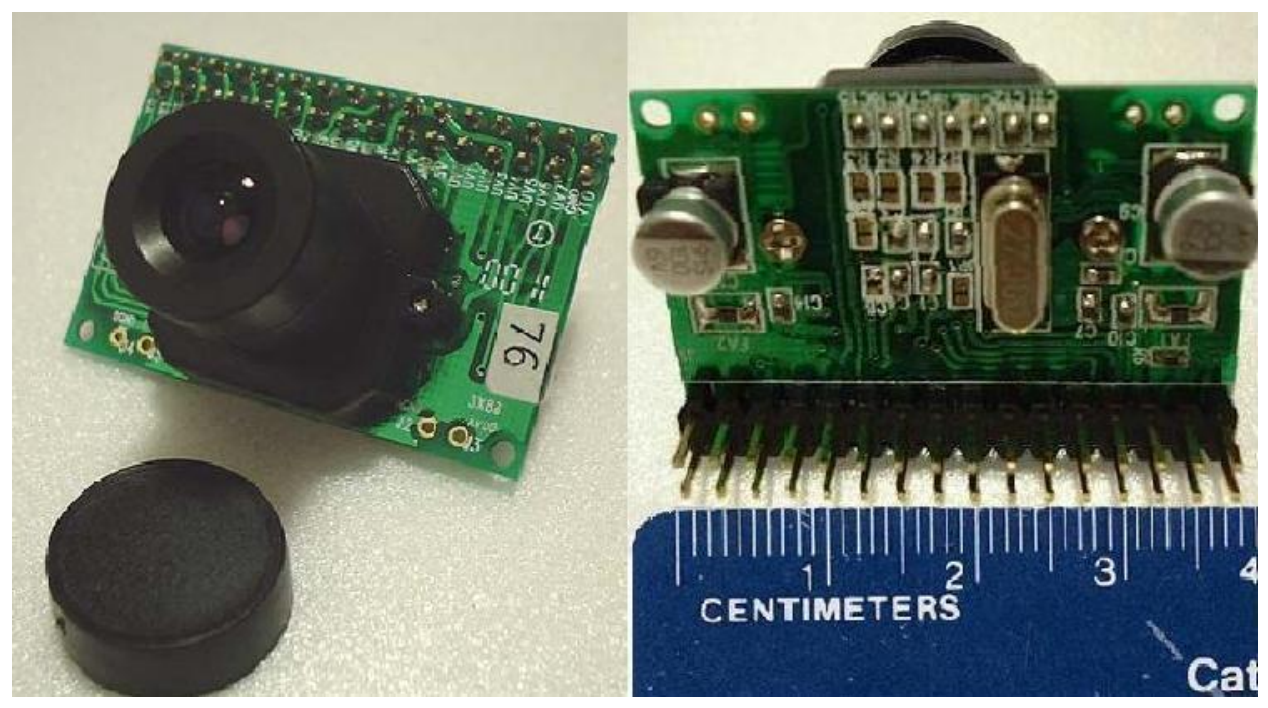

Figura 3.3: Foto da câmera CMOS (C3188A - 1/3")

O módulo embutido na câmera é composto por um único circuito integrado CMOS (OV7620). Os principais blocos que compõem este integrado são: matriz (janela para captar a cena) de 640x480 microsensores para captura de uma imagem de 640x480 pixels, processador de sinal analógico, conversor de sinal A/D de 10 bits, interface I2C, multiplexador de vídeo analógico, porta de vídeo e padronizador de dado digital. Estes blocos do circuito integrado são apresentados na figura 3.4. 


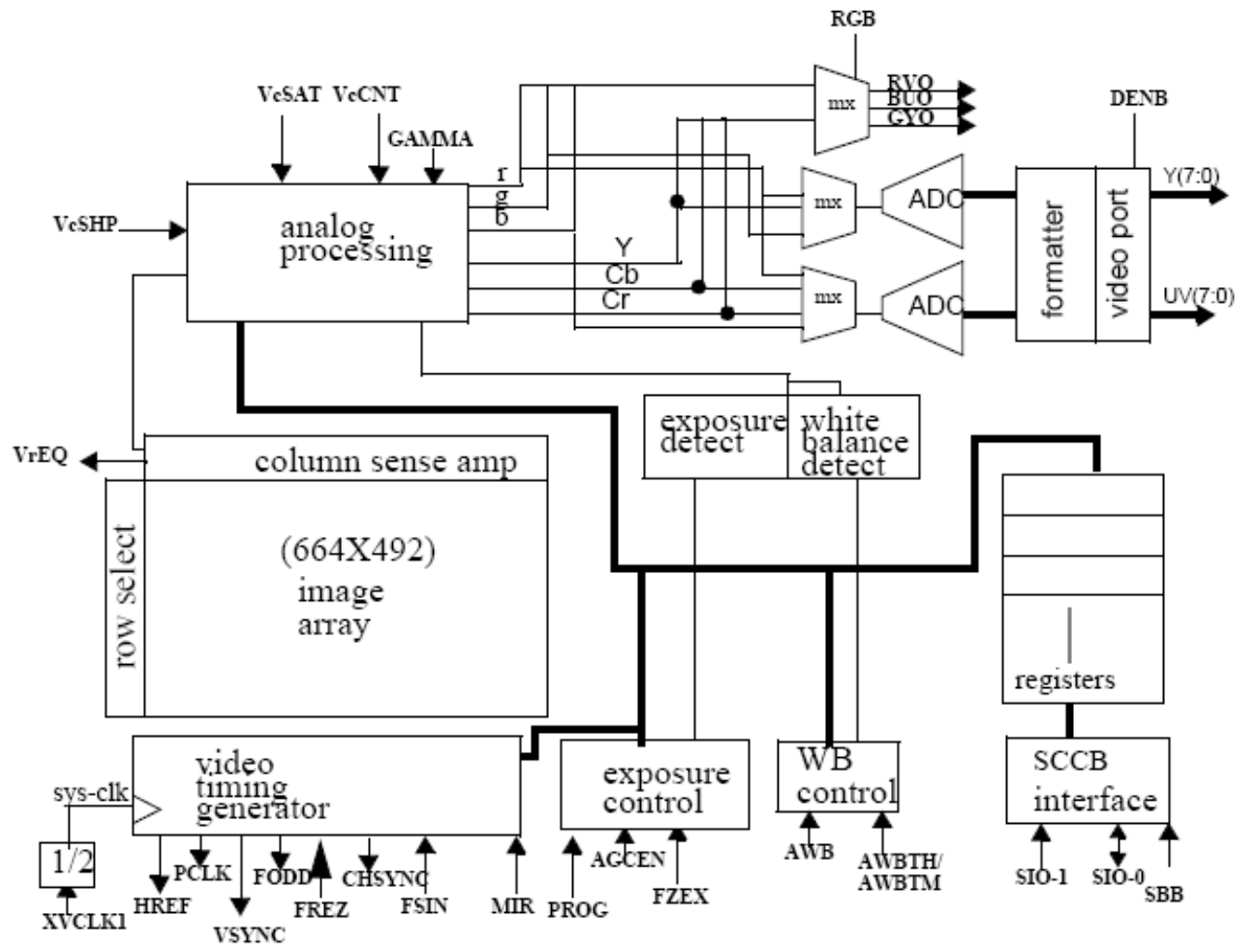

Figura 3.4: Diagrama em blocos do circuito integrado OV7620

\subsection{Conexão da Câmera com a Placa de Desenvolvimento}

A câmera CMOS e a placa de desenvolvimento Nios são conectadas fisicamente para que os sinais possam ser enviados entre elas. Para realizar esta tarefa, é necessário analisar a compatibilidade dos sinais, principalmente em relação aos níveis de tensão e consumo de corrente. Na placa de desenvolvimento Nios há conectores de expansão de propósito geral onde há pinos que fornecem tensões de alimentação nos níveis de 1,5, 3,2 e 5,0 Vcc; sinais de terra (ground) e pinos que podem ser utilizados como meio para entrada ou saída, dependendo da programação, de sinais no sistema. A alimentação da câmera é 5,0 Vcc e a potência de operação $120 \mathrm{~mW}$, deste modo, é utilizado o 5,0 Vcc fornecido pelo conector de expansão, que pode drenar corrente de até 1 Amper. A câmera considera nível lógico 0, todo o sinal com nível de tensão menor ou igual a 0,8 Vcc e o FPGA da placa de desenvolvimento os sinais menores ou iguais a 0,7 Vcc. Nível lógico 1 é considerado pela câmera sinais de 2 Vcc ou maior, já o FPGA se for igual ou maior a 1,7 Vcc. Estas informações analisadas servem de base para certificar a compatibilidade, pois além destes 
dados, há necessidade de analisar a corrente fornecida e consumida por estes sinais e as freqüências que estes dispositivos de hardware podem operar. Na figura 3.5 é apresentado a câmera CMOS conectada na placa de desenvolvimento Nios.

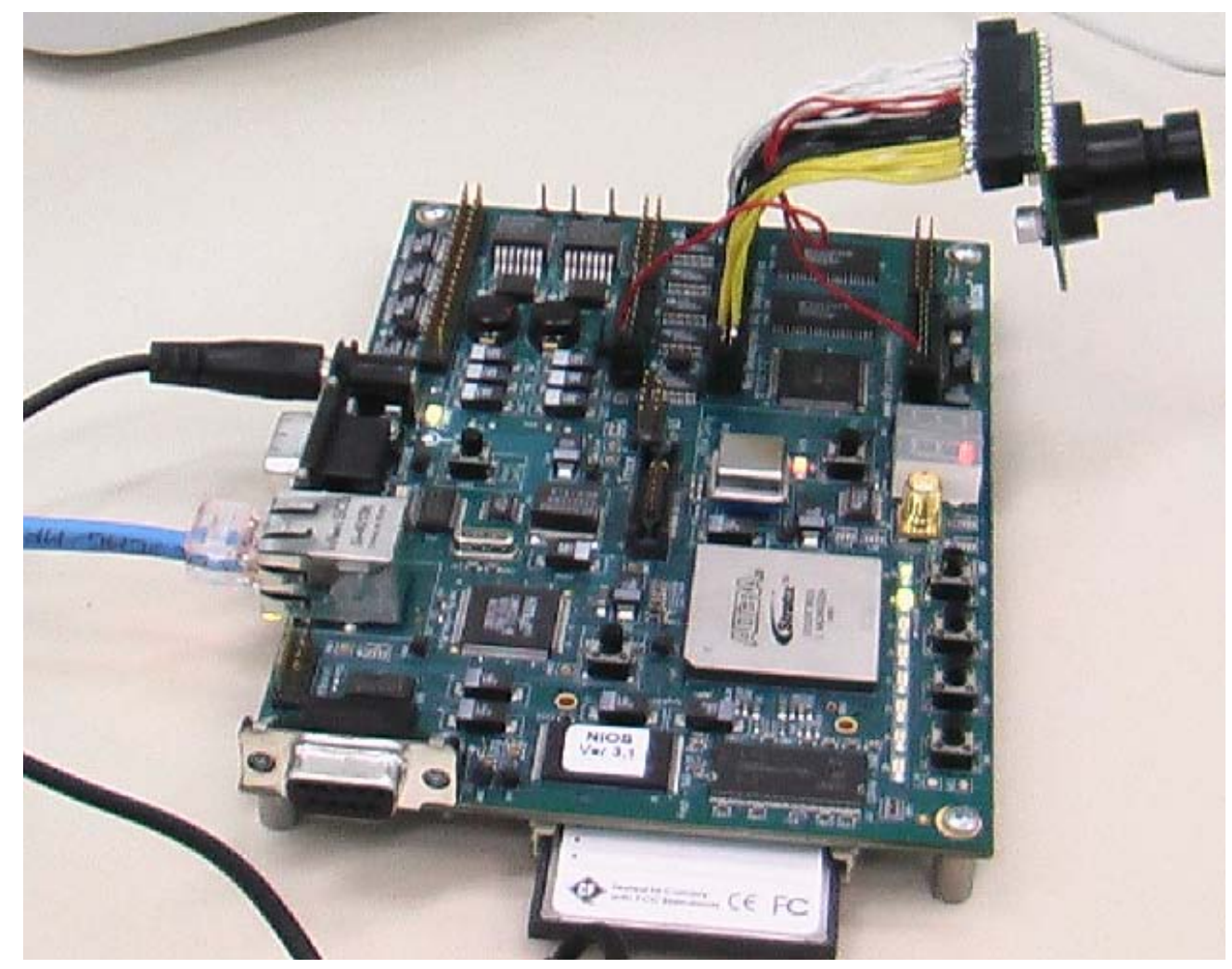

Figura 3.5: Câmera CMOS e a placa de desenvolvimento Nios

\subsection{Monitoramento da Imagem no Sistema}

Os sinais fornecidos pela câmera CMOS são digitais, podendo ser utilizados diretamente pelo FPGA. Essa é uma das vantagens em relação ao uso de câmeras que fornecem sinais analógicos, pois o mesmo teria de ser convertido para digital. Em contra partida, para reproduzir as imagens seria mais fácil, pois é comum encontrar aparelhos eletrônicos, como televisores e computadores, com entrada de vídeo analógico capaz de reproduzir imagens em diversos padrões. Uma das soluções encontradas para monitorar a imagem que está sendo fornecida pela câmera digital é implementar em software a comunicação da placa de desenvolvimento Nios, através de sua porta ethernet, com um computador. Além de monitorar diretamente a imagem fornecida pela câmera, o uso de monitoramento via 
ethernet permite que o usuário monitore internamente as transformações que a imagem sofre durante as fases de processamento do sistema. Isso auxilia o desenvolvimento, pois permite a verificação do funcionamento dos blocos do sistema de visão computacional.

O kit de desenvolvimento Nios fornece suporte para implementar o software de comunicação via ethernet em diversos protocolos (ARP, IP, ICMP, UDP e TCP). Os protocolos TCP/IP foram escolhidos para realizarem a comunicação com o computador, o qual comunica-se com um programa implementado através da linguagem de programação Delphi, utilizando-se sockets. Para que a imagem seja monitorada, basta digitar o número IP e a porta de comunicação que estão associados a placa de desenvolvimento Nios. Com este ambiente também foi implementada uma "câmera fotográfica digital" para a realização dos testes de captura de imagem, que funcionou plenamente obtendo-se fotos coloridas de boa qualidade. 


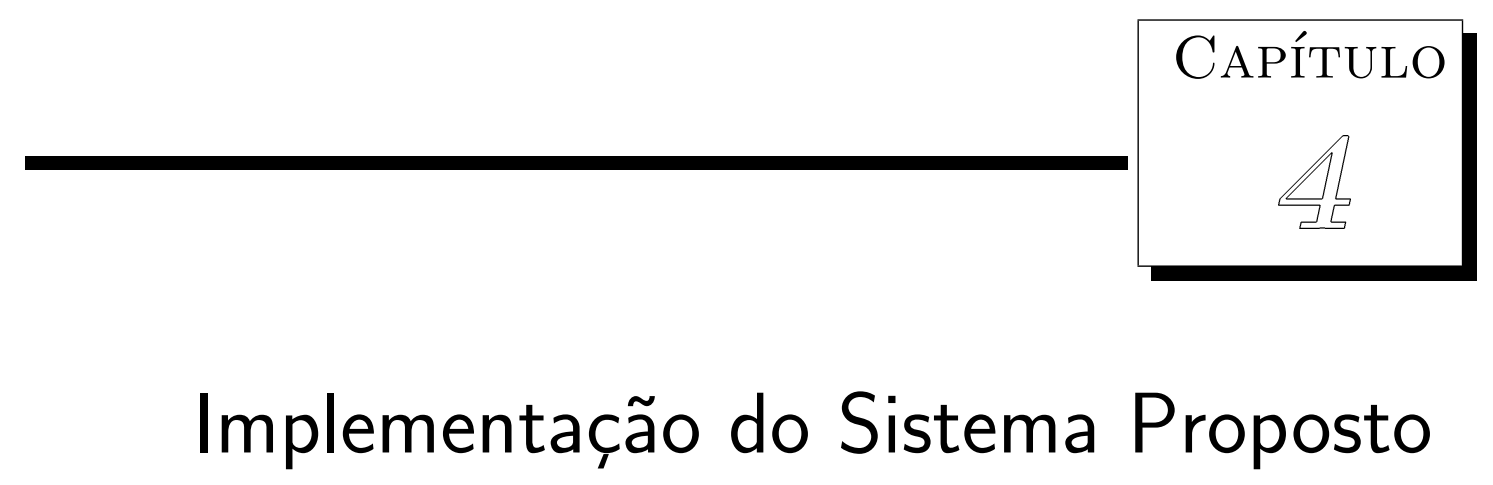

Este capítulo apresenta a implementação e os resultados obtidos do módulo de aquisição e de pré-processamento de imagem colorida proposto neste trabalho. Além disso, é apresentada a implementação de um sistema de monitoramento de imagens, utilizado para auxiliar no desenvolvimento do sistema. Todas as funcionalidades apresentadas neste capítulo foram implementadas utilizando-se a ferramenta EDA Quartus II e o dispositivo reconfigurável (FPGA) existentes no kit de desenvolvimento apresentado na seção 3.1. A implementação das funcionalidades foi realizada utilizando-se a linguagem de programação VHDL e alguns componentes lógicos fornecidos pela ferramenta Quartus II. A figura 4.1 mostra as etapas existentes na compilação e execução do sistema em FPGA, onde inicialmente é descrito as funcionalidades utilizando-se a linguagem de descrição de hardware e por fim obtem-se o sistema implementado na placa de desenvolvimento do kit. Todas estas etapas são realizadas utilizando-se as ferramentas EDA do Kit.

A figura 4.2 apresenta em forma de blocos os periféricos e a organização das funcionalidades implementadas no sistema proposto. Esta figura está dividida em dois níveis, onde o nível A agrupa as funcionalidades do módulo de aquisição e de pré-processamento de imagem e o nível B é utilizado para implementação de funções específicas de processa- 
Código fonte VHDL

\begin{tabular}{|c|c|c|}
\hline \multicolumn{3}{|l|}{ ENTITY read pixel is } \\
\hline PORT(rst,vsync, fodd, pclk, href & $:$ in & STD LOGIC; \\
\hline$U V, Y$ & $:$ in & STD_LOGIC_VECTOR (7 downto 0$)$; \\
\hline rst cam,pwdn, exclk, rgb ready & : out & STD LOGIC; \\
\hline$r, g, b$ & : out & STD_LOGIC_VECTOR ( 7 downto 0$)$; \\
\hline address & : out & STD LOGIC_VECTOR ( 16 downto 0 ) \\
\hline ); & & \\
\hline \multicolumn{3}{|l|}{ END read_pixel; } \\
\hline \multicolumn{3}{|l|}{ ARCHITECTURE arch OF read_pixel IS } \\
\hline \multicolumn{3}{|l|}{ TYPE estados IS(p1,p2); } \\
\hline \multicolumn{3}{|l|}{ SIGNAL state: estados; } \\
\hline \multicolumn{3}{|l|}{ SIGNAL rasc_rgb_ready: STD_LOGIC; } \\
\hline \multirow{2}{*}{\multicolumn{3}{|c|}{$\begin{array}{l}\text { SIGNAL rasc_g: STD_LOGIC_VECTOR (7 downto } 0) \text {; } \\
\text { SIGNAL rasc } b \text { : STD LOGIC VECTOR }(7 \text { downto } 0) \text {; }\end{array}$}} \\
\hline & & SIGNAL rasc_b : STD_LOGIC_VECTOR (7 downto 0); \\
\hline BEGIN & & \\
\hline rst cam < = '0'; & & \\
\hline
\end{tabular}
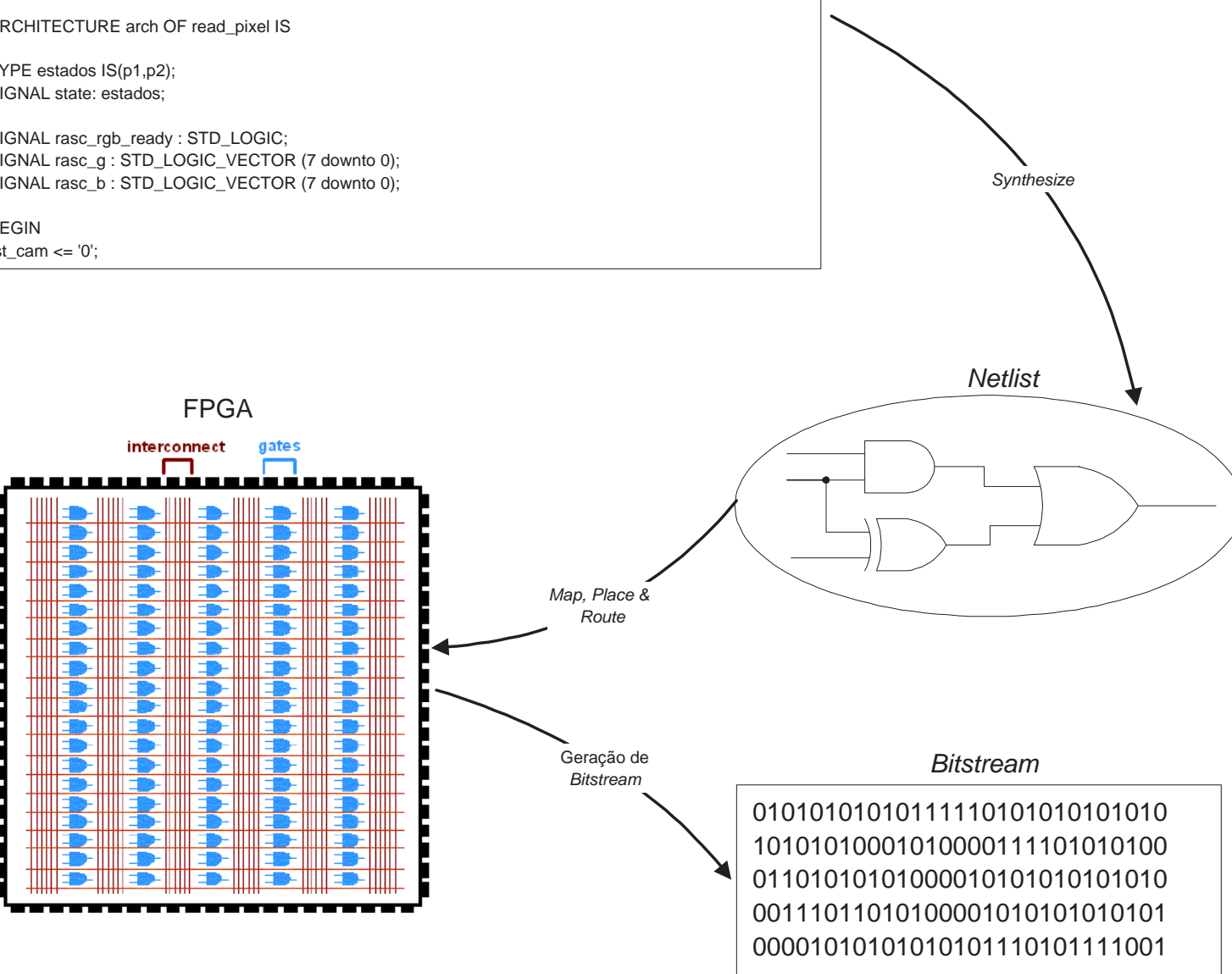

Placa do Kit Nios (edição Stratix) e a Câmera Digital

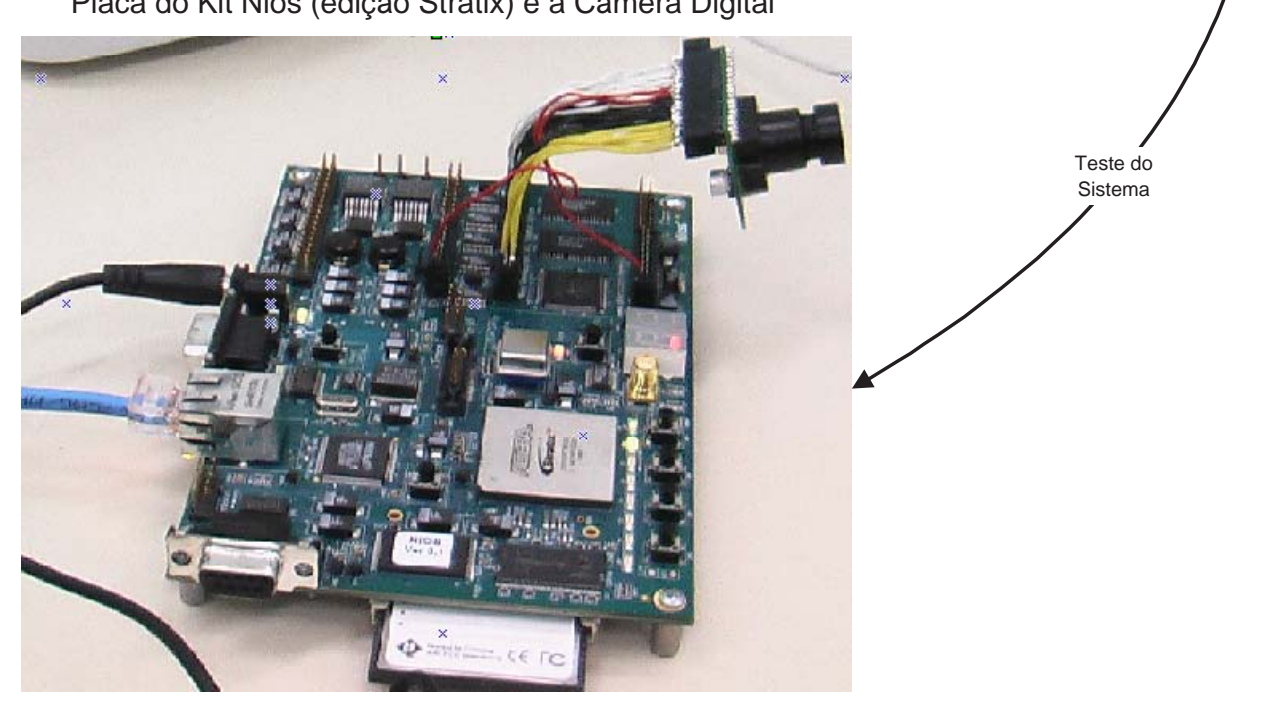

Figura 4.1: Descrição, compilação e teste do sistema 
mento de imagem.

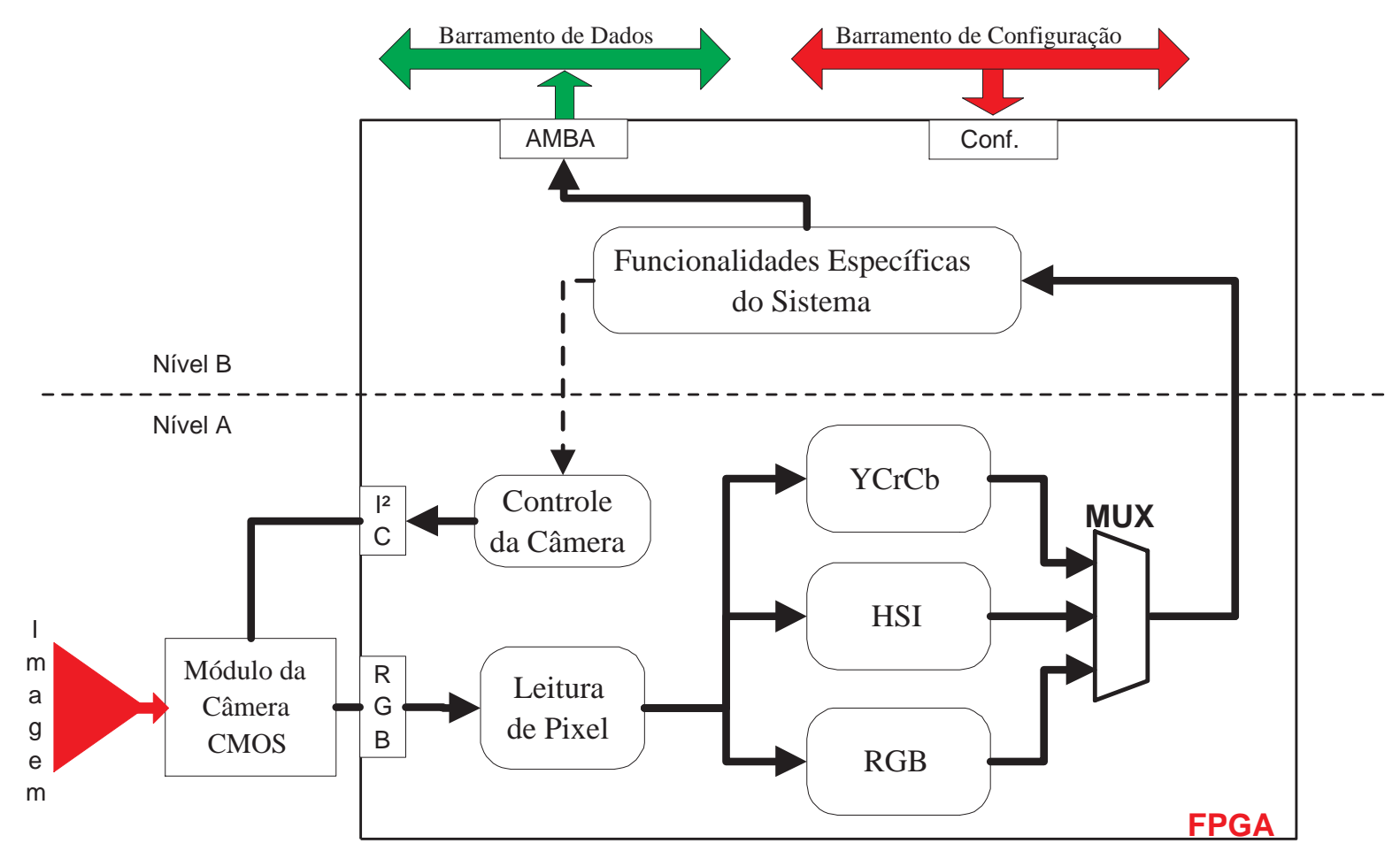

Figura 4.2: Periféricos e funções do sistema

\subsection{Monitoramento do Processamento de Imagem}

Um dos grandes problemas para realizar a implementação de sistemas em hardware é a maneira de como verificar se a implementação das funcionalidades do sistema estão realizando as operações desejadas, ou ainda, como identificar certos problemas que tanto podem ser oriundos do hardware (ruídos), como da lógica implementada. As ferramentas EDA utilizadas para o desenvolvimento de sistemas em hardware normalmente fornecem recursos para verificação da lógica implementada através de simulação, mesmo assim, é difícil verificar se o sistema está funcionando corretamente, pois em sistemas de processamento de imagem há uma grande quantidade de dados sendo recebida e enviada através das funções implementadas no sistema. Além disso, é difícil garantir que a lógica simulada na ferramenta irá se comportar da mesma maneira que no hardware. Essa diferença pode ocorrer devido a variação de temperatura dos dispositivos, interferências externas como ruídos na alimentação e etc.. 
A solução encontrada para auxiliar no desenvolvimento do sistema proposto, foi desenvolver um outro sistema para monitoramento das transformações que ocorrem na imagem durante as diversas fases de processamento. Essa amostragem é realizada através de um monitor de um computador conectado ao sistema através da rede ethernet. A estrutura desenvolvida pode ser utilizada não somente para o monitoramento neste sistema, mas também para auxiliar no desenvolvimento de quaisquer outros sistemas, desde que haja recursos disponíveis de hardware para implementar um processador e uma porta de comunicação via ethernet. A figura 4.3 apresenta o diagrama de blocos deste sistema de monitoramento.

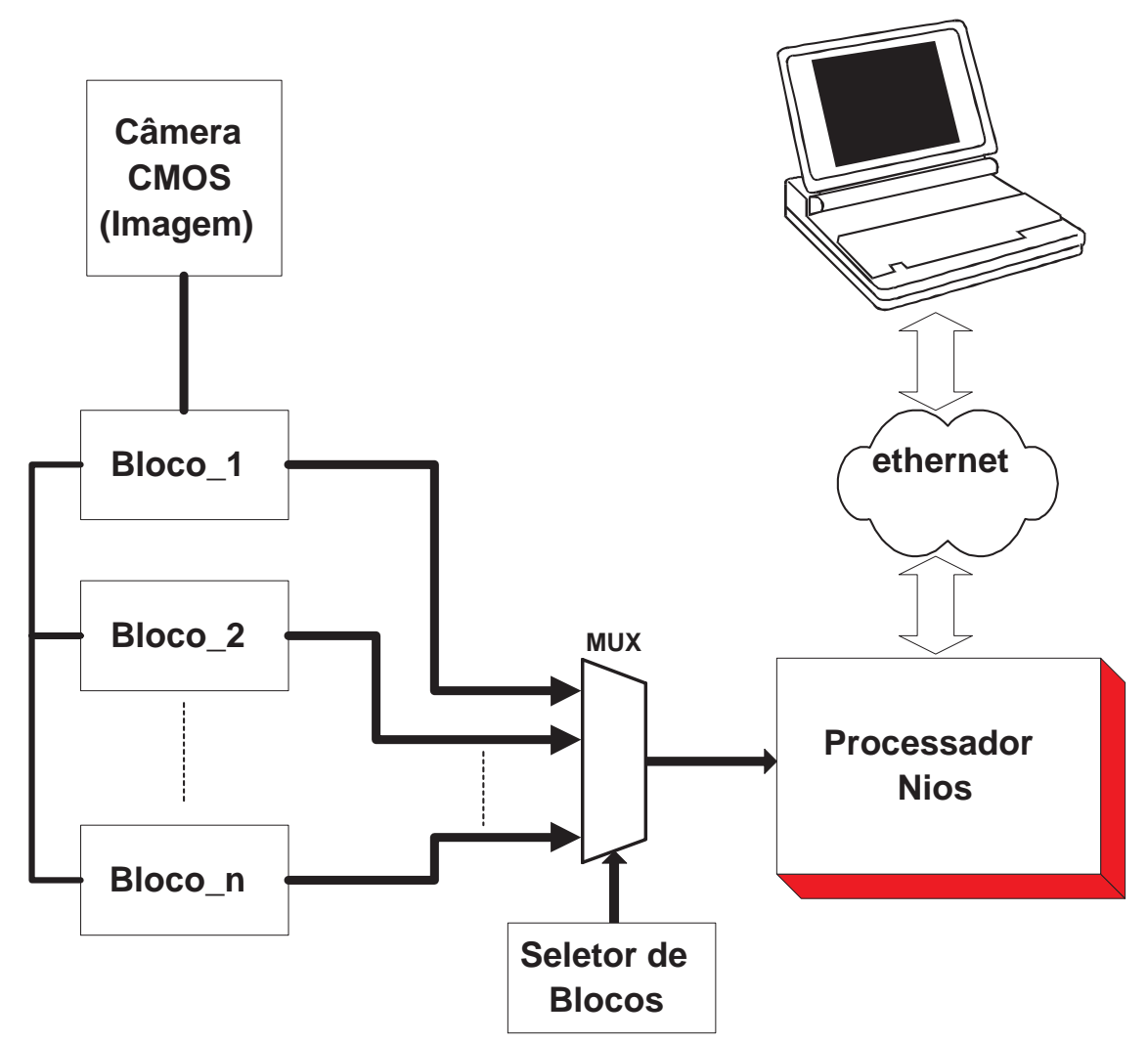

Figura 4.3: Diagrama de blocos do sistema de monitoramento

A função do sistema de monitoramento é capturar os dados fornecidos pelos blocos funcionais do sistema e transmiti-los ao computador via ethernet para que possam ser vistos no monitor. Nesta estrutura apresentada, somente um bloco de cada vez pode apresentar os dados no monitor. Para selecionar os blocos, é adicionado um multiplexador (MUX da figura 4.3) que recebe em sua entrada os dados de todos os blocos do sistema e apresenta em sua saída os dados do bloco que for desejado pelo usuário. Essa seleção é 
feita através dos sinais de controle do multiplexador (Seletor de Blocos da figura 4.3), que são gerados através de botões pressionados pelo usuário. O envio dos dados fornecidos pelo multiplexador ao computador via ethernet é realizado por um processador (Processador Nios da Altera (Altera, 2003e)), que estabelece uma conexão entre o sistema implementado em hardware e o computador. A comunicação é estabelecida através de socket ${ }^{1}$, utilizando o protocolo TCP/IP. A implementação de socket no processador Nios é obtida através da linguagem de programação C e das bibliotecas fornecidas no Kit de desenvolvimento Nios edição Stratix (Altera, 2003f). No computador o socket é obtido através da linguagem de programação Delphi. O uso de socket permite abstrair os detalhes de implementação dos protocolos de comunicação utilizados na transmissão de dados, assim, o usuário que deseja estabelecer a comunicação do sistema implementado no hardware, somente informa qual o número da porta e do IP.

Para que o monitoramento de dados dos blocos funcionais implementados no sistema pudessem ser selecionados através de um multiplexador, foi necessário criar um padrão para estabelecer a maneira como os dados são fornecidos pelos blocos. Assim, independente do bloco, o processador obtem os dados através da mesma porta e reutiliza a lógica para fazer a decodificação dos mesmos. Todos estes blocos fornecem os dados da seguinte maneira: o valor do pixel e seu relativo endereço são fornecidos na porta de saída do bloco, após a sua estabilização, um sinal indicando que os dados estão estáveis para leitura é ativado. Além de permitir a utilização de multiplexador para o monitoramento dos blocos, a padronização permitiu a criação de um sistema complexo, composto de vários blocos funcionais, porém fácil de ser compreendido.

\subsection{Sistema de Aquisição e Pré-Processamento Básico de Imagem}

Esta seção apresenta a implementação dos blocos funcionais de aquisição e pré-processamento de imagem colorida propostos neste trabalho. Inicialmente são descritas as funcionalidades implementadas pelos blocos e em seguida é apresentado tabelas contendo o desempenho

\footnotetext{
${ }^{1}$ É um mecanismo de comunicação originalmente implementado no sistema operacional UNIX da versão BSD, que é utilizado para comunicação entre computadores
} 
e o recurso de hardware necessário para a implementação em FGPA de todos os blocos descritos no texto.

\subsubsection{Aquisição da Imagem}

As imagens utilizadas no sistema são adquiridas a partir da câmera digital CMOS modelo C3188A, apresentada na figura 3.3 da seção 3.1. Para adquirir as imagens é necessário implementar blocos funcionais capazes de realizar a comunicação com a câmera e de interpretar os dados disponíveis no seu barramento. Os blocos que realizam estas operações são apresentados a seguir.

\section{Controle da Câmera}

Os sinais de controle da câmera são definidos através do bloco de Controle da Câmera (figura 4.2), o qual ajusta o dispositivo conforme a aplicação e o ambiente de trabalho do robô. A comunicação entre a câmera e o bloco de controle é realizado através do protocolo I2C (padrão criado pela Philips 20 anos atrás (Philips, 2003)). A câmera possui um conjunto de registradores de controle e de fornecimento de informação que são acessados através do protocolo de comunicação I2C. A comunicação com estes registradores é feita da seguinte forma: o primeiro byte indica o endereço do chip (câmera) com o qual desejase comunicar, no segundo byte é informado o endereço do registrador a ser acessado e o terceiro byte contém o valor a ser escrito no registrador, caso a operação seja de escrita, ou informa o valor contido no registrador, caso a operação for de leitura. O bit menos significativo do primeiro byte indica se a operação será de escrita ou de leitura, sendo o valor zero para escrita e um para leitura. Caso se deseja ler ou escrever em um bloco de registradores de endereço contínuo, a operação pode continuar sem a necessidade de repetição do primeiro e do segundo byte, ou seja, o sistema incrementa automaticamente o endereço do registrador a ser acessado.

Dentre os diversos registradores de controle e de fornecimento de informação, conforme são apresentados em Electronics (2004), os registradores acessados e modificados 
pelo sistema foram os seguintes: controle automático de ganho (reg 0x13) ${ }^{2}$, modo de atualização do controle automático de ganho (reg 0x20), controle de brilho (reg 0x24 e 0x25), controle de exposição (reg 0x10), o número de frames por segundo (reg 0x11) e o modo como os dados são fornecidos no barramento (reg 0x12). Estes registradores modificados pelo sistema permitiram adequar o funcionamento e a qualidade das imagens conforme as necessidades do sistema. Os demais registradores mantiveram os valores originais.

\section{Interpretador de Dados do Barramento da Câmera}

A imagem capturada é fornecida através de um barramento específico existente na câmera. Este barramento é conectado ao bloco Leitura de Pixel (figura 4.2) para que os dados fornecidos pela câmera sejam interpretados. De acordo com a configuração da câmera, os dados fornecidos são os valores de RGB ou YCrCb de cada pixel. Além dos dados RGB e YcrCb, a câmera também fornece sinais de sincronismo, que indicam quando os dados estão disponíveis no barramento, e os sinais de sincronismo horizontal e vertical, que informam início e fim de linhas e frames.

O barramento de dados da câmera pode ter 8 bits ou 16 bits de largura. Neste sistema o barramento está configurado para 16 bits, sendo necessário dois ciclos de leitura para compor um pixel, visto que as componentes $\mathrm{R}, \mathrm{G}$ e B ou $\mathrm{Y}, \mathrm{Cr}$ e $\mathrm{Cb}$ dos modelos de cores são compostas por 8 bits cada. No primeiro ciclo são fornecidos os valores de B/Y e G/Cr e no segundo ciclo os valores de $\mathrm{G} / \mathrm{Y}$ e $\mathrm{R} / \mathrm{Cb}$, sendo que num dos ciclos o $\mathrm{G} / \mathrm{Y}$ pode ser descartado. O uso de 16 bits ao invés de 8 bits de largura de barramento permite o acréscimo de $1 / 3$ da taxa de transferência de pixels. Como o sistema proposto é de tempo real, o uso de 16 bits foi adotado. A figura 4.4 apresenta uma imagem capturada utilizando este bloco funcional.

\subsubsection{Modelos de cor $\mathrm{RGB}$ e $\mathrm{YCrCb}$}

Tanto o modelo de cor RGB como o YCrCb são fornecidos pela própria câmera. Para escolher entre estes padrões o usuário programa o bit 3 do registrador 0x12, sendo 1 para

\footnotetext{
${ }^{2}$ Informa o número do registrador em hexadecimal
} 


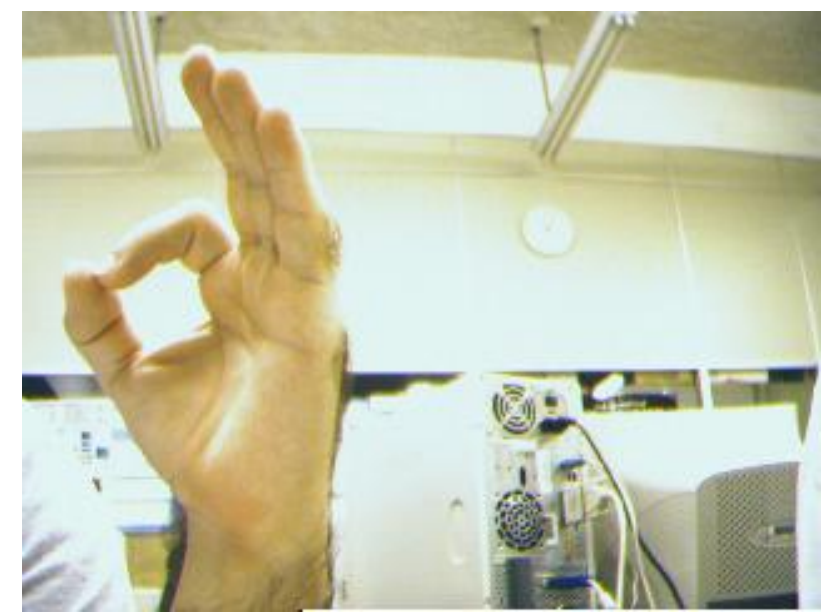

Figura 4.4: RGB (320x240 pixels)

RGB e 0 para YCrCb. O bloco de leitura dos dados do barramento da câmera é capaz de interpretar os dois modelos, sem nenhuma alteração adicional. Na saída deste bloco é fornecido os valores das três componentes do modelo de cor selecionado, sendo $\mathrm{R} / \mathrm{Cb}$, G/Cr e B/Y e o endereço do pixel fornecido. Quando o dado do pixel e o endereço relativo ao pixel estiverem estáveis no barramento de saída do bloco, um outro sinal é gerado, sinalizando que os dados estão prontos no barramento e podem ser lidos.

\subsubsection{Conversão de RGB para HSI}

A conversão do padrão de cor RGB para HSI é realizada pelo bloco HSI da figura 4.2. Esta conversão é utilizada para converter o padrão de cor dos pixels em RGB, composto pelas cores Red (R), Green (G) e Blue (B), para o padrão de cor HSI, composto pelas componentes Hue (H), Saturation (S) e Intensity (I). Este é um método bastante utilizado em sistemas de processamento de imagem, pois os componentes do H, S e I do pixel são valores independentes e conseqüentemente operações individuais podem ser aplicadas, diferentemente do R, G e B que são dependentes (Russ, 1995). Além disso, a separação do I torna o sistema menos sensível a variação de luminosidade do ambiente de trabalho.

A figura 4.5 apresenta a imagem obtida pela conversão deste bloco funcional. 


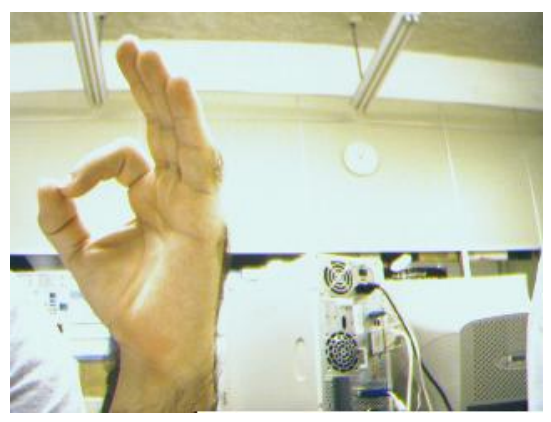

(a) RGB

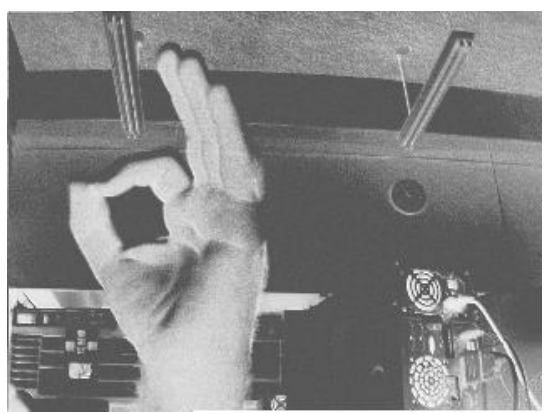

(c) $\mathrm{S}$

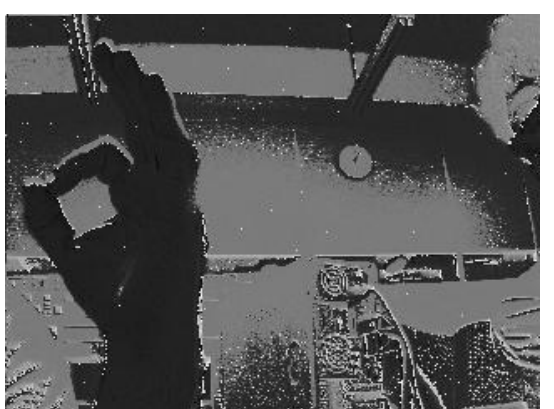

(b) $\mathrm{H}$

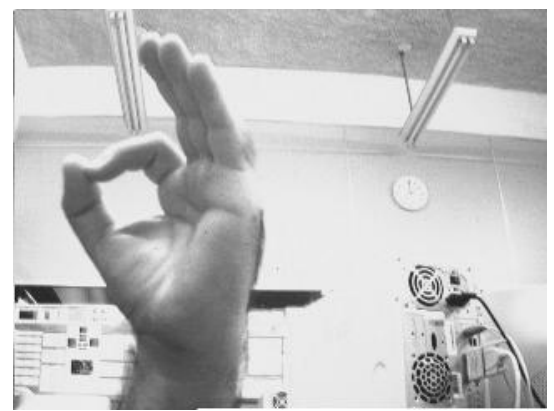

(d) I

Figura 4.5: Imagens em RGB (a), Hue (b), Saturation (c) e Intensity (I) com resolução de 320x240 pixels

\subsubsection{Análise dos Resultados}

Nesta seção são apresentadas as análises dos resultados obtidos referentes ao desempenho e recursos de hardware necessários para realizar a implementação num FPGA EP1S10F780C6 da família Stratix do Kit de Desenvolvimento Nios. Na tabela 4.1 é apresentado o desempenho obtido de cada bloco funcional existente no módulo de aquisição e pré-processamento de imagem. Os dados referentes ao desempenho foram obtidos do simulador de formas de ondas da ferramenta de desenvolvimento Quartus II. A partir deste simulador é possível determinar qual a freqüência máxima de operação dos blocos lógicos, pois o simulador estima o tempo de propagação dos sinais existentes na lógica em simulação de acordo com o dispositivo selecionado, neste caso, o FPGA EP1S10F780C. A coluna PS desta tabela representa o número de pixels por segundo que os blocos conseguem processar. Porém no bloco Controle da Câmera a tabela apresenta o número máximo de bits que podem ser convertidos para o padrão $\mathrm{I}^{2} \mathrm{C}$. A análise de desempenho não considera o tempo de propagação entre as portas de entrada e saída do FPGA, esta 
análise apresenta qual à freqüência máxima que os blocos conseguem executar as suas operações.

Tabela 4.1: Desempenho do sistema. A tabela representa os seguintes dados: Freqüência de Operação (FO), Pixel por Segundo (PS) ou Bits por Segundo*, Tamanho da Imagem (TI) e Frames por Segundo (FS)

\begin{tabular}{|c||c|c|c|c|}
\hline Blocos do Sistema & $\begin{array}{l}\text { FO } \\
(\mathbf{M H z})\end{array}$ & $\begin{array}{l}\text { PS } \\
\mathbf{( M )}\end{array}$ & TI & FS \\
\hline \hline Controle da Câmera & 269,11 & $134,55^{*}$ & - & - \\
\hline Leitura de Pixel & 422,12 & 211,06 & $320 \times 240$ & $1.374,08$ \\
\hline HSI & 16,88 & 2,41 & $320 \times 240$ & 31,88 \\
\hline
\end{tabular}

Os recursos de hardware utilizados na implementação do módulo de aquisição e préprocessamento de imagem são apresentados na tabela 4.2. Nesta análise é possível constatar o número de elementos lógicos e a taxa de ocupação referentes a cada bloco funcional existente no sistema. As informações da tabela foram obtidas através da análise dos relatórios de compilação, fornecidos pelo software de desenvolvimento Quartus II.

Tabela 4.2: Recursos utilizados para implementação do sistema de aquisição e préprocessamento de imagem. A tabela representa os seguintes dados: Número de Elementos Lógicos (LE) e a Taxa de Ocupação (TO) do FPGA EP1S10F780C6

\begin{tabular}{|c||c|c|}
\hline Blocos do Sistema & LE & $\begin{array}{l}\text { TO } \\
\mathbf{( \% )}\end{array}$ \\
\hline \hline Controle da Câmera & 71 & 0,67 \\
\hline Leitura de Pixel & 84 & 0,79 \\
\hline HSI & 684 & 6,47 \\
\hline \hline Total & 839 & 7,93 \\
\hline
\end{tabular}




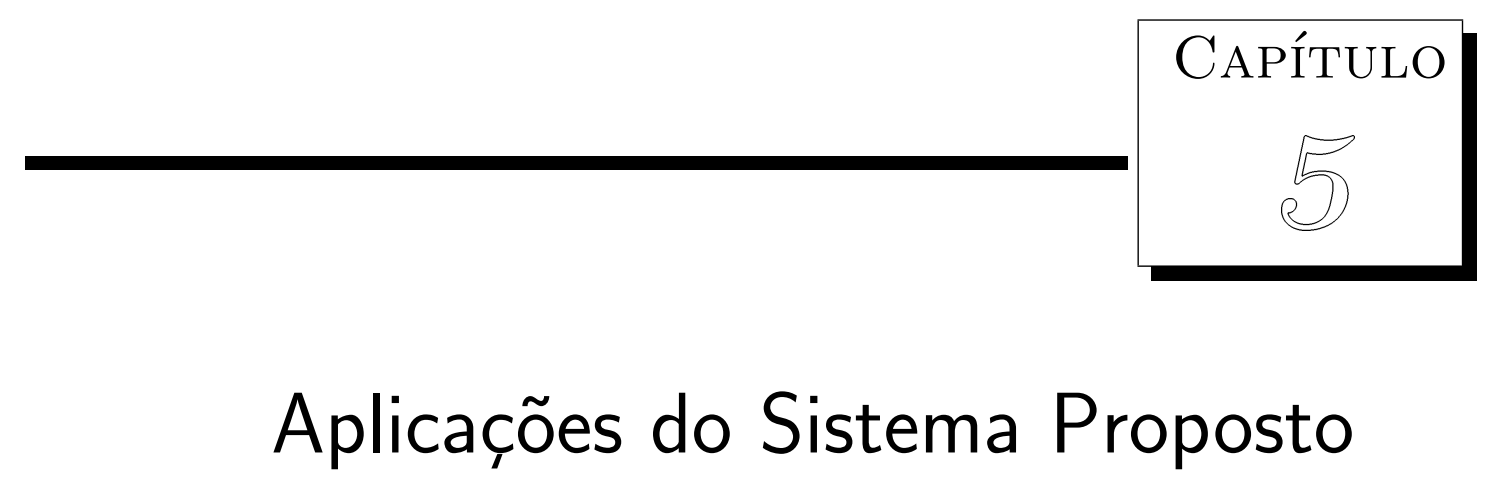

O sistema de aquisição e pré-processamento de imagem proposto e implementado neste trabalho, tem como objetivo servir de base para a construção de sistemas específicos de processamento de imagem em FPGA. Este capítulo apresenta a implementação de sistemas para reconhecimento de gestos e de sinais de navegação (docking) utilizado no controle de robôs móvel. Estas implementações, além de comprovarem a funcionalidade do sistema de aquisição e pré-processamento de imagem, contribuem com a construção de RPU (Reconfigurable Processing Unit) para a biblioteca do Architec-R, que é uma ferramenta de desenvolvimento de robôs reconfiguráveis que está sendo desenvolvida pelo laboratório de computação reconfigurável (LCR) (Gonçalves et. al., 2001) (Gonçalves et. al., 2003). A figura 1.1 apresenta a estrutura da biblioteca de RPUs do Architect-R, onde pode se verificar a maneira como são integradas e quais as funcionalidades estão sendo implementadas. As principais funcionalidades são: gerenciamento de tarefas, controle de navegação, cálculo de campos potenciais, mapeamento topológico, controle dos sensores e DSP (Digital Signal Processing), controle dos motores, configuração de FPGA, comunicação através da ethernet sem fio, sistema de controle inteligente distribuído, execução de algoritmos genéticos e um módulo de processamento de imagem, que serve para im- 
plementar as RPU de reconhecimento de gestos e de sinais de navegação.

\subsection{Sistema para Reconhecimento de Gestos}

Esta implementação apresenta a construção de uma RPU (Reconfigurable Processing Unit) para reconhecimento de gestos em tempo real através de uma interface de interação Homem-Robô. Esta RPU de reconhecimento dos gestos irá compor o sistema Architec-R incorporando na sua biblioteca a funcionalidade necessária para, não somente reconhecer gestos, mas também para servir de base a outras aplicações que necessitem reconhecimento de padrões de imagem. Com isto é possível interagir com o robô de uma maneira natural aos seres humanos, sem a necessidade de contato físico entre os dois.

Sistemas de visão computacional, para a interação homem-robô, tem evoluído muito na última década, porém a maioria dos sistemas não são robustos, não podem ser utilizados em sistemas embarcados e ainda possuem baixo desempenho (Turk, 2004). O sistema proposto busca superar estes problemas, baseando-se em trabalhos de pesquisa desenvolvidos nesta área (Stefan Waldherr e Thrun, 2000).

A estrutura deste sistema de visão é apresentada no diagrama de blocos da figura 5.1. A organização desta estrutura forma um pipeline de operações de processamento de imagem, pois todos os blocos realizam operações em paralelo e os buffers possuem portas de leitura e escrita independentes. Este sistema é implementado como um SoC, o que permite realizar o reconhecimento de gestos em tempo real. Cada um destes blocos é responsável por uma etapa de processamento de imagem, tais como captura de imagem, conversão do padrão de cor RGB para HSI, segmentação da imagem, redução e filtragem da imagem e finalmente a centralização da imagem. Estes passos de pré-processamento são realizados a fim de preparar a imagem para a interpretação dos gestos através da rede neural(mostrada na seção 5.1.1).

Para integrar o sistema de reconhecimento de gestos ao robô, conforme visto na figura 5.1, são utilizados dois barramentos de comunicação entre estes sistemas, sendo: o Configuration Bus, utilizado para configurar o FPGA, e o Data Bus, utilizado para envio dos comandos interpretados através dos gestos ao gerenciador do robô. 


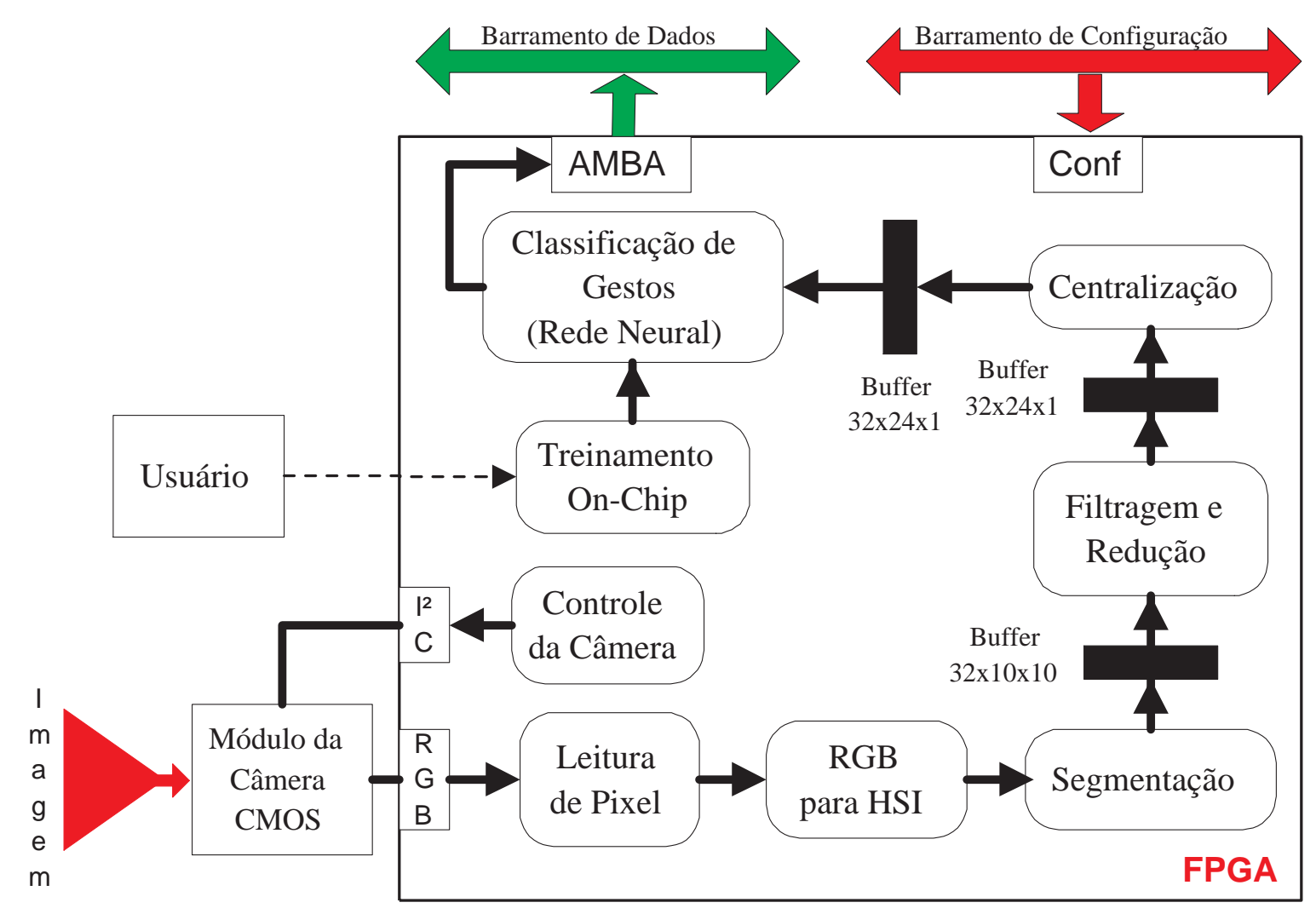

Figura 5.1: Diagrama de blocos do sistema de Pré-Processamento

Na fase de pré-processamento de imagem deste sistema são realizadas as operações de captura de imagem, conversão do padrão de cor RGB para HSI, segmentação da imagem, operações de filtragem e redução da imagem e centralização da região segmentada. As duas primeiras operações são realizadas através do sistema de aquisição e pré-processamento de imagem apresentado no capítulo 4, sendo as imagens capturadas e processadas com resolução de 320x240 pixels. Já as implementações das operações restantes são apresentadas a seguir.

\section{Segmentação da Imagem}

O bloco de segmentação deste projeto tem como objetivo obter uma imagem binarizada de 320x240 pixels a partir de uma imagem, também de 320x240 pixels, representada através do espaço de cor HSI. Várias técnicas de segmentação baseadas no HSI têm sido propostas, sendo diferenciadas basicamente pela maneira como cada técnica relaciona os componentes H, S e I (ChiZhang, 2000) (Cummings et. al., 2003). O sistema proposto 
implementa duas técnicas de segmentação, sendo a primeira baseada no valor de $\mathrm{H}$ e a segunda baseada nos valores H, S e I. As duas técnicas utilizam a equação 5.1, sendo f(i,j) os valores de H, S ou I e T1 e T2 os limiares inferiores e superiores para determinar quando um pixel pertence a região de interesse. O valor de cada limiar é constante e definido empiricamente. Neste sistema, os gestos são obtidos utilizando a parte interna da mão, assim sendo, mesmo pessoas de diferentes cores de pele tem seus gestos interpretados, pois nesta parte da mão, a cor sofre pouca alteração. Na primeira técnica, o resultado da equação 5.1 são os pixels que constituem a imagem segmentada, já na segunda técnica, os pixels são obtidos a partir da lógica AND entre os resultados da equação 5.1 para os valores H, S e I. A região da mão, segmentada a partir da primeira técnica, apresentou bons resultados, portanto, é a que está sendo utilizada neste sistema. A figura 5.2 apresenta o resultado da segmentação baseado no valor de H. Esta imagem e todas as outras apresentadas neste trabalho, foram geradas pelo próprio hardware do sistema (Stratix FPGA).

$$
f(x, y)= \begin{cases}1 & \text { if } \quad\left[T_{1}<=f(i, j)<=T_{2}\right] \\ 0 & \text { otherwise }\end{cases}
$$

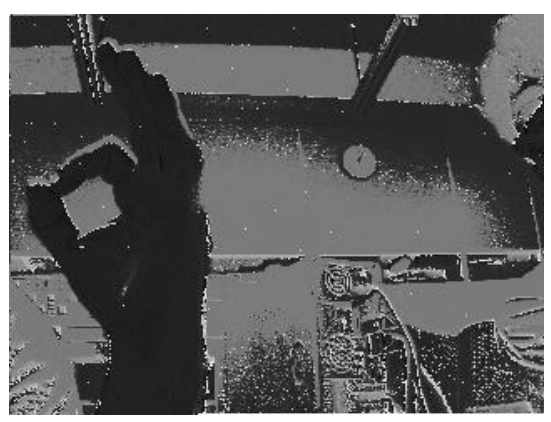

(a) $\mathrm{H}$

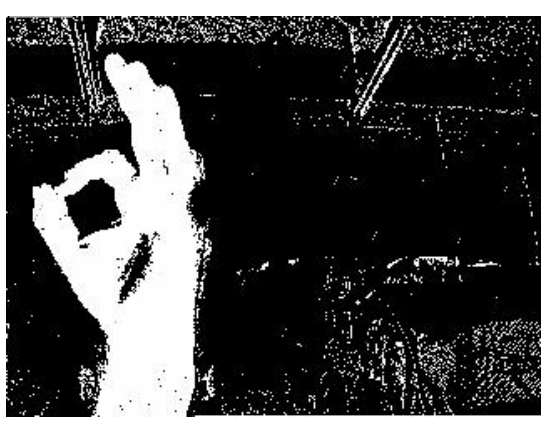

(b) Segmentada

Figura 5.2: Componente H (a) e imagem binariza (b)

\section{Operações de Filtragem e Redução da Imagem}

A imagem obtida do bloco de segmentação é binária, com resolução de 320x240 pixels, sendo nível lógico 1 a região da mão e 0 caso contrário. Apesar do processo de segmentação 
ter o objetivo de manter em nível lógico 1 somente os pixels pertencentes à mão, alguns pixels podem ser identificados de forma incorreta devido ao ruído. Para a remoção ou atenuação destes pixels "falsos", é aplicado um filtro baseado na informação da vizinhança do pixel em análise. Além da operação de filtro, este bloco altera a resolução de imagem de 320x240 para 32x24 pixels, a fim de reduzir o número de entradas da rede neural, pois neste sistema, todos os pixels da imagem são conectados à rede neural. As duas funções implementadas neste bloco são realizadas através da equação 5.2. Dada uma região da imagem $\mathrm{f}(\mathrm{x}+\mathrm{m}, \mathrm{y}+\mathrm{n})$, onde $\mathrm{m}$ e $\mathrm{n}$ variam de 0 até 10 , é verificado se existe mais do que $60 \%$ deste pixels em nível lógico 1, se verdadeiro toda a região desta imagem é convertida num único pixel de nível lógico 1. Estes parâmetros foram determinados a partir da análise dos resultados obtidos de diversas simulações. Além de reduzir o tamanho da imagem, esta operação serve de filtro, pois normalmente, somente a região da mão apresenta mais de $60 \%$ dos pixels em nível lógico 1, eliminando com isso a presença de pixels "falsos". Para a remoção de ruídos, também foram realizados experimentos com as operações morfológicas de erosão seguida da dilatação, que caracterizam a técnica morfológica de abertura (Costa e Cesar Jr., 2000). O resultado apresentado, assemelha-se ao obtido pela equação 5.2, dessa maneira a técnica de abertura não foi adotada, pois exige mais tempo de processamento, comprometendo o desempenho do sistema. O resultado do processamento deste bloco é apresentado na figura 5.3.

$$
g(x, y)= \begin{cases}1 & \text { if }\left[\sum_{m=0}^{n-1} \sum_{n=0}^{n-1} f(x+m, y+n)\right] \geq 60 \\ 0 & \text { otherwise }\end{cases}
$$

\section{Centralização da Região Segmentada}

A função deste bloco é transladar a região onde se encontra a mão para o centro da imagem. Esta translação é importante, pois ocorre uma padronização da posição da região e conseqüentemente a taxa de acerto da rede neural aumenta. A importância desta translação foi detectada através da realização de diversos testes para a convergência da rede neural. Para realizar esta operação, calcula-se a diferença do centro de massa 


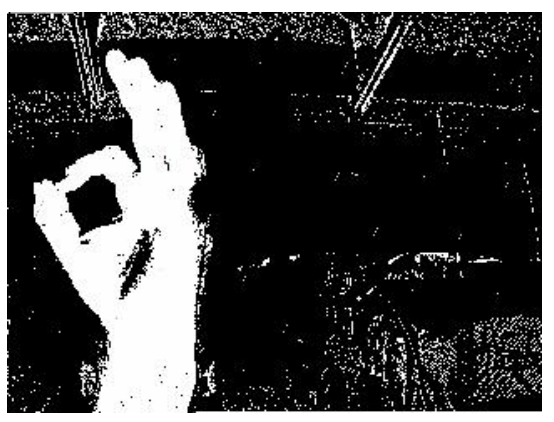

(a) $(320 \times 240)$

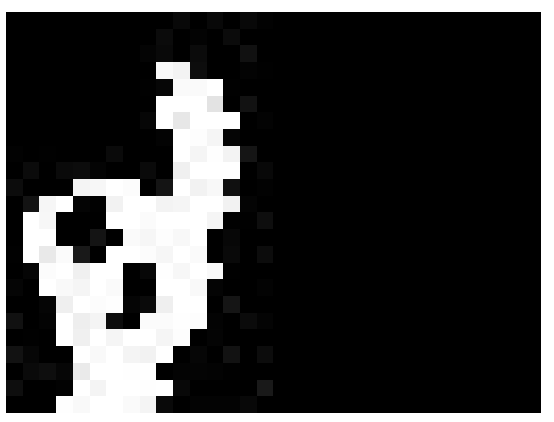

(b) $(32 \times 24)$

Figura 5.3: Imagem com ruído segmentada (a) e reduzida sem ruído (b)

da região com o centro da imagem e realiza-se a translação conforme o resultado deste cálculo. O centro de massa é obtido através das equações 5.3, 5.4 e 5.5 (Gonzalez e Woods, 1992). Já o cálculo da diferença, ou translação, entre o centro da imagem e o centro de massa da região é obtido através da equação 5.6. Para calcular o centro de massa, as equações dividem a soma das coordenadas X e Y pela área da região a ser translada, já o cálculo da translação é obtido através subtração entre o centro da imagem, que no caso é $32 / 2$ para a coordenada X e $24 / 2$ para a coordenada $\mathrm{Y}$, pelas coordenadas X e Y do centro de massa. A figura 5.4 apresenta o resultado de uma região translada para o centro da imagem.

$$
\begin{gathered}
\text { Area }=\sum_{x} \sum_{y} f(x, y) \\
\text { Coord }_{x}=\sum_{x} \sum_{y} x f(x, y) \quad \text { Coord }_{y}=\sum_{x} \sum_{y} y f(x, y) \\
X_{c}=\frac{\text { Coord }_{x}}{\text { Area }} \quad Y_{c}=\frac{\text { Coord }}{\text { Area }} \\
\text { Dif }_{x}=\frac{32}{2}-X_{c} \quad D_{i}=\frac{24}{2}-Y_{c}
\end{gathered}
$$




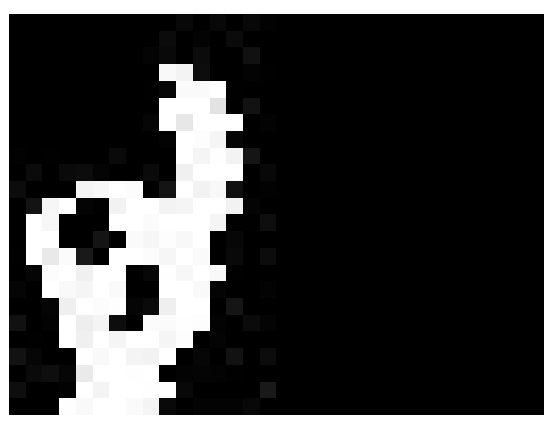

(a) Original

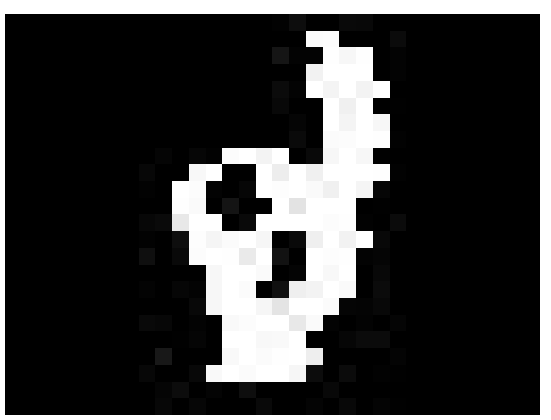

(b) Transladada

Figura 5.4: Imagem original (a) e o resultado da centralização (b).

\subsubsection{Reconhecimento dos Gestos Através da Rede Neural RAM-Based}

A interpretação dos gestos é realizada através de uma RAM-Based Neural Network (ntuple classifier) implementada no FPGA, com treinamento on-chip. Esta é uma rede neural sem peso, que opera com dados binários e de fácil implementação em hardware (Austin, 1998) (Carvalho, 1994). Os gestos que são utilizados para comandar os movimentos do robô são realizados através da mão do usuário, que determinam os seguintes comandos:

- Halt

- Go

- Go Back

- Left $90^{\circ}$

- Left $45^{\circ}$

- Right $90^{\circ}$

- Right $45^{\circ}$

Estes comandos são apresentados na figura 5.5. Estas imagens foram geradas diretamente do FPGA, sendo a primeira coluna, as imagens obtidas da câmera e a segunda coluna, as imagens que são fornecidas à rede neural. Os gestos podem ser alterados de acordo com a necessidade do usuário, já que o treinamento é realizado on-chip. Como podemos perceber, todos os gestos apresentados neste trabalho utilizam a parte interna da 
mão, dessa maneira, mesmo comandos realizados por usuários de cores de pele diferentes podem ser interpretadas pelo robô. Ao inicializar o sistema, o robô aguarda por um dos gestos válidos para executar os comandos de navegação. Quando um gesto é interpretado, o seu comando é mantido até que outro gesto seja interpretado pelo sistema. Com a introdução desta interface de gestos no ambiente apresentado na figura 1.1, pretende-se futuramente construir um robô móvel para transporte de pessoas idosas e deficientes (por isso os gestos são realizados por apenas uma mão) em museus, aeroportos, supermercados e etc., sem a necessidade do volante tradicional encontrado neste tipo de carinho de transporte.

A rede neural RAM, utilizada neste sistema, é implementada conforme a estrutura geral apresentada na figura 5.6, que basicamente é composta por células de memória (neurônios representados por $\mathrm{N}$ ), endereçadas pelo dado de entrada. A entrada da rede neural é composta por um vetor de 768 bits (32x24 pixels), que representa o gesto após as etapas de pré-processamento vistas anteriormente. Para cada padrão existem 96 neurônios de 256 bits (8-input neurons), sendo cada um endereçado por 8 pixels da imagem. Os pixels ligados nas entradas dos neurônios são conectados de modo aleatório através da tabela Random Table Address. Na fase de treinamento, o gesto é apresentado a um conjunto de neurônios, e todas as células selecionadas através do endereço gerado pela combinação dos pixels são setadas em nível lógico 1. Para cada padrão existe um conjunto específico de neurônios, conforme apresentado na figura 5.6. Antes de inicializar o treinamento, todas as células do padrão a ser treinado são inicializadas com nível lógico 0. Após a fase de treinamento da rede neural, novas imagens são apresentadas a fim de serem reconhecidas. O reconhecimento é realizado através da soma de todas as saídas dos neurônios de cada padrão. O resultado desta soma é armazenado no respectivo contador de cada padrão. O contador que tiver o maior valor é considerado vencedor, indicando o gesto contido na imagem de entrada. Na figura 5.7 é apresentado o diagrama esquemático da implementação desta rede neural booleana implementada em FPGA. A classificação dos gestos também foi realizada utilizando-se a rede neural do tipo MLP (Multi Layer Perceptron), no entanto, os resultados apresentados não foram satisfatórios, ficando com 


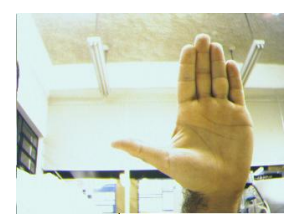

(a) Halt

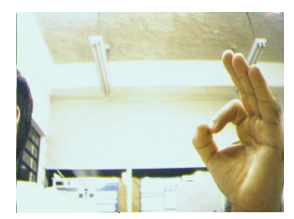

(c) Go

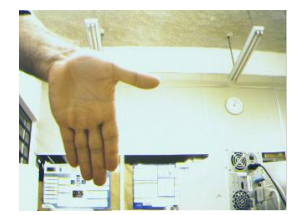

(e) Go Back

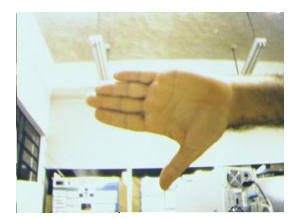

(g) Right $90^{\circ}$

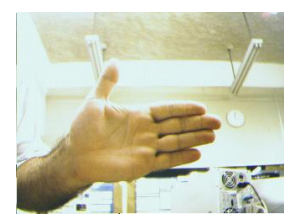

(i) Left $90^{\circ}$

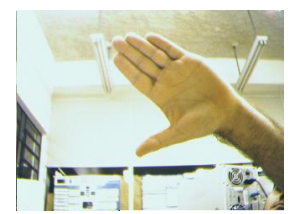

(k) Right $45^{\circ}$

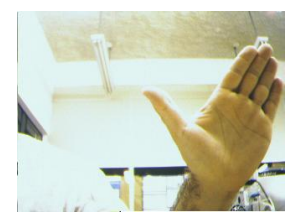

(m) Left $45^{\circ}$

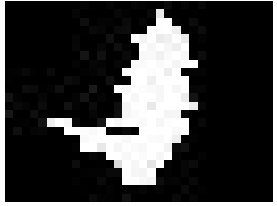

(b) Halt

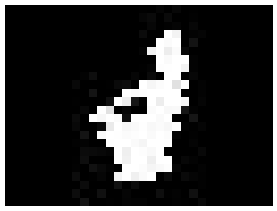

(d) Go

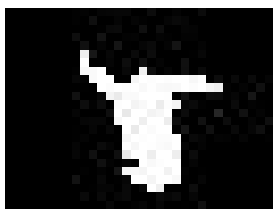

(f) Go Back

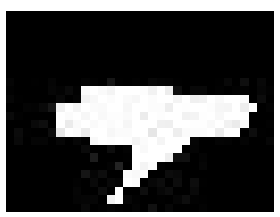

(h) Right $90^{\circ}$

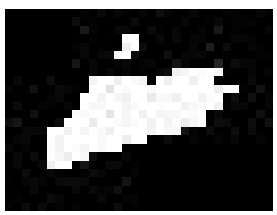

(j) Left $90^{\circ}$

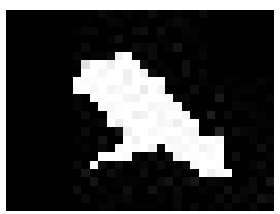

(l) Right $45^{\circ}$

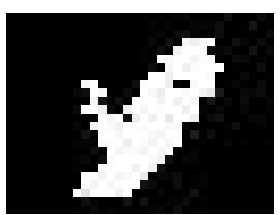

(n) Left $45^{\circ}$

Figura 5.5: Conjunto de gestos reconhecidos pelo robô, sendo (a),(c),(e),(g),(i),(k),(m) as imagens em RGB de entrada e (b),(d),(f),(h),(j),(l),(n) as imagens fornecidas à rede neural 
uma taxa de acerto entorno de $80 \%$. Já a rede neural RAM, apresentou ótimos resultados, conforme apresentado a seguir.

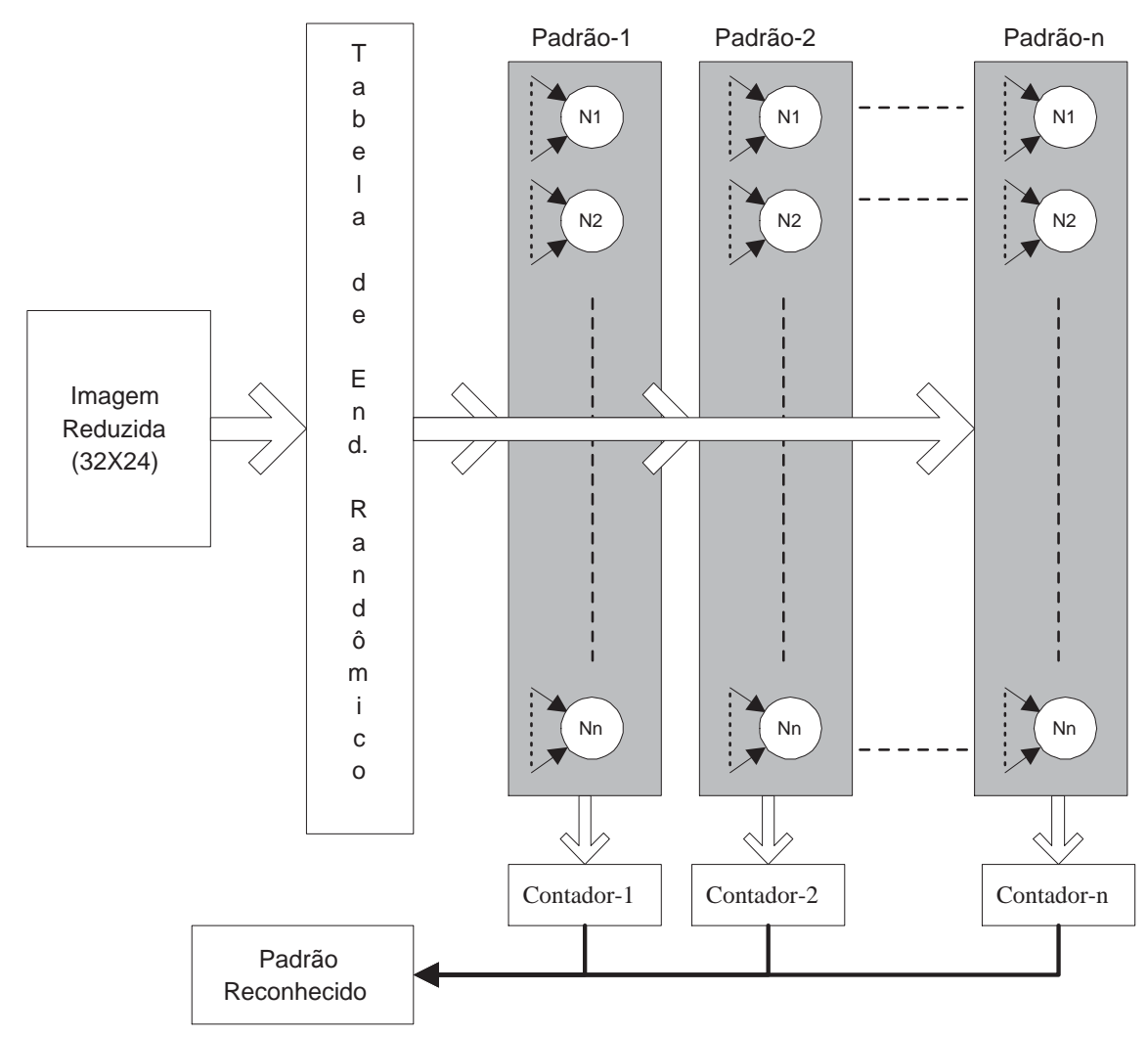

Figura 5.6: Diagrama de blocos da rede neural RAM

\subsubsection{Resultados Obtidos}

Esta seção apresenta os recursos utilizados, o desempenho obtido e a eficiência do sistema de reconhecimento de gestos apresentado neste trabalho. O desenvolvimento do sistema foi realizado utilizando-se o software de desenvolvimento Quartus II V3.0, que é uma ferramenta EDA (Electronic Design Automation) para desenvolvimento de sistemas em FGPA da Altera, e a placa de desenvolvimento Nios - Edição Stratix (Altera, 2003f). O hardware reconfigurável desta placa é um FPGA EP1S10F780C6 da família Stratix, composto por 10.570 elementos lógicos (LE) e 920 Kbits de memória RAM. A tabela 5.1 apresenta os recursos necessários do FPGA para a implementação do sistema proposto. Estas informações foram obtidas através da análise dos relatórios de compilação, fornecidos pelo software de desenvolvimento Quartus II. A rede neural, apesar de ser 


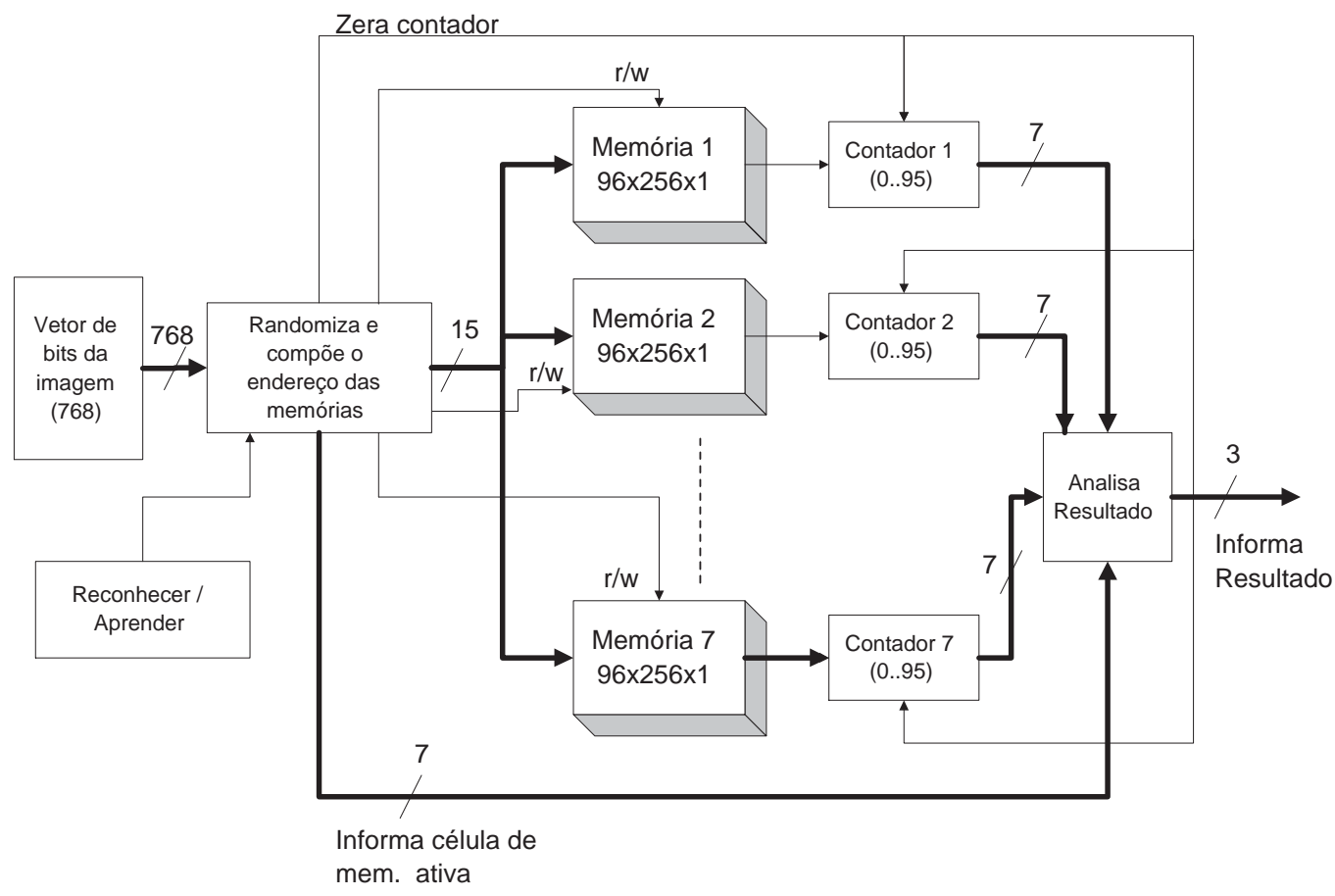

Figura 5.7: Diagrama esquemático da rede neural RAM implementada no FPGA

basicamente composta de memória, utilizou uma grande quantidade de elementos lógicos em relação aos outros blocos existentes no sistema. Esta quantidade é devido a criação de um barramento interno capaz de disponibilizar todos os bits da imagem em paralelo para todas as entradas da rede neural, que por conseqüência, permitiu obter uma rede neural de alto desempenho. A tabela 5.2 e a tabela 5.3 apresentam o desempenho obtido dos blocos funcionais do sistema de reconhecimento de gestos implementado em hardware no FPGA. Todos os blocos do sistema têm capacidade de processar no mínimo 31,88 frames por segundo, que é a taxa máxima suportada pela câmera.

Tabela 5.1: Recursos utilizados de Memória RAM (Mem), número de Elementos Lógicos (LE) e a Taxa de Ocupação (TO) de elementos lógicos do FPGA EP1S10F780C6

\begin{tabular}{|c||c|c|c|}
\hline Blocos do Sistema & $\begin{array}{l}\text { Mem } \\
\text { (Kbits) }\end{array}$ & LE & $\begin{array}{c}\text { TO } \\
\mathbf{( \% )}\end{array}$ \\
\hline \hline Controle da Câmera & 0 & 71 & 0,67 \\
\hline Leitura de Pixel & 0 & 84 & 0,79 \\
\hline RGB para HSI & 0 & 684 & 6,47 \\
\hline Segmentação & 0 & 33 & 0,31 \\
\hline Filtragem e Redução & 5 & 252 & 2,38 \\
\hline Centralização & 1 & 180 & 1,70 \\
\hline Rede Neural & 229 & 1.650 & 15,61 \\
\hline \hline Total & 235 & 2.702 & 27,94 \\
\hline
\end{tabular}


Tabela 5.2: Desempenho do sistema implementado em hardware dedicado. A tabela representa os seguintes dados: Freqüência de Operação (FO), Pixel por Segundo (PS) ou Bits por Segundo*, Tamanho da Imagem (TI) e Frames por Segundo (FS)

\begin{tabular}{|c||c|c|c|c|}
\hline $\begin{array}{l}\text { Blocos de } \\
\text { Pré-Processamento }\end{array}$ & $\begin{array}{l}\text { FO } \\
(\mathbf{M H z})\end{array}$ & $\begin{array}{l}\text { PS } \\
(\mathbf{M})\end{array}$ & TI & FS \\
\hline \hline Controle da Câmera & 269,11 & $134,55^{*}$ & - & - \\
\hline Leitura de Pixel & 422,12 & 211,06 & $320 \times 240$ & $1.374,08$ \\
\hline RGB para HSI & 16,88 & 2,41 & $320 \times 240$ & 31,88 \\
\hline Segmentação & 109,79 & 109,79 & $320 \times 240$ & $1.429,60$ \\
\hline Filtragem e Redução & 48,89 & 16,29 & $320 \times 240$ & 212,10 \\
\hline Centralização & 18,50 & 2,64 & $32 \times 24$ & $3.437,50$ \\
\hline
\end{tabular}

Tabela 5.3: Análise de desempenho da rede neural RAM implementada em hardware dedicado. O desempenho apresentado nesta tabela independe do número de padrões da rede neural, pois são processados paralelamente

\begin{tabular}{|c||c|}
\hline \multicolumn{2}{|c|}{ Desempenho da Rede Neural em Hardware - RAM } \\
\hline \hline Freqüência Máxima de Operação & $73,48 \mathrm{MHz}$ \\
\hline Número de Neurônios Processados por Segundo & $36,74 \mathrm{M}$ \\
\hline Número de Neurônios da Rede Neural & 96 \\
\hline Padrões Verificados por Segundo & $382.708,33$ \\
\hline
\end{tabular}

O teste de eficiência do sistema foi realizado através da apresentação de gestos e da verificação do resultado obtido. Estes resultados apresentaram variações dependendo do número de amostras utilizadas durante a fase de treinamento da rede neural. Após, vários testes, constatou-se que 50 imagens de cada gesto são suficientes para obter $99.57 \%$ de acerto. Para determinar que 50 imagens são suficientes, foram analisados os valores dos contadores para cada padrão da rede neural durante a fase de reconhecimento dos gestos. A rede neural RAM, implementada neste sistema, permite que os contadores variem de 0 a 95. Como o padrão (gesto) vencedor é o de maior contagem, foi verificada qual a diferença entre o vencedor e os outros colocados, na ordem decrescente dos valores dos contadores. O treinamento realizado com menos de 50 imagens, apresenta baixa contagem no contador vencedor e pouca diferença em relação ao segundo colocado. Já o treinamento realizado com mais de 50 imagens, tende a saturar a rede neural, pois os contadores têm seus valores próximos a sua máxima contagem (95). A partir da definição do número de imagens de treinamento, foi realizado o teste de eficiência do sistema. O sistema foi treinado para reconhecer 7 gestos, sendo todos representados pela parte interna da mão, conforme visto 
na seção anterior. Foram apresentados 700 gestos ao sistema, sendo 100 gestos de cada tipo. Para cada apresentação, foi verificado e registrado qual a interpretação do sistema, conforme apresentado na tabela 5.4. A coluna Taxa de Acerto apresenta o percentual de interpretação correta do gesto. Já as colunas da Taxa de Erro, apresentam o percentual de gestos que foram apresentados ao sistema, porém não detectados (Sem Detecção) e o percentual de gestos que foram interpretados de forma incorreta pelo sistema (Falsa Detecção).

\begin{tabular}{|c||c|c|c|}
\hline \multirow{2}{*}{ Gestos } & Taxa de & Acerto & \multicolumn{2}{|c|}{ Taxa de Erro (\%) } \\
\cline { 3 - 4 } & (\%) & $\begin{array}{l}\text { Sem } \\
\text { Detecção }\end{array}$ & $\begin{array}{l}\text { Falsa } \\
\text { Detecção }\end{array}$ \\
\hline \hline Halt & 100 & 0 & 0 \\
\hline Go & 100 & 0 & 0 \\
\hline Go Back & 98 & 0 & 2 \\
\hline Right $90^{\circ}$ & 100 & 0 & 0 \\
\hline Left $90^{\circ}$ & 100 & 0 & 0 \\
\hline Right $45^{\circ}$ & 99 & 0 & 1 \\
\hline Left $45^{\circ}$ & 100 & 0 & 0 \\
\hline \hline Total & $\mathbf{9 9 , 5 7}$ & $\mathbf{0}$ & $\mathbf{0 , 4 3}$ \\
\hline
\end{tabular}

Tabela 5.4: Taxa de Acerto e de Erro para cada gesto apresentado ao sistema com 50 amostras para cada padrão apresentado no treinamento

\subsection{Sistema de Visão para Condução de Robôs Móveis}

Este trabalho apresenta a construção de uma RPU para a navegação de robôs móveis através de sinais visuais, também conhecidos como visual docking (Angelo M. Sabatini e Maini, 2003) (Milo C. Silverman e Sukhatme, 2003) (Kyu-Hyun et. al., 2002) (Miller e Wright, 1995). Projetistas de robôs móveis que necessitam implementar funcionalidades para controle de navegação através de sinais visuais, podem utilizar esta RPU. Este é um sistema implementado em hardware e software num único dispositivo reconfigurável (FPGA). As funcionalidades implementadas em hardware realizam a aquisição da imagem e em software realizam as operações de pré-processamento de imagem e interpretação dos sinais. O hardware que realiza a aquisição da imagem é obtido do sistema de aquisição proposto neste trabalho, conforme apresentado no capítulo 4. As operações implementadas 
em software são idênticas às operações realizadas em hardware no sistema de reconhecimento de gestos visto na seção 5.1. A única diferença está na segmentação, onde o sistema de reconhecimento de gestos segmenta a partir do valor de $\mathrm{H}$ (Cor), já neste sistema a segmentação é baseada no valor de I (Intensidade). A figura 5.8 apresenta o diagrama de blocos do sistema implementado em software e hardware. O software é executado no processador Nios da Altera, que é uma arquitetura RISC de 32 bits, fornecido através do Kit de desenvolvimento Nios (Altera, 2003f).

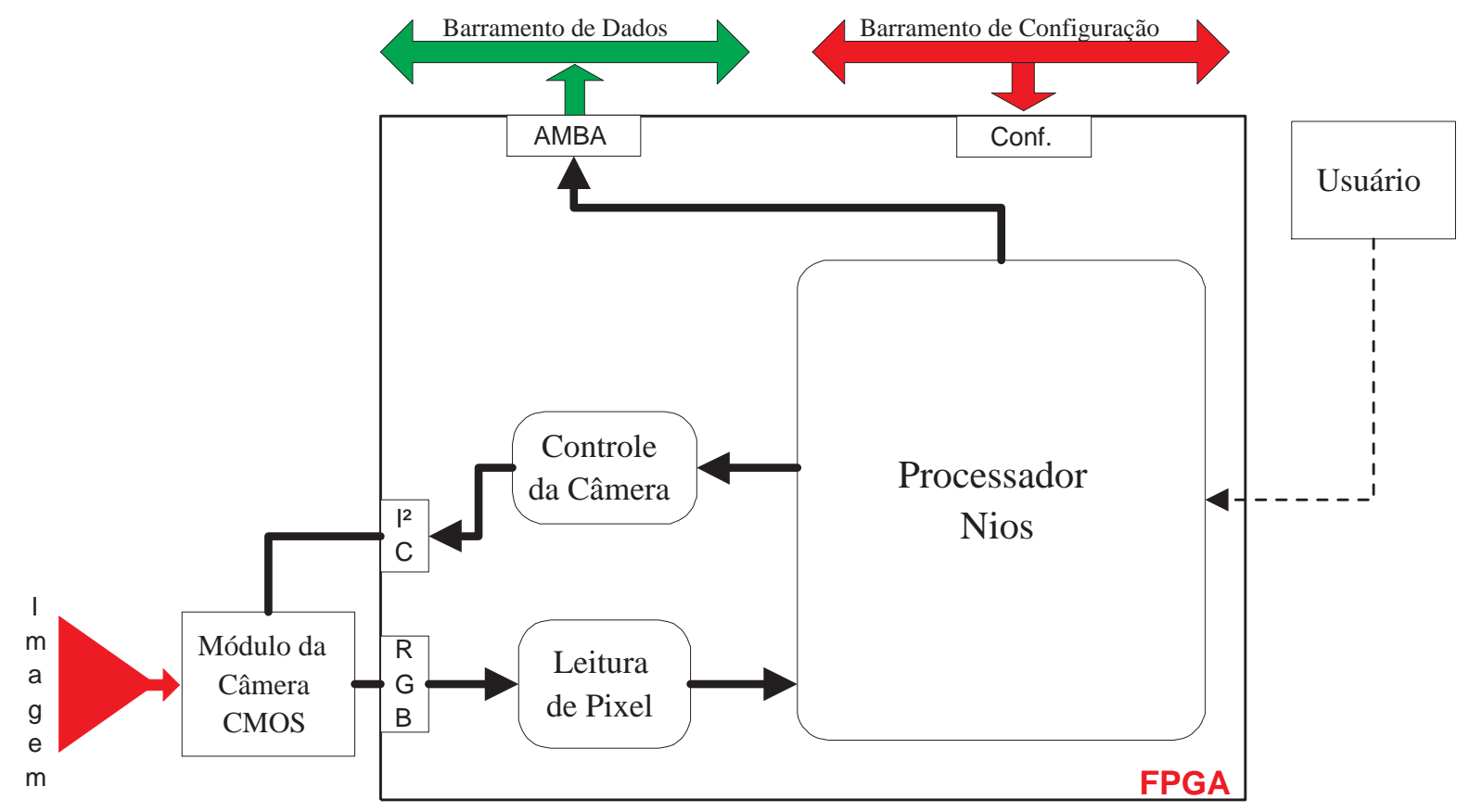

Figura 5.8: Diagrama de bloco do Sistema

O conjunto de sinais interpretado por este sistema é visto na figura 5.9, os quais são fixados e organizados no ambiente onde o robô está localizado de acordo com o trajeto de navegação desejado. Este sinais podem ser facilmente substituídos por outros, pois o sistema é composto por uma rede neural com treinamento on-chip, conforme visto no sistema de reconhecimento de gestos.

\subsubsection{Resultados Obtidos}

O sistema de reconhecimento de sinais foi implementado utilizando os recursos de hardware e de software para executar os algoritmos. Essa é a principal diferença entre 


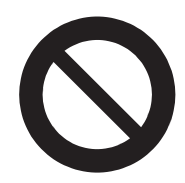

(a) Halt

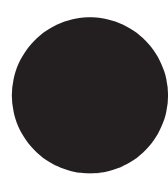

(b) Go

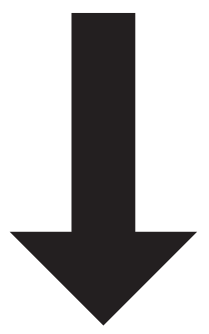

(c) Go Back

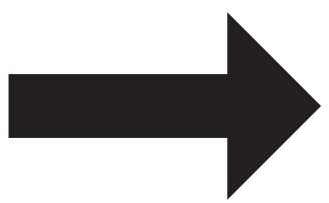

(d) Turn Right $90^{\circ}$

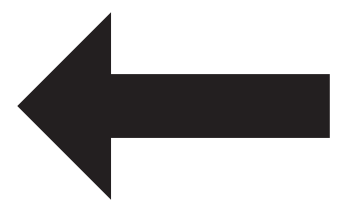

(e) Turn Left $90^{\circ}$

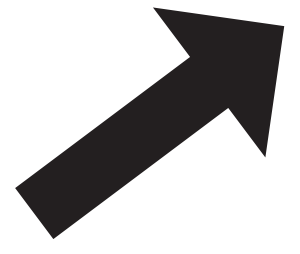

(f) Turn Right $45^{\circ}$

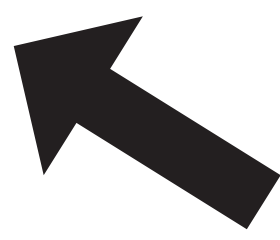

(g) Turn Left $45^{\circ}$

Figura 5.9: Sinais de navegação do sistema (docking)

esta implementação e a implementação para reconhecimento de gestos, onde os algoritmos são executados totalmente em hardware. A tabela 5.5 apresenta os recursos necessários para a implementação do sistema de reconhecimento de sinais. Comparando os dados desta tabela com a tabela 5.1 do sistema de reconhecimento de gestos, constatou-se que é necessário dispender mais elementos lógicos do FGPA para implementar o sistema em hardware e software, do que somente em hardware. Apesar desta desvantagem, a implementação dos algoritmos em software é mais fácil de ser realizada do que hardware, pois as linguagens de programação de software, geralmente são mais flexíveis.

Tabela 5.5: Memória RAM (M), Elementos Lógicos (EL) e Taxa de Ocupação (TO) necessário para implementar o sistema num FPGA EP1S10F780C6

\begin{tabular}{|c||c|c|c|}
\hline Blocos do Sistema & M(Kbits) & EL & TO (\%) \\
\hline \hline Controle da Câmera & 0 & 71 & 0,67 \\
\hline Leitura de Pixel & 0 & 84 & 0,79 \\
\hline Processor Nios & 512 & 4.900 & 46,36 \\
\hline
\end{tabular}

As tabelas 5.6 e 5.7 mostram o desempenho obtido para cada bloco funcional do sistema de reconhecimento de sinais implementado em software. Na tabela 5.6 é apresentado o desempenho de cada programa existente no pré-processamento de imagem e o desempenho total obtido. Através desta tabela é constatado que o processamento mais lento 
ocorre na conversão de RGB para HSI. Para obter um sistema de maior desempenho, esta conversão poderia ser realizada pelo hardware dedicado utilizado no sistema de reconhecimento de gestos apresentado anteriormente. O conteúdo da tabela 5.7 mostra o desempenho obtido da implementação em software do modelo de rede neural n-tuple, sendo constatado que 12 é o número máximo de padrões verificados por segundo.

Tabela 5.6: Desempenho dos blocos de pré-processamento de imagem executando a $50 \mathrm{MHz}$ no processador Nios. A tabela representa os seguintes dados: Tempo em milisegundos(TF) para executar um frame, Tamanho da Imagem (TI) e Frame por segundo (FS)

\begin{tabular}{|c||c|c|c|}
\hline $\begin{array}{l}\text { Blocos de } \\
\text { Pré-Processamento }\end{array}$ & $\begin{array}{l}\text { TF } \\
(\mathbf{m s})\end{array}$ & TI & FS \\
\hline \hline RGB para HSI & 1.602 & $320 \times 240$ & 0,62 \\
\hline Segmentação & 87 & $320 \times 240$ & 11,49 \\
\hline Filtragem e Redução & 85 & $320 \times 240$ & 11,76 \\
\hline Centralização & 5 & $32 \times 24$ & 200 \\
\hline \hline Desempenho Final & 1.779 & - & 0,56 \\
\hline
\end{tabular}

Tabela 5.7: Análise de desempenho da rede neural RAM implementada em software (50MHz no Processador Nios)

\begin{tabular}{|c|c|}
\hline \multicolumn{2}{|c|}{ Desempenho de Rede Neural em Software - RAM } \\
\hline \hline Freqüência de Operação & $50 \mathrm{MHz}$ \\
\hline Número de Neurônios Processados por Segundo & 1.152 \\
\hline Número de Neurônios da Rede Neural & 96 \\
\hline Padrões Verificados por Segundo & 12 \\
\hline
\end{tabular}

Conforme visto nas tabelas de desempenho apresentadas anteriormente, o processamento realizado em software é mais lento do que o realizado em hardware dedicado. Além disso, para obter o desempenho real do sistema não basta considerar o tempo de processamento do bloco funcional mais lento, como é feito nos sistemas implementados totalmente em hardware dedicado. Devido ao fato das operações serem executadas seqüencialmente por um único processador, o cálculo de desempenho do sistema deve ser baseado na soma de todos os tempos necessários para a execução de cada etapa de processamento existente no sistema. O sistema de reconhecimento de gesto, que foi implementado totalmente em hardware dedicado, é capaz de processar 31,88 frames por segundo, já o sistema de reconhecimento de sinais implementado em hardware e software é capaz de processar apenas 0,56 frames por segundo. 
A tabela 5.8 apresenta os resultados obtidos referentes ao reconhecimento dos sinais através da rede neural. Para o treinamento da rede foram apresentados 30 amostras de cada sinal, sendo diferenciados na escala e na translação. Após o treinamento foram apresentados 100 sinais de cada padrão e contabilizado a taxa de acerto e erro, conforme visto na tabela 5.8 .

Tabela 5.8: Taxa de reconhecimento e de erro para cada padrão

\begin{tabular}{|c||c|c|}
\hline Sinais & Taxa de Reconhecimento (\%) & Erro (\%) \\
\hline \hline Halt & 96 & 4 \\
\hline Go & 94 & 6 \\
\hline Go Back & 100 & 0 \\
\hline Turn Right $90^{\circ}$ & 98 & 2 \\
\hline Turn Left $90^{\circ}$ & 100 & 0 \\
\hline Turn Right $45^{\circ}$ & 98 & 2 \\
\hline Turn Left $45^{\circ}$ & 100 & 0 \\
\hline \hline Média & $\mathbf{9 8 , 0 0}$ & $\mathbf{2 , 0 0}$ \\
\hline
\end{tabular}

Finalmente, cabe ressaltar que as duas aplicações de robóticas apresentadas neste capítulo, juntamente com o hardware de aquisição e pré-processamento visto no capítulo 4 , geraram 5 artigos submetidos para 4 congressos que vão ocorrer no segundo semestre de 2004 e 1 workshop que já foi realizado, onde o artigo foi aceito e apresentado. A seguir é listado o nome dos autores, o título dos artigos e o congresso aos quais foram submetidos.

- Bonato, Vanderlei; Sanches, Adriano K.; Simões, E. D. V. e Marques, Eduardo. Implementação em Hardware de uma Rede Neural Booleana para Reconhecimento de Gestos. WCBIO 2004.

- Bonato, Vanderlei; Sanches, Adriano K.; Fernandes, M. M.; Cardoso, João M. P.; Simões, E. D. V. e Marques, Eduardo. A Real Time Gesture Recognition System for Mobile Robots. ICINCO 2004.

- Bonato, Vanderlei; Menotti, Ricardo; Molz, Rolf Fredi; Simões, E. D. V. e Marques, Eduardo. Controle de Acesso à TV Interativa. SEMISH 2004.

- Bonato, Vanderlei; Wolf, Denis; Sanches, Adriano K.; Simões, E.D.V. e Marques, Eduardo. Formas de Implementação de Redes Neurais Baseada em Computação Reconfigurável. SBRN 2004. 


\section{Conclusão}

A construção do módulo de aquisição e de pré-processamento utilizando-se uma câmera digital CMOS foi de crucial importância para as pesquisas do Laboratório de Computação Reconfigurável. Isto possibilita inúmeras aplicações embarcadas que serão num futuro próximo desenvolvidas.

O uso do kit de desenvolvimento Nios edição Stratix, que é basicamente composto por uma placa com um FPGA da família Stratix e alguns circuitos auxiliares e por ferramentas de desenvolvimento de software embarcado (EDA), possibilitou o pleno desenvolvimento do sistema apresentado neste trabalho. A implementação de todo o hardware utilizando-se a linguagem de descrição de hardware VHDL demonstrou-se robusta e bastante eficiente. A qualidade original da imagem capturada pela câmera pôde ser classificada como ótima por ser uma tecnologia nova e de baixo custo (aproximadamente 70 dólares).

O maior problema enfrentado foi a eliminação dos ruídos introduzidos pelos fios que conectam a câmera à placa do kit de desenvolvimento Nios. Estas interferências introduzidas pelo ruído foram eliminadas e não influenciou no desenvolvimento do sistema que atingiu $99,57 \%$ de taxa de acerto operando a 31,88 frames por segundo, o que pode ser considerado excelente.

O uso de um sistema auxiliar para o monitoramento das transformações que ocorrem no processamento da imagem, desde a sua captura até o final do processamento, foi muito útil para verificar o que realmente estava ocorrendo no hardware. Na implementação de 
sistema on-chip são encontrados diversos problemas que normalmente não há em implementações realizadas em software utilizando computadores pessoais. Como por exemplo, considerar o tempo de propagação dos sinais através das portas lógicas. O tempo necessário para compilar o sistema chegou a ser 18 minutos utilizando-se uma máquina Athlon 1.6 GHz com 1GB de memória RAM, o qual poderia ser reduzido entorno de 50\% se não houvesse o sistema de monitoramento.

Por último, o trabalho envolveu diversas áreas de conhecimento tais como: préprocessamento de imagem, projeto de hardware com HDL, manipulação de cores, conhecimento do protocolo TCP/IP (sockets), teoria de redes neurais e conhecimento da tecnologia de hardware reconfigurável (FPGA); que possibilitaram um crescimento profissional ao mestrando, numa área carente do Brasil. 


\section{Trabalhos Futuros}

Uma vez que o hardware de aquisição e pré-processamento de imagem ocupou apenas $12,3 \%$ e o hardware da rede booleana para reconhecimento de gestos $15,6 \%$ do FPGA EP1S10F780C6 da família Stratix, pode-se concluir que é possível a implementação de um sistema para reconhecimento de gestos tolerante a falhas com taxa de acerto de 100\%, conforme proposta apresentada na figura 5.10.

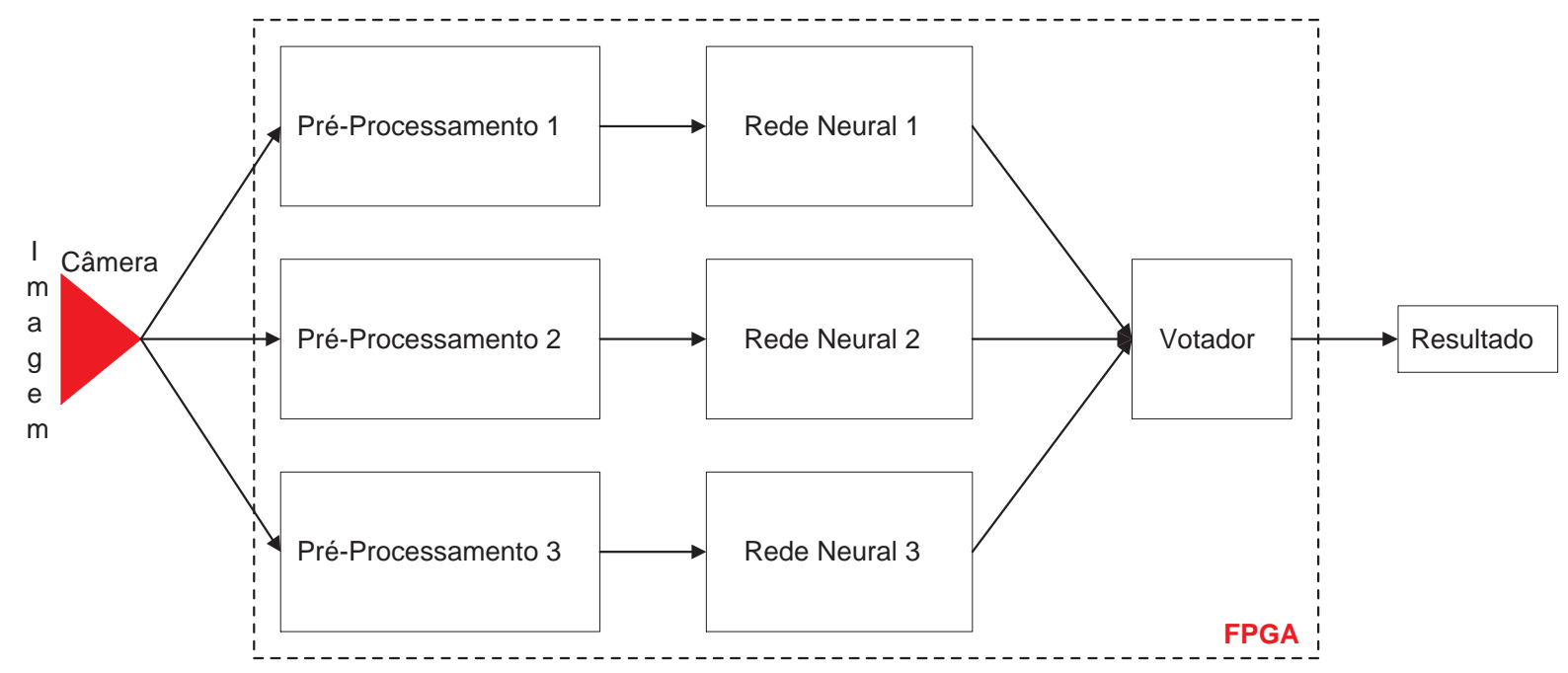

Figura 5.10: Proposta de um sistema de reconhecimento de gestos com $100 \%$ de acerto

A imagem do mesmo gesto seria computada em três instantes de tempo diferentes (onde as variações de luz e proximidades da mão variam) e os frames associados a cada captura submetidos a sua específica rede neural booleana. Após a detecção do gesto, um votador majoritário para cada rede neural booleana decidiria o gesto final reconhecido. 
Acreditamos que neste caso a taxa de acerto máximo seria atingida, o que possibilita o uso do sistema em aplicações que exigem alto grau de confiabilidade, ou seja, seguro.

Outros trabalhos poderiam ser desenvolvidos na criação de blocos de hardware dedicados para funções de pré-processamento de imagem. Algumas das funções poderiam ser filtros passa alta para o realce ou detecção de bordas, filtros passa baixa para a suavização de imagem, técnicas de esqueletização e operações morfológicas, como por exemplo abertura e fechamento. Essas funcionalidades poderiam ser implementadas, validadas e incorporadas neste trabalho. Por existir atualmente FPGA de alta capacidade, é possível que sistemas complexos de processamento de imagem sejam projetados internamente num único chip (SoC).

O bloco de conversão de RGB para HSI, implementado em harwdare neste sistema, poderia ser aprimorado a fim de obter desempenho acima de 31,88 frames por segundo. Nesta implementação não houve a necessidade de melhor desempenho, pois a câmera estava configurada para fornecer no máximo 30 frames por segundo. Porém, em situações onde esta taxa não satisfaz os requisitos do sistema, a criação de um bloco de conversão de cor mais paralelizado poderia ser desenvolvido.

Por fim, o avanço em tecnologia VLSI permitirá que uma nova geração de sistema de visão inteligentes sejam implementados utilizando-se uma grande quantidade de câmeras de baixo custo e processadores dedicados de alta performance numa rede distribuída. Redes de câmeras inteligentes distribuídas são tecnologias emergentes que podem ser utilizadas no reconhecimento de humanos e animais, vigilância, análise de movimentos, conferências inteligentes, detecção de faces e etc.. Por ter acesso à cenas de várias direções, a rede de câmeras tem potencial para sintetizar informações maior do que em sistemas de uma única câmera. No entanto, a interpretação das cenas geradas a partir de uma rede distribuída de câmeras apresenta vários desafios, como o processamento em tempo real e o desenvolvimento de algoritmos e arquiteturas eficientes. Alguns trabalhos relacionados a rede de câmeras inteligentes podem ser vistos em Wolf et. al. (2002) e Bhattacharyya et. al. (2004). 


\section{Referências Bibliográficas}

Altera 2003a.

Disponível em http://www.altera.com (Acessado em 10/2003)

Altera Avalon bus specification - reference manual, 2003b.

Disponível em http://www.altera.com/literature/manual/mnl_avalon_bus.pdf (Acessado em 11/2003)

Altera Gnu tools, 2003c.

Disponível em http://www.altera.com/products/software/embedded/products/ gnupro/emb-gnupro.html (Acessado em 07/2003)

AlterA Introduction to quartus II, 2003d.

Disponível em http://www.altera.com/literature/manual/intro_to_quartus2. pdf (Acessado em 07/2003)

Altera Nios 3.0 CPU, 2003e.

Disponível em http://www.altera.com/literature/ds/ds_nioscpu.pdf (Acessado em $11 / 2003)$

Altera Nios development kit, stratix edition, 2003f.

Disponível em http://www.altera.com/products/devkits/altera/kit-nios_ 1S10.html (Acessado em 07/2003) 
Altera Hardcopy device handbook, volume 1, 2004.

Disponível em http://www . altera.com/literature/hb/hrd/hc_h5v1.pdf (Acessado em $02 / 2004)$

Angelo M. Sabatini, V. G.; Maini, E. S. Be-viewer: vision-based navigation system to assist motor-impaired people in docking their mobility aids. Em: Proceedings of the 2003 IEEE International Conference on Robotics $\&$ Automation, Taipei, Taiwan, 2003.

Austin, J. Rambased neural network. London: World Scientific Publishing Co. Pte. Ltd., 1998.

Berger, A. Embedded systems design. Kansas: CMP Books, 2002.

Bhattacharyya, S.; Chellappa, R.; Wolf, W. Distributed smart cameras, 2004. Disponível em http://www.ece.umd.edu/DSPCAD/projects/smartCameras/ smartcamera.html (Acessado em 04/2004)

Blanc, N. CCD versus CMOS-has CCD imaging come to an end?. Relatório técnico pp. 131-137, Herbert Wichmann Verlag, Heidelberg, 2001.

Boyle, W.; Smith, G. Charge coupled semiconductor devices. Relatório técnico vol 49 pp. 587, Bell Systems Technical Journal, 1970.

Brown, S.; VRanesic, Z. Fundamentals of digital logic with vhdl design. Toronto: Mc Graw Hill, 2000.

Carvalho, A. C. P. D. L. F. D. Towards as integrated boolean neural network for image recognition. Tese de doutorado, University of Kent at Canterbury, Canterbury - Kent, 1994.

ChiZhang, P. W. A new method of color image segmentation based on intensity and hue clustering. Em: IEEE International Conference on Pattern Recognition - ICPR, 2000, pg. 3617.

Company, E. K. Charge-coupled device CCD image sensors, 2003a.

Disponível em http://www.kodak.com (Acessado em 05/2003) 
Company, E. K. CMOS vs CCD and future of imaging, 2003b.

Disponível em http://www.kodak.com (Acessado em 05/2003)

Costa, L. D. F.; Cesar JR., R. M. Shape analysis and classification. New York: Phillip A. Laplante, 2000.

Cummings, R. E.; Pouliquen, P.; M. Lewis, A. A vision chip for color segmentation and pattern matching. EURASIP JASP, pgs. 703-712, 2003.

EleCtronics, Q. 2003.

Disponível em http://www.quasarelectronics.com (Acessado em 03/2003)

Electronics, Q. 2004.

Disponível em http://www.electronic-kits-and-projects.com/kit-files/ovt/ OV7620_0V7120_v1.2whole.pdf (Acessado em 03/2004)

Filho, O. M.; Neto, H. V. Processamento digital de imagens. Rio de Janeiro: Brasport Livros e Multimídia, 1999.

Gonçalves, R.; Wolf, D. F.; Rodrigues, M. I.; Osorio, L. F.; Moraes, P. A.; Genuário, L. B.; Teixeira, M. A.; Ribeiro, A. A. L.; Romero, R. A. F.; MARques, E. Architect-r: A system for reconfigurable robots design - an overview and initial results. Em: VLSI-SOC'01, 2001, pgs. 60-64.

Gonçalves, R. A.; Moraes, P. A.; Cardoso, J. M. P.; Wolf, D. F., F. M. M.; Romero, R. A. F.; Marques, E. Architect-r: a system for reconfigurable robots design. Em: Proceedings of the 2003 ACM symposium on Applied computing, ACM Press New York, NY, USA, 2003.

Gonzalez, R. C.; Woods, R. E. Digital image processing. New York: AddisonWesley Company, 1992.

Hamblen, J. O.; Furman, M. D. Rapid prototyping of digital systems. $2^{\mathrm{a}}$ ed.. Boston: Kluwer Academic Publishers, 2001. 
K., P.; Mourad, S. Digital design using field-programmable gate arrays. Prentice Hall, 1994.

Kyu-Hyun, O.; Jung-Yup, Kim A-nd Ill-Woo, P.; Jungho, L.; Jun-Ho, O. A study on the control of auv's homing and docking. Em: 9th IEEE Conference on Mechatrinics and Machine Vision in Practice, Chiang Mai, Thailand, 2002.

MAxwell, B. A. A real-time vision module for interactive perceptual agents. Lecture Notes in Computer Science, , no. 2095, pgs. 190-200, 2001.

McCullough, W.; Pitts, W. A logical calculus of the ideas imminent in nervous activity. Bull Math Biophys, pgs. 5:113-133, 1943.

Miller, D. P.; Wright, A. Autonomous spacecraft docking using multi-color targets. Em: In Proceedings of the 6th Topical Meeting on Robotics, Monterey, CA, 1995.

Milo C. Silverman, Boyoon Jung, D. N.; Sukhatme, G. S. Staying alive longer: Autonomous robot recharging put to the test. Relatório técnico, Center for Robotics and Embedded Systems - University of Southern California, 2003.

Murgai, R.; Brayton, R. K.; Sangiovanni-Vincentelli, A. Logic synthesis for field-programmable gate arrays. Kluwer Academic, 1995.

Oldfield, J. V.; Dorf, R. C. Field programmable gate arrays. John Wiley \& Sons, 1995.

DE Oregon, U. Evolving towards the perfect CCD, 2003.

Disponível em http://zebu.uoregon.edu/ccd.html (Acessado em 06/2003)

PAUli, J. Learning-based robot vision: principles and applications. Lecture Notes in Computer Science, , no. 2048, pgs. 5-6, 2001.

PhILIPs The i2c-bus specification, 2003.

Disponível em http://www.semiconductors.philips.com/acrobat/literature/ 9398/39340011.pdf (Acessado em 10/2003) 
Ramesh, J.; Rangachar, K.; Schunck, B. G. Machine vision. New York: McGraw-Hill, 1995.

Russ, J. C. The image processing handbook. $2^{\text {a }}$ ed.. Boca Raton: CRC Press, 1995.

Stefan Waldherr, R. R.; Thrun, S. A gesture based interface for human-robot interaction. Autonomous Robots, vol. 9, no. 7, pgs. 151-173, 2000.

SWEnson, R. L. A real-time high performance universal colour transformation hardware system. Tese de doutorado, University of Kent at Canterbury, Canterbury - Kent, 2000.

TAYLOR, S. A. CCD and CMOS imaging array technologies: Technology review. Relatório técnico EPC-1998-106, Cambridge Laboratory, 1998.

Technology, M. I. 2003.

Disponível em http://www.micron.com (Acessado em 06/2003)

Turk, M. Computer vision in the interface. ACM Press New York, NY, USA, 2004, pgs. $60-64$.

WeEKS JR., A. R. Fundamentals of electronic image processing. Washington: SPIE - The international Society for Optical Engineering, 1996.

Wolf, D. F. Projeto de uma rede neural usada no reconhecimento de gestos por rôbos móveis utilizando-se computação reconfigurável. Dissertação de mestrado, ICMC-USP, 2001.

Wolf, W.; Ozer, B.; Lv, T. Smart cameras as embedded systems. IEEE Computer Society, pgs. 48-53, 2002. 